\title{
TEGRAM:
}

\section{UM SISTEMA TUTOR DE GEOMETRIA PLANA BASEADO NO TANGRAM}

Marcelo Augusto Santos Turine

Orientadora

Profa. Dra. Maria das Graças Volpe Nunes 


\title{
TEGRAM: \\ UM SISTEMA TUTOR DE GEOMETRIA PLANA BASEADO NO TANGRAM
}

\section{Marcelo Augusto Santos Turine}

\author{
Orientadora
}

Profa. Dra. Maria das Graças Volpe Nunes

Dissertação apresentada ao Instituto de Ciências Matemáticas de São Carlos da Universidade de São Paulo como parte dos requisitos para a obtenção do título de Mestre em Ciências - Área: Ciências de Computação e Matemática Computacional.

Instituto de Ciências Matemáticas de São Carlos

Universidade de São Paulo São Carlos - Setembro de 1994 


\section{DEDICATÓRIA}

"A alegria da conscientização de um ideal supera o cansaço da luta, do temor e das incertezas passadas. Nada é mais gratificante do que viver hoje a certeza da conquista e o começo de um futuro melhor."

Dedico este trabalho em especial aos meus pais, Maucyr e Esmeralda, e aos meus irmãos, Carla e Plínio, pelo carinho, paciência, amor e compreensão que tiveram durante a realização de meus estudos. 
"Eu estou neste mundo, vivendo o presente. Qualquer coisa boa que eu possa fazer, ou qualquer alegria que puder dar aos outros, por favor, diga-me. Não me deixe adiar ou esquecer, pois jamais tornarei a viver este momento novamente."

(Henry Drummond) 
"Nunca se afaste de seus sonhos, porque se eles se forem, você continuará vivendo, mas terá deixado de existir."

(Mark Twain) 
"Um mestre não é um homem que ensina.

$O$ mestre é alguém que acorda.

Não é aquele que tem algumas informações para lhe dar, é um homem que lhe proporciona vislumbres do seu próprio ser."

(Rajneesh) 


\section{AGRADECIMENTOS}

A Deus, pelas forças concedidas para enfrentar mais este desafio.

À Profa. Maria das Graças Volpe Nunes, orientadora e amiga, por me incentivar a enfrentar desafios e ajudar a vencê-los.

À Profa. Maria Dolores Ceccato Mendes, pelas valiosas contribuições, pelo incentivo e apoio indispensáveis à realização deste trabalho, além da amizade, "paciência" e atenção sempre concedidas.

Ao Prof. Odelar Leite Linhares por sua constante dedicação ao ensino.

Aos professores Wagner, Jorge (da Beth), Claúdio (da Dolores), Carmo, Carolina, Cristina, Chú, Solange, Sandra e Andreucci pela amizade e ajuda durante todos estes anos.

Aos professores Maria Augusta Brandão e Raul Aragão Martins pela amizade e incentivo dados para iniciar este mestrado.

Às secretárias da pós-graduação, Beth e Laura, pela simpatia, carinho, atenção e eficiência com que sempre me atenderam.

Às funcionárias da biblioteca: Silvana, Maria, Sandra, Gislene, Rose, e aos funcionários do laboratório (LDCC): Ângelo, Elien, Luciano, Carmem, Sônia e Jacques, pela colaboração durante todos os meus estudos realizados neste Instituto (ICMSC).

Ao Carlão, aluno de iniciação científica, que muito contribuiu para este trabalho.

Aos amigós da república: Marquinhos, Gawa e Benevides pelo apoio, incentivo e companheirismo em todas as horas.

Aos amigos que direta ou indiretamente, contribuiram com o seu apoio e amizade durante estes anos em São Carlos, em especial: Rô, Cam, Stein, Renata e Roberta, Neyva, Ana, Di, Vera, Marcão, Cybelle, Titi, Pastel, Taísa, Delamaro, Sadao, Zero, Lenz, Rose, Luiza, Cidinho, Lilian, Paty (do Vinicius), Aninha, Jaqueline, amigos do convênio USP/Itautec (Teresa, Sandrinha, Claudete, Lúcia), amigos da minha graduação (Du, Ana, Minas, Alex, Estela, Lazanha, Raquel) e amigos de Bonifácio (Ivan, Patrícia, Joseliza, Lafa, Flávia, Andrea). trabalho.

À CAPES, pelo apoio financeiro fornecido durante todo o desenvolvimento deste 
“A melhor equipe não é aquela que reúne membros perfeitos, mas aquela na qual cada um aceita os defeitos do outro e consegue perdão para os próprios defeitos."

(Jacques Loew) 


\section{CONTEÚDO}

LISTA DE FIGURAS.................................................................... iv

RESUMO

ABSTRACT

1. INTRODUÇÃO 1

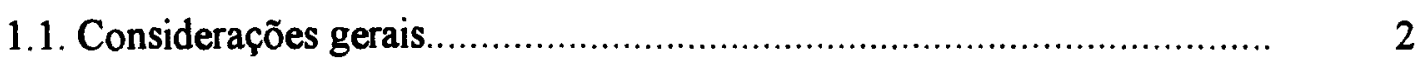

1.2. Motivações e objetivos........................................................................... 8

1.3. Organização da dissertação ................................................................ 9

2. SISTEMAS TUTORES INTELIGENTES 11

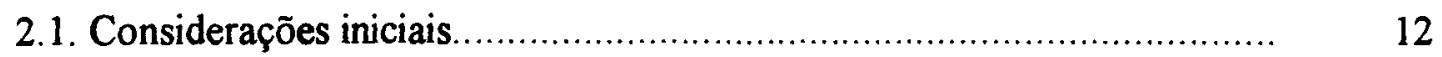

2.1.1. Histórico ................................................................. 12

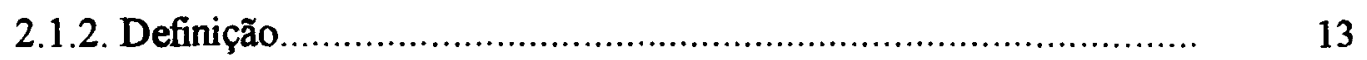

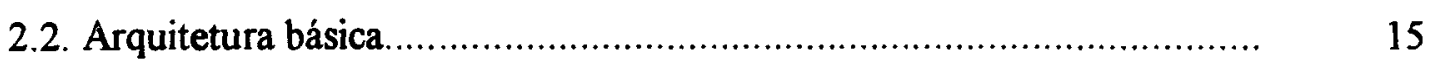

2.2.1. O módulo do domínio............................................................. 16

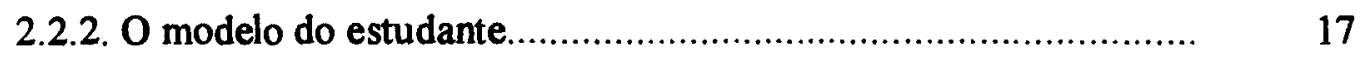

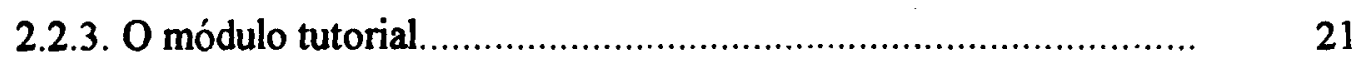

2.2.4. O módulo de comunicação....................................................... 22

2.3. Sistemas tutores para o ensino da Matemática...................................... 24

2.3.1. Vantagens e desvantagens.....................................................

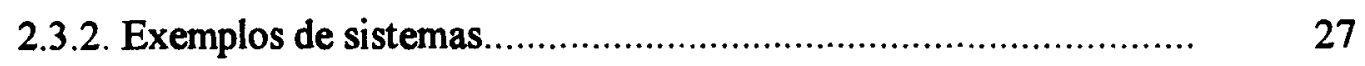

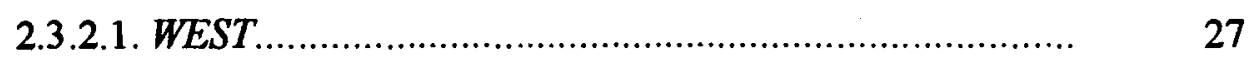

2.3.2.2. SORT EQUIVALENT FRACTIONS............................. 28

2.3.2.3. GREEN GLOBS.............................................. 29

2.4. Considerações finais ................................................................... 
3. O USO DO TANGRAM NO ENSINO DE CONCEITOS GEOMÉTRICOS 32

3.1. O Tangram: definição e construção...................................................... 33

3.2. O Tangram como um recurso didático............................................. 34

3.3. Atividades com o Tangram.............................................................. $\quad 35$

3.3.1. Atividades lúdicas - Jogo Chinês......................................... 36

3.3.2. Atividades envolvendo conceitos matemáticos ......................... 37

3.4. Considerações finais................................................................. 45

4. O SISTEMA TEGRAM 46

4.1. Considerações iniciais.................................................................. 47

4.2. Arquitetura do sistema TEGRAM............................................... 48

4.2.1. Módulo do domínio ............................................................. 49

4.2.1.1. Rede de conceitos e atividades..................................... 49

4.2.1.2. Rede de definições.................................................... 53

4.2.2. Modelo do estudante............................................................. 55

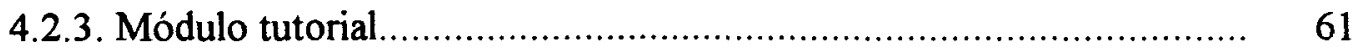

4.2.4. Módulo de comunicação de atividades....................................... 62

4.3. Ambiente de desenvolvimento........................................................ 64

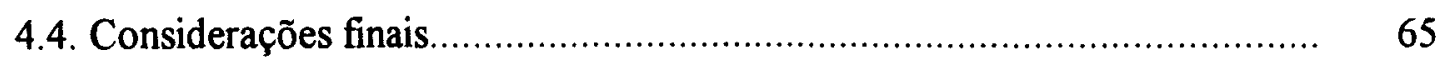

5. INTERAÇÃO COM O SISTEMA TEGRAM 66

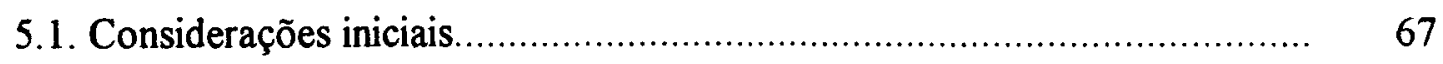

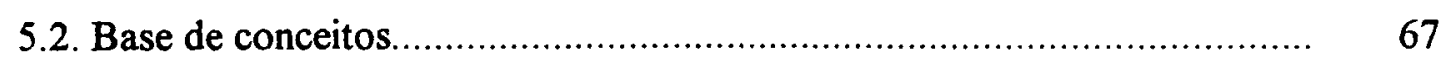

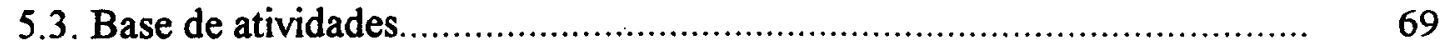

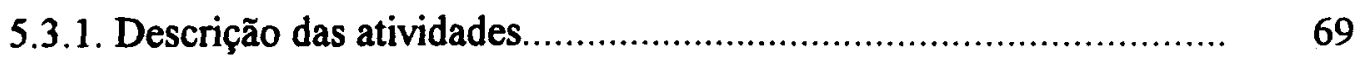

5.3.2. Componentes da janela da atividade...................................... 74

5.4. Exemplo de uma sessão com um estudante........................................ 80

5.4.1. Estudante novato ............................................................. 81

5.4.2. Estudante não novato..................................................... 89

5.5. Considerações finais.............................................................. 90

6. CONCLUSÕES 91

6.1. Considerações iniciais.............................................................. 92

6.2. Contribuições deste trabalho.......................................................... 92

6.3. Propostas de trabalhos futuros........................................................ 95 
BIBLIOGRAFIA CITADA

BIBLIOGRAFIA CONSULTADA E RECOMENDADA …………............... 109

APÊNDICE I - GLOSSÁRIO ............................................................. 114

APÊNDICE II - TABELA DE SISTEMAS TUTORES .............................. 117 


\section{LISTA DE FIGURAS}

Figura 1: STI - Intersecção entre IA, Psicologia Cognitiva e Educação.................. 15

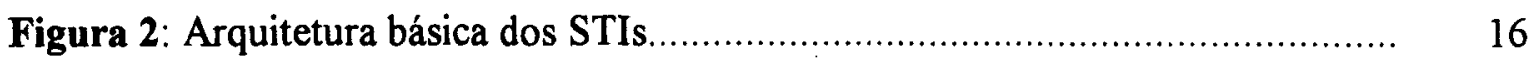

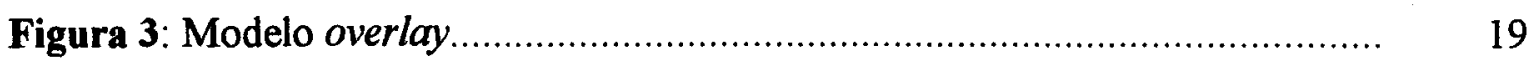

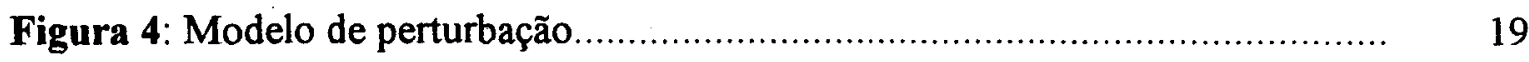

Figura 5: Modelo procedimental.......................................................... 20

Figura 6: Modelo diferencial....................................................................... 20

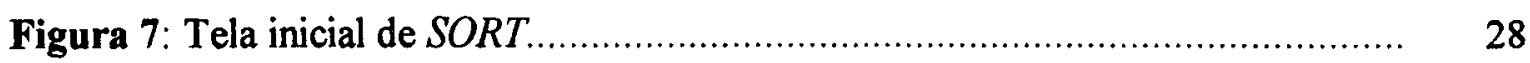

Figura 8: Classificação das frações.................................................................... 29

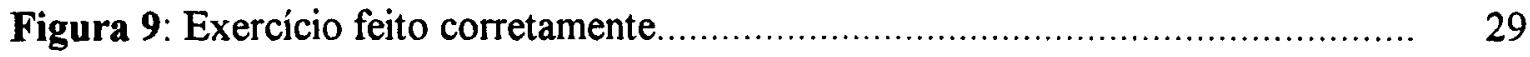

Figura 10: Tela inicial do jogo Green Globs .................................................. $\quad 30$

Figura 11: Exemplo de uma segunda tela do jogo Green Globs............................ 30

Figura 12: As sete peças que formam o Tangram............................................... 33

Figura 13: Representação de um gato e um chinês.................................................. 36

Figura 14: Quadrado com duas peças............................................................ 38

Figura 15: Quadrado com três peças................................................................. 38

Figura 16: Quadrado com quatro peças........................................................ 38

Figura 17: Quadrado com cinco peças............................................................... 38

Figura 18: Congruência entre figuras............................................................ $\quad 39$

Figura 19: Semelhança entre dois paralelogramos............................................... 39

Figura 20: Eqüivalência de áreas................................................................ 40

Figura 21: Composição das peças para cálculo das áreas........................................ 41

Figura 22: Perímetro da peça t............................................................... 42

Figura 23: Interpretação geométrica do Teorema de Pitágoras................................. 42

Figura 24: Lados das peças a serem calculados................................................... 43

Figura 25: Medida dos lados dos triângulos t e M............................................... 43

Figura 26: Triângulo, retângulo e quadrado formados com as sete peças................... 44 
Figura 27: Arquitetura do sistema TEGRAM.......................................... 48

Figura 28: Classificação dos conceitos matemáticos......................................... 50

Figura 29: Exemplo de uma rede de conceitos................................................ 51

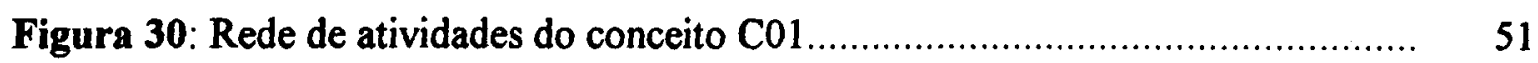

Figura 31: Exemplos de sobreposição de peças................................................. 55

Figura 32: Janela de definição do Tangram...................................................... 63

Figura 33: Janela principal do sistema TEGRAM....................................... 64

Figura 34: Dígrafo formado pelos conceitos matemáticos do sistema TEGRAM....... 68

Figura 35: Quadrados possíveis com duas peças........................................... $\quad 70$

Figura 36: Triângulo, paralelogramo e trapézio formados com duas peças............... 71

Figura 37: Quadrado com três peças....................................................... 71

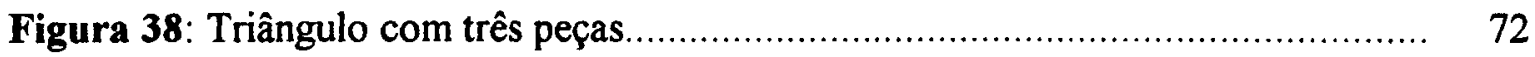

Figura 39: Paralelogramo com três peças................................................ 72

Figura 40: Trapézio com três peças.......................................................... 73

Figura 41: Retângulo com três peças........................................................ 73

Figura 42: Janela da atividade QUADRADO_3_PEÇAS.................................. 75

Figura 43: Estudante clicou o button Pronto da atividade QUADRADO_3_PEÇAS. 76

Figura 44: Exemplo do menu de conceitos pré-requisitos ................................ 77

Figura 45: Estudante clicou o button Sobre Botão (BOTÃO DE ROTAÇÃO).. 78

Figura 46: Estudante clicou o button Sobre Botão (BOTÃO DE REFLEXÃO). 79

Figura 47: Estudante clicou o button Sobre Botão (BOTÃO DE ENTRADA DE

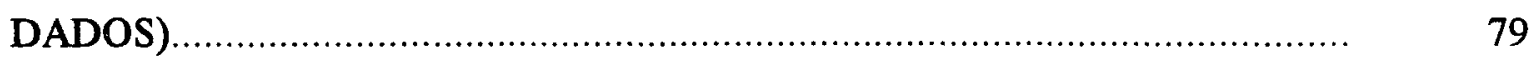

Figura 48: Janela de apresentação do sistema TEGRAM................................. $\quad 80$

Figura 49: Primeira janela de identificação do sistema TEGRAM........................... $\quad 81$

Figura 50: Segunda janela de identificação do sistema TEGRAM........................ 82

Figura 51: Exemplo do menu de atividades.................................................. 83

Figura 52: Janela da atividade IDENTIFICAR_QUADRADO........................... 84

Figura 53: Estudante clicou o button Pronto da atividade

IDENTIFICAR_QUADRADO............................................................... 85

Figura 54: Estudante clicou a opção Conceitos Vistos...................................... 87

Figura 55: Janela da atividade QUADRADO_2_PEÇAS...................................... 88

Figura 56: Estudante clicou o button Pronto da atividade QUADRADO_2_PEÇAS. 88

Figura 57: Terceira janela de identificação do sistema...................................... 90

Tabela 1: Os dois paradigmas das escolas americanas........................................ 6 


\title{
TEGRAM: UM SISTEMA TUTOR DE GEOMETRIA PLANA BASEADO NO TANGRAM
}

\author{
Autor: Marcelo Augusto Santos Turine \\ Orientadora: Profa. Dra. Maria das Graças Volpe Nunes
}

RESUMO

O objetivo desta dissertação é apresentar o projeto de construção do sistema TEGRAM: um sistema tutor destinado a auxiliar o processo de ensino-aprendizagem de conceitos relacionados à Geometria Plana para estudantes do 10 grau. No intuito de despertar a curiosidade e o interesse dos estudantes, fazendo com que eles se envolvam com as atividades e sintam-se estimulados em resolvê-las, todas as atividades propostas pelo sistema baseiam-se num jogo chinês milenar chamado Tangram. $O$ sistema funciona de tal modo que o usuário/estudante é levado à compreensão de conceitos que são formalizados a posteriori. A arquitetura do sistema TEGRAM é baseada numa arquitetura básica de Sistemas Tutores Inteligentes: módulo do domínio, modelo do estudante, módulo tutorial e módulo de comunicação. 


\title{
TEGRAM: A TUTORING SYSTEM OF PLANE GEOMETRY BASED ON TANGRAM
}

\author{
Author: Marcelo Augusto Santos Turine \\ Adviser: Profa. Dra. Maria das Graças Volpe Nunes
}

ABSTRACT

The goal of this dissertation is to present the project of the system TEGRAM: a tutoring system which is intended to be part of a teaching/learning environment to be used by elementary school students, for acquiring concepts related to Plane Geometry. The system's activities are based on a millenary Chinese game called Tangram, which stimulates the students through a non-traditional way of learning and provides a large number of activities that lead the students to the building of Plane Geometry concepts, which are formalized a posteriori. The system architecture is based on the traditional Intelligent Tutoring Systems architecture: domain module, student model, tutorial module and communication module. 


\section{CAPÍTULO 1}

\section{INTRODUÇÃO}
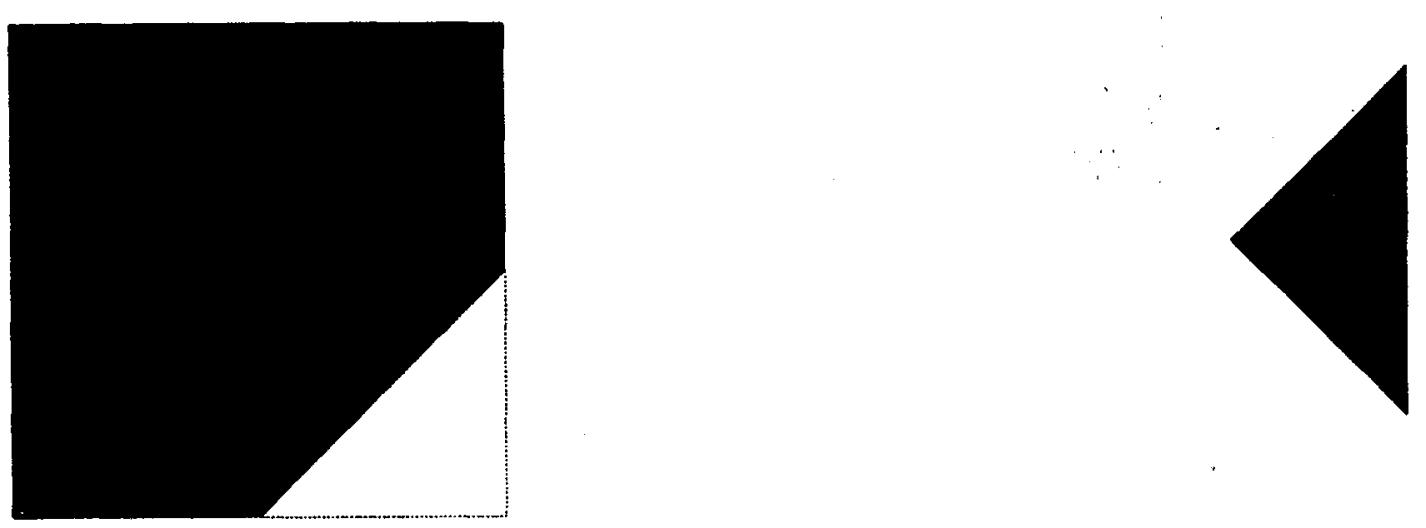


\subsection{Consideraçø̃es gerais}

sociedade atual está dominada pela informação e por processos que ocorrem A de maneira muito rápida e quase imperceptível. É indiscutivel que os computadores têm uma importância sempre crescente nesta sociedade cada vez mais complexa. De fato, desde a invenção da escrita e da imprensa, nada tem causado tanto impacto social e estimulado tantas mudanças quanto o uso de computadores.

A introdução e utilização de meios informatizados na Educação têm provocado uma verdadeira revolução no processo de ensino-aprendizagem. De acordo com Stahi [STA90], os computadores distinguem-se de muitos outros meios de ensino pela capacidade de controle e pela habilidade de apresentar, receber, processar e gerenciar informações. Estes atributos assemelham-se às representações e processos envolvidos na aprendizagem humana.

O uso do computador a serviço do processo educacional pode possibilitar o ensino de muito mais coisas a um número cada vez maior de pessoas. Os computadores têm potencial para estimular o desenvolvimento de habilidades cognitivas em várias áreas do conhecimento e aplicar novos e, possivelmente, melhores meios de ensino e aprendizagem. Este é o embasamento de grande parte das investigações sobre o uso de computadores na Educação.

A aplicação de computadores na Educação aponta para uma nova diretriz: o uso desta tecnologia não como máquina de ensinar mas como uma nova mídia educacional [VAL91]. Algumas pessoas imaginam que o processo educacional se transforme em um processo frio e mecânico. Outras temem que transforme os estudantes em robôs, seres mecanizados e incapazes de pensar. Os objetivos do uso do computador na Educação não devem ser estes, nem tampouco o de substituir o professor na sala de aula.

O objetivo fundamental da utilização de computadores no processo educacional é fazer com que o computador seja uma ferramenta complementar, de aperfeiçoamento e de possivel melhoria na qualidade do ensino. Segundo Lidtke e Moursund [LID93], um outro objetivo é que os computadores podem ajudar a alcançar as metas de ensino existentes no sistema educacional. Isto pode ser alcançado modificando o conteúdo atual do currículo das escolas, relacionando as atividades com a tecnologia computacional emergente.

Enfim, o computador não pode ser visto como um possível tutor automatizado que transmite informações para o estudante. Deve, antes, ser considerado uma ferramenta educacional de auxílio no desenvolvimento do raciocínio sobre um determinado assunto, 
propiciando a formalização dos conhecimentos intuitivos do estudante. Assim, o aprendizado, por parte do estudante, deve ocorrer através da realização de tarefas (por exemplo, resolução de problemas de diversos domínios do conhecimento e representação desta solução em uma linguagem de programação) por intermédio do computador e não simplesmente por uma tentativa de transmissão de informações vindas da máquina e/ou do professor.

Segundo Valente [VAL93a], as possibilidades de usar o computador como ferramenta educacional estão crescendo e os limites desta expansão são desconhecidos. Cada dia surgem novas maneiras de usar o computador como um recurso para enriquecer $\mathrm{e}$ favorecer o processo de aprendizagem.

Papert [PAP80] [PAP87], por exemplo, vê no computador o catalisador das idéias que poderão revolucionar o sistema educacional. Este novo sistema fará com que seus beneficiários sejam capazes de usar seus próprios conhecimentos, tornando-se pensadores ativos e críticos do assunto ensinado. Estes beneficiários seriam capazes de conhecer o seu potencial intelectual, utilizando-o no desenvolvimento de suas habilidades e aquisição de novos conhecimentos. Para que estas idéias pudessem ser alcançadas, Papert criou a filosofia educacional $\operatorname{Logog}^{1}$, cujo objetivo é enriquecer a Educação através da utilização da ciência computacional.

O Logo possui tanto uma linguagem computacional quanto uma metodologia de ensino-aprendizagem. Tem sido amplamente utilizado por estudantes de 10 e 20 graus e pela educação especial (por exemplo, deficientes fisicos). $O$ enfoque do Logo é criar um ambiente de aprendizagem onde o estudante, mesmo em idade pré-escolar, programa (orienta) o computador, ao invés de ser "programado" por ele. A visão de Papert é que o estudante que ensina, aprende. $O$ estudante deve ser "desafiado" e estimulado, assim, a pensar. $O$ que a filosofia educacional Logo pretende é propiciar à criança uma vivência no ambiente natural da ciência em questão, propiciando o "aprender-fazendo" [PON84].

No ambiente de aprendizagem Logo, a criança programa o computador e, ao orientar o computador a "pensar", a criança embarca em uma exploração sobre a maneira como ela própria pensa. Para facilitar a idéia de programação, é introduzida no ambiente uma tartaruga. A tartaruga é um animal cibernético controlado pelo computador. Ela foi desenvolvida para facilitar a associação de seu movimento com o movimento que uma pessoa faz com o corpo quando se desloca no espaço. Assim, podese utilizar o "conhecimento do corpo" e tentar formalizá-lo através de comandos ou programas de computador que movimentam a tartaruga. Portanto, o papel da tartaruga é o de ser um objeto de transição, um objeto para espelhar o nosso conhecimento de deslocamento espacial [VAL91]. Ela existe dentro do ambiente Logo, que é a linguagem computacional usada para se comunicar com a tartaruga.

O ambiente Logo tem sido usado principalmente para ensinar conceitos de geometria através de atividades que possibilitam ao estudante desenhar na tela do computador (atividades espaciais). A abordagem é baseada na construção de um

1 A filosofia Logo foi desenvolvida, aproximadamente em 1960, por Seymour Papert, Wallace Feurzeig e Daniel Bobrow em um dos mais conhecidos centros de pesquisa dos EUA, o Instituto de Tecnologia de Massachussets (MIT). 
conjunto de procedimentos para guiar a tartaruga, fazendo com que a criança explore conceitos geométricos. No ensino de geometria pelo Logo, o professor (instrutor) informa que existem, por exemplo, seis comandos para a "tartaruga geométrica" que, ao se deslocar, pode riscar no vídeo (tela do computador) a sua trajetória, como: PF (para frente), PT (para trás), PLE (para o lado esquerdo), PLD (para o lado direito), RT (retrocesso) e RA (risque ou apague). Uma vez que isto é apresentado ao estudante, resta ao professor gerar o estímulo inicial, pedindo à criança para ensinar a "tartaruga simulada" a fazer algo. Por exemplo, em uma atividade para traçar um quadrado, a criança poderá assimilar que terá que medir os passos da tartaruga para que os lados do quadrado sejam iguais. Poderá visualizar na tela que a tartaruga deverá girar na mesma direção ao fim de cada percurso (lado) e que o giro terá que ser igual ( $90^{\circ}$ para cada ângulo). No final desta atividade a criança poderá entender, entre outras coisas, os conceitos de ângulos e graus.

Existe uma grande pressão na área de informática aplicada à Educação para mostrar resultados, no sentido de melhorar o desempenho do estudante dentro do currículo tradicional. Segundo Ann, em [VAL93c], o computador não pode ser visto como um catalisador de mudanças na Educação. $O$ aproveitamento da tecnologia do computador é desejado do ponto de vista psicopedagógico, pois possibilita um melhor entendimento do processo de aprendizagem. $O$ computador funciona como se fosse uma nova lente para analisar o que se passa na cabeça do estudante.

Nos países desenvolvidos foram observadas conquistas significativas nas diversas experiências que utilizam o computador como tecnologia educacional e, em particular, no ensino de conceitos relacionados à Matemática. Estudos realizados pelo EPIE ${ }^{2}$ identificaram em 1983, nos EUA, mais de 7.000 pacotes de software educacional no mercado, sendo que a cada mês eram adicionados mais 125 , abrangendo, principalmente, as áreas de Matemática, Ciências, Leitura, Artes e Estudos Sociais. Cummings [CUM89] também registrou que o uso de computadores na Educação tem demonstrado ser mais eficiente nas áreas de Matemática e Leitura.

A aprendizagem da Matemática pode ser considerada como um processo através do qual a criança estabelece uma relação mais freqüente e sistemática com $o$ conhecimento matemático. Segundo Santos [SAN90], existe um certo consenso entre os professores que a aprendizagem da Matemática, tal como a aprendizagem da Leitura e Escrita, é uma necessidade incontestável para a criança desde os seus primeiros anos de escolarização. Assim, aprender Matemática na escola representa (ou deveria representar) a continuidade de um processo de construção do conhecimento lógico-matemático que a criança já vem desenvolvendo desde cedo. Este processo de construção é realizado através de observações, experiências e ações sobre objetos do mundo físico, do seu espaço ou do seu universo sócio-cultural.

2 Educational Products Information Exchange (EPIE) Institute. Teachers College, Columbia University, New York, 1983. apud [PAP80]. 
Enfim, não é dificil entender a busca crescente de softwares educacionais (também denominados de coursewares) na área de Matemática. No ensino tradicional, a Matemática é vista como uma disciplina abstrata que envolve um tipo de conhecimento acessivel apenas a uma parcela da sociedade. Aprender Matemática ou fazer Matemática na escola é, muitas vezes, sinônimo de fobia, de aversão à escola e, em grande parte, responsável pela repulsa ao aprender. $\mathrm{O}$ raciocínio matemático utilizado pela sociedade se justifica mais por técnicas do que pela intuição. Por exemplo, o estudante adquire técnicas de como resolver uma equação do primeiro ou do segundo grau e dificilmente o processo de "fazer matemática", ou seja, pensar sobre um problema, cuja solução pode ser expressa segundo uma equação matemática e resolvida através da técnica de resolução de equações [VAL93b].

Para a proposição deste trabalho, concebe-se "aprender Matemática" como algo além de aprender técnicas de utilização imediata. É saber interpretar, criar significados, sensibilizar-se para perceber os problemas tanto quanto preparar-se para resolvê-los, a fim de desenvolver o raciocínio lógico ${ }^{3}$. Desta forma, a dificuldade de se mostrar a aplicabilidade de vários conceitos matemáticos faz da disciplina um terreno propício a grandes decepções. Isto, ao mesmo tempo, serve como estímulo para a criação de softwares educacionais, cujo objetivo é construir ambientes que forneçam oportunidades para o estudante explorar seu potencial intelectual e tentar quebrar esta barreira existente entre o mundo real e o mundo imaginário criado pela Matemática [BAR93]. Papert, por exemplo, comentou em [PAP80,p.21] que:

“... as dificuldades com conceitos relacionados à Matemática são os primeiros passos para um processo intelectual agressivo que nos conduz a um amontoado de aptidões e inaptidões... Assim, as deficiências tornam-se a identidade dos estudantes, e o aprendizado dos conceitos é transformado em uma tarefa desagradável, rodeada de inseguranças e restrições autoimpostas."

Um estudo sobre o papel da tecnologia na reestruturação do sistema educacional nos EUA foi realizado pelo ISTE ${ }^{4}$. Uma de suas principais conclusões é que todos os estudantes aprendem mais e melhor quando são livres para usarem tecnologias ao sentirem necessidade deste tipo de ajuda. Esta conclusão também é defendida pelos adeptos da utilização de jogos no processo educacional, cuja filosofia é que a criança aprende melhor quando ela é livre para descobrir relações por ela mesma, ao invés de ser explicitamente ensinada. Para alcançar esta reestruturação nas escolas americanas, há a necessidade de se alterar o paradigma atual das escolas para um novo paradigma apoiado por muitos educadores [BRA93]. Os dados da Tabela 1 refletem esta mudança e são muito interessantes, pois também refletem a realidade das atuais escolas brasileiras. Estes dados poderiam servir de estímulo e justificativa a várias pesquisas sobre o uso da tecnologia (por exemplo, o computador) na Educação e, principalmente, nas escolas.

3 Proposta curricular de Matemática - 10 grau. São Paulo, SE/CENP, 1988. apud [SAN90].

4 ISTE (International Society for Technology in Education). Vision TEST: Recommendations for American educational decision-makers. University of Oregon, Agate Street, Eugene, (503) 346-4414, 1990. apud [BRA93]. 


\begin{tabular}{|c|c|}
\hline O paradigma atual das escolas & Um novo paradigma para as escolas \\
\hline $\begin{array}{l}\text { Sistema de ensino rígido, com todos os } \\
\text { estudantes recebendo o mesmo tratamento. }\end{array}$ & $\begin{array}{l}\text { Sistema de ensino flexivel, com ambientes de } \\
\text { aprendizagem projetados para exercitar as } \\
\text { habilidades e necessidades de cada estudante. }\end{array}$ \\
\hline $\begin{array}{l}\text { Professores são considerados a fonte de } \\
\text { todo o conhecimento (são os donos da } \\
\text { verdade). Os estudantes estăo sempre prontos } \\
\text { para receberem as informaçöes. Săo entes } \\
\text { passivos. }\end{array}$ & $\begin{array}{l}\text { Professores são considerados facilitadores e } \\
\text { guias de conhecimento para estudantes ativos. }\end{array}$ \\
\hline $\begin{array}{l}\text { Estudantes são considerados } \\
\text { recipientes vazios que serão preenchidos com } \\
\text { os mesmos conhecimentos. }\end{array}$ & $\begin{array}{l}\text { Estudantes são considerados individuos, } \\
\text { tendo estilos de aprendizagem único e individual. }\end{array}$ \\
\hline $\begin{array}{l}\text { Estudantes trabalham isoladamente. } \\
\text { Fazem aquisição de fatos e técnicas com } \\
\text { pequena relação com as aplicaçðes do mundo } \\
\text { real. }\end{array}$ & $\begin{array}{l}\text { Estudantes trabalham cooperativamente em } \\
\text { ambientes de aprendizagem. Desenvolvem } \\
\text { habilidades tomando decisões, resolvendo problemas } \\
\text { e processando informações. }\end{array}$ \\
\hline
\end{tabular}

Tabela 1: Os dois paradigmas das escolas americanas [BRA93,p.68].

A utilização de computadores para auxiliar o processo de ensino-aprendizagem no Brasil ainda é muito escassa, devido a vários problemas sociais e econômicos. Por outro lado, o ensino público brasileiro de 10 e 20 graus enfrenta algumas dificuldades que, talvez, pudessem ser amenizadas com o uso do computador, tais como:

a) o problema de evasão escolar: hoje as escolas dispõem de métodos de ensino que são aplicados de forma geral para toda a população escolar. Enquanto alguns estudantes se adaptam ao método de ensino adotado, outros não se adaptam e acabam abandonando a escola. São estes estudantes que mais poderiam se beneficiar destas novas concepções de ensino e de aprendizagem. A diversidade de modalidades do uso do computador na Educação propiciará um maior número de opções. Estas, certamente, atenderão a um número maior de usuários;

b) o problema da atualização na qualidade do ensino: os fatos, conceitos e alguns processos específicos que a escola ensina tornam-se, algumas vezes, rapidamente obsoletos e inúteis. Portanto, ao invés de memorizar informações, os estudantes devem ser incentivados a procurar e usar estas informações. Estas mudanças podem ser introduzidas com a presença do computador que, por sua vez, deve propiciar as condições para os estudantes exercitarem sua capacidade de procurar/selecionar informações e resolver problemas, e

c) o problema de formação dos professores: Valente [VAL91] enfatiza que a função do aparato educacional não deve ser exclusivamente a de ensinar, mas sim a de criar condições de aprendizagem. Isto significa que o professor deixa de ser o transmissor (repassador) de informação (esta é a 
qualidade de muitos professores no ensino brasileiro). 0 computador pode fazer isto mais eficientemente e o professor assume, então, um papel de aconselhador, mentor, criador de ambientes de aprendizagem e facilitador do processo de desenvolvimento intelectual do estudante.

Valente, em [PAP80,p.7], resumiu a situação do ensino brasileiro como:

“...o argumento mais usado no Brasil para justificar o problema da Educação é a atual situação sócio-politico-econômica que vivemos. A crise da Educação geralmente é atribuida à falta de verbas, à má remuneração do professor, ao fato de a escola não ter giz, papel, etc. $\grave{E}$ claro que não podemos negar a existência e o peso destes problemas... Porém, a crise da Educação deve ser vista como a superposição de dois subproblemas que devem ser tratados separadamente: a questão sócio-político-econômica e a questão de melhoria do ensino em si. Ambos devem ser envolvidos, mas cabe principalmente às pessoas dedicadas ao ensino a proposição de condições, metodologias e idéias que nos levem a uma escola que efetivamente contribua para a educação da criança..."

Apesar de todos os problemas, não faltam tentativas de educadores em pesquisar e oferecer metodologias mais atraentes e eficientes que efetivamente contribuam para a educação dos estudantes. Um exemplo desta tentativa, na área de Matemática, é a série de livros intitulada "Atividades Matemáticas" que contém vários materiais didáticos simples para serem aplicados ao ensino de Matemática no 10 grau 5 [AMA83a] [AMA83b] [AMA84] [AMA86] [AMA91].

Por outro lado, não se pode deixar de considerar viável, num futuro próximo, o uso de computadores nas salas de aulas brasileiras. Atualmente, algumas instituições particulares, se não oferecem um computador para cada estudante, possuem pelo menos "laboratórios computacionais de ensino". Muitas usam a filosofia educacional Logo, a qual, como já foi apresentada, é um ambiente de aprendizagem que propicia à criança explorar conceitos de diferentes domínios, como Matemática, Física, entre outros.

O computador, porém, não deve ser visto como uma panacéia para resolver todos os problemas educacionais. Ele sozinho é praticamente nada; necessita de um forte aparato educacional, capaz de fornecer dados sobre questões essenciais para o processo educativo, tais como: um levantamento dos problemas mais freqüentes relacionados ao assunto a ser ensinado, as atividades mais adequadas para cada estudante em um determinado momento, um perfil do estudante que está interagindo com o sistema, entre outros. Enfim, o computador deve ser visto como um elemento a mais no ambiente de ensino-aprendizagem, que propicie a realização de tarefas diferentes, em consonância com as aptidões, experiências anteriores, ritmos e preferências dos diferentes estudantes [TUR93b]. De acordo com Papert, em [PAP80,p.23]:

5 “Atividades Matemáticas”: material subsidiário ao trabalho do professor. Foram criadas em 1983, no Estado de São Paulo, e contêm propostas de atividades Matemáticas desde o Ciclo Básico até a $4^{a}$ série do 10 grau. 
"Embora a tecnologia desempenhe um papel essencial no futuro da Educação, o foco central não pode ser a máquina e sim a mente $e$, particularmente, a forma em que os movimentos intelectuais $e$ culturais se autodefinem e crescem em cada pessoa envolvida neste processo educacional."

\subsection{Motivações e objetivos}

Este trabalho apresenta o projeto de construção do sistema TEGRAM - um sistema tutor destinado a auxiliar o processo de ensino-aprendizagem de conceitos relacionados à Matemática a ser utilizado por estudantes do 10 grau.

A existência de metodologias para o ensino da Matemática, consagradas na literatura (por exemplo, "Atividades Matemáticas"), que podem ser implementadas em um sistema computacional, bem como a opinião de que o uso de uma nova tecnologia pode estimular tanto os estudantes como professores, têm servido de motivação para o estudo, definição e implementação de um sistema destinado a ensinar conceitos dentro do domínio da Matemática. Além disso, a investigação de sistemas de auxílio ao processo de ensino-aprendizagem é de interesse de um grupo de pesquisa existente no Instituto de Ciências Matemáticas de São Carlos - ICMSC (USP - São Carlos). Alguns resultados de pesquisa do grupo podem ser encontrados em [HAS93] [MAL93a] [MAL93b] [MEN94] [NUN93a] [NUN93b] [NUN93c] [SOU93] [TAK93a] [TAK93b] [TUR93a] [TUR93b].

Técnicas de Inteligência Artificial (IA) têm sido usadas cada vez mais na construção de sistemas computacionais de auxilio ao processo de ensino-aprendizagem [BUR88] [AIK89] [KEL93]. Algumas características para que estes sistemas computacionais sejam classificados como sistemas inteligentes de auxílio ao ensino são: possuir o conhecimento tanto do domínio a ser ensinado quanto das estratégias de ensino, representados de maneira explícita e em módulos separados; saber diferenciar o estudante a qual estão ensinando; compartilhar o controle da interação com o estudante; saber justificar suas respostas (geração de explicação), ou seja, possuir capacidade de prover explicações sobre seu comportamento aos usuários; saber interromper os estudantes no momento certo, entre outras [BIE91]. Mecanismos eficazes de representação e manipulação do conhecimento constituem um dos principais requisitos destes sistemas. Um dos vários tipos de sistemas inteligentes é o Sistema Tutor Inteligente (STI).

O estudo de sistemas deste tipo oferece a oportunidade de vivência de uma experiência interdisciplinar, que envolve diversas áreas do conhecimento, tais como Computação, Educação ${ }^{6}$, Comunicação, além daquelas específicas do domínio escolhido para ser ensinado.

Este trabalho, ainda que não pretenda atender a todos os requisitos de um sistema tutor inteligente, tem o objetivo de implementar um protótipo de um sistema tutor,

\footnotetext{
6 Dentro da área de Educação estão a Psicologia Cognitiva e a Didática.
} 
chamado TEGRAM, destinado a auxiliar o processo de ensino-aprendizagem que vá além de um simples "expositor eletrônico" de material didático.

A escolha do assunto a ser explorado foi guiada, naturalmente, pela questão de viabilidade quanto às ferramentas e tempo disponíveis, bem como pela possibilidade de explorar o computador naquilo que ele pode, no caso deste trabalho, oferecer de melhor. Assim, a escolha não recaiu sobre tópicos que geralmente são melhor explorados com o uso de argumentações verbais e/ou que requerem um diálogo mais sofisticado com o professor. Procurou-se escolher tópicos que seriam beneficiados por recursos melhor utilizados em computadores - como é o caso daqueles que envolvem Geometria eleita como o domínio a ser explorado pelo sistema.

Neste trabalho são selecionados alguns conceitos relacionados às figuras geométricas planas para compor o material a ser ensinado. Como se trata de um assunto bastante extenso - desde a definição das figuras até resultados mais complexos como as aplicações em geometria espacial, passando por conceitos de área, perímetro e resultados correlatos -, a seleção, ainda dentro deste assunto, baseou-se no perfil dos usuáriosestudantes que se pretende atingir. Enfim, a idéia é criar um sistema em que possam ser acrescentados novos materiais, ampliando, assim, o universo de estudantes que venham utilizá-lo.

No intuito de motivar o estudante, procurando ensinar de maneira distinta da tradicional, todas as atividades didáticas propostas pelo sistema são baseadas num jogo chinês milenar chamado Tangram. $O$ Tangram é formado por sete figuras geométricas $\mathbf{e}$ é utilizado de forma a levar o estudante a descobrir ou deduzir alguns conceitos matemáticos relacionados a estas figuras. Como conseqüência, o sistema utiliza recursos e técnicas de computação gráfica para a manipulação e reconhecimento de figuras, bem como de recursos naturalmente apelativos neste domínio, como por exemplo, animação.

A possibilidade de que a construção do protótipo desenvolvido possa evoluir para um sistema de ensino que seja de utilidade prática e que possa oferecer subsídios para futuras pesquisas em IA e Educação, também são motivações e objetivos deste trabalho.

\subsection{Organização da dissertação}

No primeiro capítulo discute-se o uso de computadores na Educação de forma geral e no ensino da Matemática em particular. Comenta-se sobre a realidade brasileira no ensino de 10 e 20 graus e são apresentados as motivações e os objetivos deste trabalho.

No capítulo dois é realizada uma revisão bibliográfica sobre Sistemas Tutores Inteligentes (STIs). Apresentam-se algumas definições de STI, um pequeno histórico e sua arquitetura básica, comentando-se as funções e as principais técnicas utilizadas em cada módulo desta arquitetura. São descritos, também, alguns sistemas tutores para o ensino de conceitos relacionados à Matemática.

No capítulo três apresenta-se o Tangram e como ele pode ser utilizado para explorar conceitos relacionados à Geometria. Alguns exemplos de atividades propostas 
na literatura que utilizam o Tangram para o ensino de conceitos de figuras geométricas planas são apresentados.

No capítulo quatro é apresentado o sistema TEGRAM, um sistema tutor para ensinar conceitos relacionados à Geometria Plana baseado no Tangram. É descrita a arquitetura do sistema bem como os módulos que a compõem.

$O$ capitulo cinco contém os conceitos $e$ as atividades que foram implementadas no sistema TEGRAM. Para visualizar melhor como funciona o sistema TEGRAM, apresenta-se neste capítulo um exemplo de uma interação real entre o sistema e um determinado estudante.

No capítulo seis são apresentadas as conclusões e as contribuições deste trabalho, além de algumas sugestões para trabalhos futuros.

$O$ apêndice I (Glossário) contém a definição de algumas palavras importantes para a área de STIs tal qual são originalmente conhecidas, pois são termos consagrados na literatura.

No apêndice II é apresentada uma tabela contendo alguns sistemas tutores encontrados na literatura, e seus respectivos domínios explorados. 


\section{CAPÍTULO 2}

\section{SISTEMAS TUTORES \\ INTELIGENTES}




\subsection{Consideraçס̃es iniciais}

$\mathbf{O}$

uso de computadores para auxiliar o processo de ensino-aprendizagem é uma das áreas de pesquisa onde as aplicações de Inteligência Artificial (IA) vêm sendo desenvolvidas nos últimos anos. A pesquisa em STIs resulta da interação entre IA e Educação.

\subsubsection{Histórico}

O uso de aparatos mecânicos que pudessem auxiliar o processo de ensinoaprendizagem fez com que, no inicio dos anos 50, fosse cogitado o uso de Instrução Programada. A instrução programada consiste em dividir o material a ser ensinado em pequenos segmentos logicamente encadeados, denominados módulos, que seriam apresentados de forma impressa. Pode ser caracterizada como uma forma autodidata de ensino, na qual as informações são apresentadas gradualmente em pequenas doses, segundo um encadeamento lógico, da mais simples a mais complexa, da mais concreta a mais abstrata, permitindo que o estudante assimile os conceitos de acordo com o seu próprio ritmo [PAR87] [VAL91].

Com o advento da Ciência da Computação, notou-se que os módulos do material instrucional poderiam ser apresentados com flexibilidade pelo computador. Assim, durante $o$ início dos anos 60 , diversos programas de instrução programada foram implementados. Com esses programas, nascia a Instrução Auxiliada por Computador (Computer-Assisted Instruction, CAI) ou Aprendizagem Auxiliada por Computador (Computer-Assisted Learning, CAL).

A abordagem de ensino ou os aspectos pedagógicos subjacentes a muitos dos sistemas CAI caracterizam a psicologia behaviorista, também conhecida como psicologia estímulo-resposta de Skinner [OBE92]. Isto resultou em sistemas limitados educacionalmente e fonte de frustrações para muitos estudantes.

Alguns fatores que limitam tanto a utilização quanto a aceitação dos sistemas CAI são:

a) a apresentação do assunto a ser ensinado não se adapta às necessidades individuais de cada estudante. A forma estática de como o assunto é organizado apresenta pouca ou nenhuma vantagem sobre as ferramentas impressas tradicionais de ensino [WEN87];

b) os sistemas CAI possuem uma habilidade limitada para analisar as. intervenções dos estudantes. Obrigam o estudante a atuar de forma 
passiva, isto é, a sua participação resume-se apenas à seleção de alternativas pré-armazenadas pelo projetista do sistema;

c) estes sistemas não fornecem um ensino individualizado. Isto significa que todos os estudantes, independentemente de suas habilidades ou préconhecimento do assunto sendo ensinado, recebem exatamente o mesmo material, na mesma seqüência;

d) a falta de conhecimento profundo sobre o domínio a ser ensinado impossibilita o sistema de responder perguntas do tipo "Por quê?" $\mathrm{e}$ 'Como?". Nos sistemas CAI, o conhecimento do assunto a ser ensinado é representado implicitamente, ou seja, está contido no material instrucional pré-armazenado pelo projetista. O computador simplesmente segue, durante a interação com o estudante, as instruções definidas pelo projetista e apresenta o material. Isto impossibilita o sistema de fornecer explicações sobre o domínio do conhecimento a ser ensinado, e

e) os sistemas CAI possuem algumas estratégias de ensino fixas que podem ser adaptadas somente para a classe de estudantes que o projetista definiu anteriormente [LES87].

Uma das necessidades dos sistemas CAI para possibilitar o aprendizado dos estudantes é possuir flexibilidade no processo de ensino. Isto significa que o sistema precisa ser capaz de deduzir e manter um modelo detalhado do que o estudante sabe e não sabe. Estas informações são utilizadas para individualizar o ensino, modificando a apresentação do conteúdo e a estratégia de ensino, conforme necessário [OBE92]. Segundo Self [SEL74], Yazdani [YAZ87], Duchastel [DUC89], Rickel [RIC89] e Nwana [NWA90], o principal problema destes sistemas é que eles não são capazes de fornecer um feedback rico ou um ensino mais individualizado para os estudantes, pois eles não foram projetados para saber o quê ensinar, para quem ensinar ou como devem ensinar. Devido a estas características, os sistemas CAI são freqüentemente referenciados como "folheadores eletrônicos de páginas".

Em resposta às limitações impostas pelos sistemas CAI, Self, em [SEL74], argumentou que a solução destas limitações não poderia ser viabilizada sem a utilização de técnicas de IA. Carbonell, em [CAR70], introduziu a idéia de usar técnicas e métodos de IA em sistemas CAI, nascendo assim, ainda na década de 70, os Sistemas Inteligentes de Instrução Auxiliada por Computador (Intelligent Computer-Assisted Instruction, ICAI), também conhecidos como Sistemas Tutores Inteligentes - STI (Intelligent Tutoring Systems, ITS). O termo Sistema Tutor Inteligente (STI) será utilizado em toda esta dissertação.

\subsubsection{Definiçåo}

Sistema Tutor Inteligente (STI) é definido como sendo um programa computacional destinado a auxiliar o processo de ensino-aprendizagem, utilizando 
técnicas e métodos de IA para representar o conhecimento e para conduzir a interação com o estudante. Métodos e técnicas de IA desempenham um papel relevante por possibilitar, em princípio, uma maior flexibilidade e participação ativa do estudante e do sistema, gerando um ambiente cooperativo para o ensino e para a aprendizagem.

Segundo Sleeman e Brown, em [SLE82,p.2], para que estes sistemas tivessem um impacto significativo no processo de ensino-aprendizagem era necessário que:

“... o sistema possuisse seu próprio especialista para resolver os problemas, suas capacidades próprias de modelagem e diagnóstico dos estudantes e capacidades próprias de mecanismos de explicação. A fim de administrar estas capacidades de raciocínio, o sistema deveria ter o controle da interação estudante-sistema e estratégias tutoriais explícitas, especificando quando interromper uma atividade de resolução de problemas do estudante, o que dizer e a melhor forma de dizê-lo."

Considerando a Educação como um processo de comunicação de conhecimento entre um professor, que tem mais conhecimento, e um estudante, que tem menos conhecimento, Wenger, em [WEN87], apresenta uma visão expandida para os STIs. Enfatiza que os STIs podem ser vistos como ambientes de comunicação de conhecimento, onde professores (ou sistemas) e estudantes se comunicam para transmitirem o conhecimento. $O$ objetivo desta comunicação é o estudante obter $o$ conhecimento ou a especialidade em algum domínio.

Existem muitos pesquisadores que não consideram os STIs como sendo sistemas de comunicação de conhecimento. Self [SEL90], por exemplo, defende a idéia de que o conhecimento não é um tipo de mercadoria que pode ser transmitida; não pode ser simplesmente recebido pelos estudantes, mas deve ser construído de alguma forma por ele. A construção deste conhecimento, ou seja, a aprendizagem por parte do estudante é, essencialmente, o resultado de um processo reflexivo. Muitas vezes, os estudantes não aprendem somente fazendo algo, mas refletindo sobre o que estão fazendo ou sobre o que já fizeram, isto é, passando pelo processo de tomada de consciência das ações [MEN89].

Decorrente de tudo que envolve a pesquisa de STIs, Ohlson [OHL87], Self [SEL88], Mizoguchi [MIZ90], Burger e Desoi [BUR92], Kemp [KEM92], apontam a necessidade de buscar premissas psicológicas, epistemológicas e pedagógicas para a construção de STIs. Portanto, o projeto e desenvolvimento destes sistemas pertencem a uma nova área de pesquisa denominada de Ciência Cognitiva ${ }^{*}$ [KEA87a] - uma área multidisciplinar que envolve a Ciência da Computação, Psicologia Cognitiva* e Educação, conforme apresenta a Figura 1. Enquanto a área de Ciência da Computação, através da IA, fornece técnicas e métodos para a representação e manipulação do conhecimento envolvido, a área de Psicologia Cognitiva traz modelos de teorias do aprendizado e modelos sobre a forma de como o indivíduo constrói o conhecimento na

* Nesta dissertação todas as palavras marcadas com asterisco (*) são definidas no Glossário (Apêndice I). 
interação organismo/meio-ambiente. Por último, a área de Educação fornece teorias para que o processo de ensino-aprendizagem seja mais flexível e proveitoso para ambas as partes (sistema e estudante).

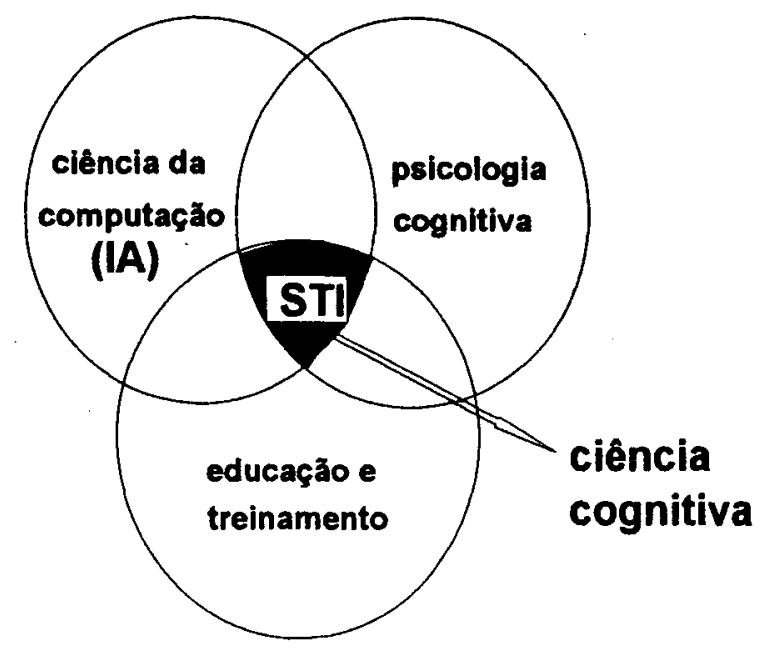

Figura 1: STI - Intersecção entre IA, Psicologia

Cognitiva e Educação [KEA87a,p.4].

\subsection{Arquitetura básica}

Observando como são organizados os vários STIs existentes na literatura, nota-se que estes podem variar um pouco quanto à arquitetura, ou seja, quais e como são organizados os módulos que a compõem. Isto se deve ao fato de que a maior parte do trabalho na área ainda é de natureza experimental, ou seja, não existe uma teoria significativa de STI. A maioria dos textos sobre STIs (por exemplo, [WEN87], [MAN88], [POL88], [PSO88]) são inteiramente discursivos, sem nenhum tipo de formalização de seus conteúdos [SEL90].

Entretanto, há quatro componentes que podem ser considerados mínimos, formando uma "arquitetura básica" para os STIs. Cada um destes componentes constitui um módulo funcional distinto e são apresentados na Figura 2, como:

a) módulo do domínio: contém o conhecimento do que será ensinado;

b) modelo do estudante: contém informações sobre o estudante que utilizou ou que está utilizando o sistema;

c) módulo tutorial: contém as estratégias de como ensinar, e

d) módulo de comunicação: responsável por administrar a interação do sistema com o estudante.

Nas próximas seções, estes quatro módulos são discutidos mais detalhadamente, abordando suas respectivas funções e os seus relacionamentos. 


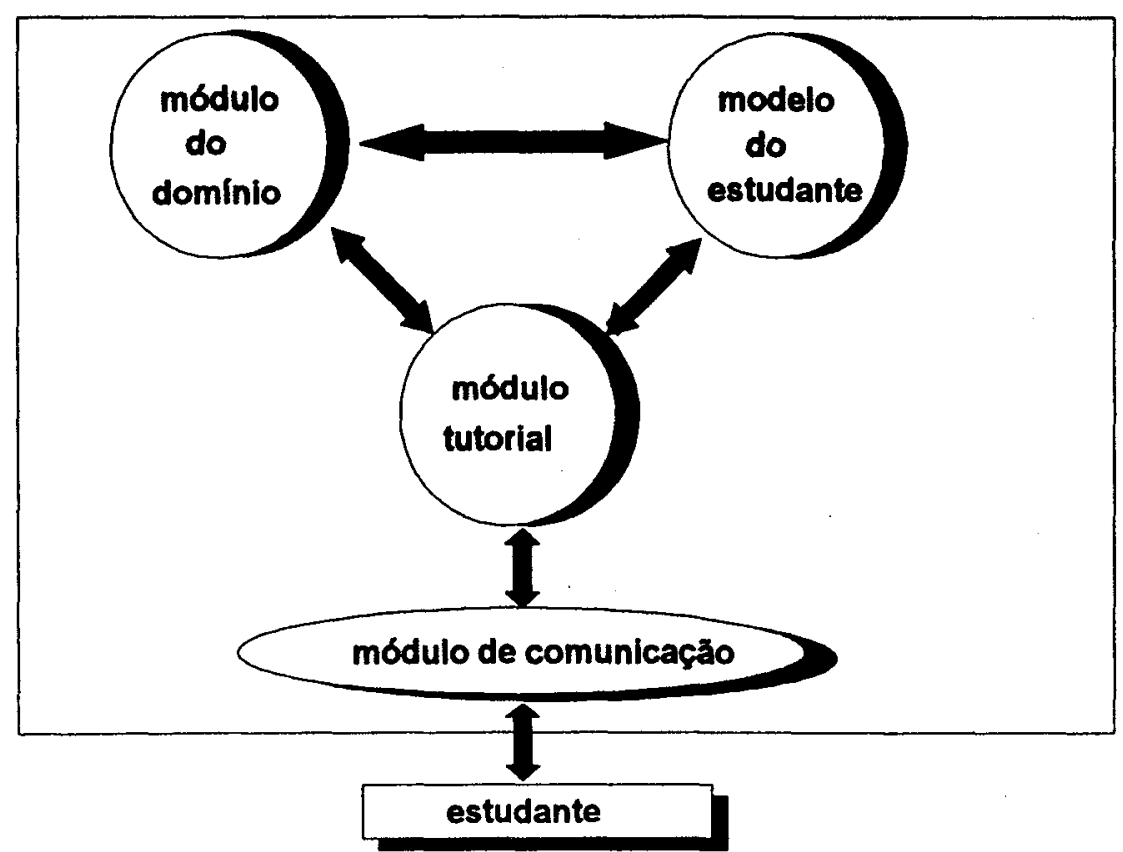

Figura 2: Arquitetura básica dos STIs.

\subsubsection{O módulo do domínio}

O módulo do domínio (também chamado módulo do especialista) contém o conhecimento de um determinado domínio que será ensinado para o estudante.

A maneira como o conhecimento deste módulo é representado (explicitamente ou implicitamente) foi uma das primeiras mudanças ocorridas na transição dos sistemas CAI para os STIs. Este conhecimento passou a ser representado explicitamente, armazenado em uma base de conhecimento, separado de informações de controle (como ensinar). Uma das vantagens desta representação é a possibilidade do sistema raciocinar sobre a estrutura do conteúdo a ser ministrado, que lhe permite ser não apenas um "folheador eletrônico de páginas" [CER87] [BRA88]. Em muitos casos, esta representação não é somente uma descrição de vários conceitos e habilidades que o estudante está para adquirir, como um currículo escolar. Pode ser considerado um modelo verdadeiro que representa um domínio especifico e restrito, fornecendo ao sistema uma forma dinâmica de experiência [WEN87] .

A forma de representação do conhecimento a ser utilizada no módulo do domínio é determinada tanto pelo domínio a ser ensinado quanto pelo tipo de manipulação a ser realizada pelo sistema tutor. A representação do conhecimento pode ser puramente declarativa (através de Redes Semânticas* ou Lógica) em domínios de natureza descritiva e teórica (por exemplo, Geografia ou História). Pode ser procedimental (via programas) em domínios orientados à execução de uma determinada tarefa (por exemplo, programação Pascal ou Lisp) ou pode ser hibrida (por exemplo, Regras de Produção* ou Frames*) quando o domínio é descritivo mas também possui procedimentos inerentes ao seu conhecimento (por exemplo, Matemática ou Física) [VIC92]. 
O módulo do domínio exerce duas funçð̃es principais:

a) serve como fonte de conhecimento do assunto a ser ensinado para o estudante. Isto inclui a capacidade de geração de explicaç̃es e respostas para os estudantes, bem como tarefas e questões a serem realizadas, $\mathrm{e}$

b) serve como um padrão para avaliar o desempenho geral do estudante. Para isto, o sistema deve ser capaz de gerar soluções para os problemas no mesmo contexto do estudante, para que suas respectivas respostas sejam comparadas. Segundo Woolf e McDonald [W0084], mesmo que o módulo do domínio não tenha necessariamente habilidades para resolver todos os problemas para o estudante, ele deve pelo menos reconhecer uma resposta incorreta.

Se, num determinado momento, o objetivo do STI é guiar ou monitorar o estudante na resolução de um tipo específico de problema, o módulo do domínio deve gerar os possiveis caminhos de solução para que os passos intermediários sejam comparados. Se o objetivo final do sistema é tentar individualizar o ensino, descobrindo qual o tipo de raciocínio utilizado pelo estudante, então é mais importante que ele seja capaz de gerar múltiplos caminhos de solução. Nesta dissertação, individualizar o ensino significa ensinar de tal forma que o estudante se sinta privilegiado no sistema, ou seja, significa apresentar materiais diferentes para diferentes estudantes, dependendo do nivel de conhecimento do estudante no assunto a ser explorado.

\subsubsection{O modelo do estudante}

Um sistema de auxílio ao ensino, cujo objetivo é alcançar um ensino mais individualizado e um comportamento mais inteligente, necessita tanto de conhecimento do assunto a ser ensinado como também de conhecimento sobre o estudante com quem está interagindo. A fim de determinar qual o próximo passo durante a interação do sistema com o estudante (pois isto não está pré-definido), é necessário que o STI tenha o conhecimento sobre o que o estudante sabe [KEA87b].

O módulo que contém uma representação do estado atual do conhecimento e do desempenho do estudante no assunto que está sendo ensinado, é denominado modelo do estudante. Este modelo é atualizado dinamicamente pelo sistema, e fornece um "quadro" representando o desempenho de um particular estudante em um determinado momento [HEG90].

Idealmente, um STI deveria saber o nivel de conhecimento do estudante no assunto que está sendo ensinado e o comportamento de aprendizagem do estudante, envolvendo aspectos como: ritmo, os métodos de apresentação aos quais o estudante responde melhor, o seu nivel de interesse e motivação pelo assunto em questão e sua área de especialidade, entre outros. De posse destas informações, o tutor poderia escolher a estratégia e os métodos de apresentação mais apropriados, podendo avaliar as respostas do estudante em termos do conhecimento supostamente adquirido. Assim, este 
modelo deveria incluir todos os aspectos relativos às características e nível de conhecimento do estudante que tenham possíveis repercussões sobre seu desempenho no processo de aprendizagem.

Portanto, construir um perfeito modelo do estudante não é trivial [WEN87] [DIE93]. Segundo Nwana [NWA90], provavelmente esta perfeição seja impossível, pois o canal de comunicação entre o STI e o estudante ainda é muito limitado (informações via teclado, tela, mouse, entre outros). Tutores humanos (professores) normalmente combinam dados de uma grande variedade de fontes, como por exemplo os efeitos da voz ou a expressão facial dos seus estudantes. Logo, quanto melhor for o canal de comunicação utilizado, maior será a facilidade para se construir dinamicamente um bom modelo do estudante.

Os modelos de estudante podem ser classificados em modelos quantitativos e qualitativos [CLA88]. Modelos quantitativos ou numéricos são baseados em valores, ou seja, o estudante é mapeado em um modelo que contém dados de quanto ele sabe sobre um determinado assunto, quantas vezes ele errou, acertou, etc. Modelos qualitativos descrevem os objetos e processos do sistema, em termos das relações espaciais, temporais e de causa-efeito, ou seja, são informações sobre o estudante, tais como: qual a forma de apresentação do material instrucional a qual o estudante melhor se adaptou, qual o nível de conhecimento do estudante, quais os tipos de exercícios preferidos, entre outros.

O modelo do estudante é utilizado por outros módulos do STI para muitos propósitos. De acordo com Self [SEL85] e Elsom-Cook [ELS93], o modelo do estudante possui seis funções básicas:

1) corretiva: ajuda a eliminar os bugs* do conhecimento do estudante. Neste caso, o modelo deve identificar a diferença existente entre o que o estudante entendeu e o conhecimento correto do assunto ensinado;

2) elaborativa: ajuda a complementar o conhecimento do estudante. Neste caso, o sistema deve identificar quais assuntos necessitam ser mais explorados;

3) estratégica: ajuda a promover mudanças significativas nas estratégias de ensino (módulo tutorial);

4) de diagnóstico: ajuda a diagnosticar os bugs do conhecimento do estudante;

5) prognóstica: ajuda a determinar as prováveis respostas do estudante às ações do tutor. Neste caso, o modelo do estudante é utilizado para antecipar o efeito de uma ação sobre o estudante, ou seja, funciona como um "simulador de ações", e

6) avaliativa: ajuda a avaliar tanto o estudante quanto o próprio STI.

Muitas vezes, as barreiras encontradas pelos estudantes estão na falta de prérequisitos e não no conceito a ser aprendido, ou seja, a manifestação de um erro não se deve ao conhecimento incompleto ou incorreto do assunto em si, mas a falhas de compreensão de outros conceitos que são pré-requisitos para este. Deste modo, o 
modelo do estudante também deve fornecer uma representação explícita dos conceitos incorretos assumidos pelo estudante. Desta forma, esta representação facilita a retomada dos pré-requisitos e a aprendizagem do conceito atual. Enfim, o modelo do estudante é uma tentativa de representação do conhecimento do estudante.

A literatura apresenta quatro tipos principais de modelo do estudante: modelo overlay, modelo de perturbação, modelo procedimental e modelo diferencial [VAN88] [DUC89] [VAS90] [NWA90]. No entanto, esta divisão em tipos nem sempre ocorre, pois dependendo da especificação do sistema e da forma como o modelo do estudante é construído, podem aparecer caracteristicas de mais de um tipo agrupadas em um mesmo modelo. Uma descrição sucinta de cada um dos tipos de modelo é apresentada a seguir.

No modelo overlay, o conhecimento do estudante é representado como um subconjunto da base de conhecimento do módulo do domínio (conhecimento de um especialista no domínio) (Figura 3). Isto permite uma fácil comparação entre o que o estudante sabe e o que ele deveria saber. $O$ estudante é modelado dentro do sistema por meio de uma lista de habilidades e/ou conceitos que se acredita conhecidos pelo estudante. Esta abordagem é limitada a situações onde especialistas e estudantes usam as mesmas habilidades. Este modelo foi introduzido por Goldstein [GOL82] e é muito utilizado atualmente.

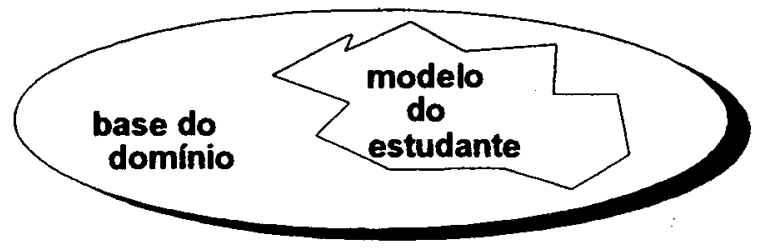

Figura 3: Modelo overlay.

O modelo de perturbação tem a mesma abordagem da representação do modelo overlay (Figura 4). Além de o estudante ser representado como um subconjunto da base de conhecimento do módulo do domínio, o modelo contém uma lista de bugs cometidos pelo estudante durante a interação com o sistema (por exemplo, uma lista de seqüências de ações errôneas do estudante) armazenadas no Catálogo de Bugs*. Pode, ainda, conter uma lista de regras do domínio ligeiramente modificadas ou perturbadas denominadas mal-rules* (por exemplo, as misconceptions* do estudante [STE79] [COS88]). Este modelo também é chamado de modelo de bugs. Um dos sistemas que utiliza esta abordagem é o sistema $B U G G Y$ [BRO78].

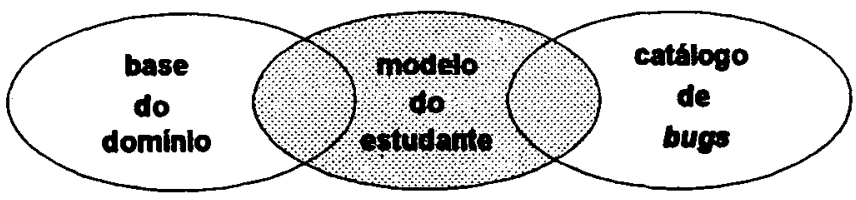

Figura 4: Modelo de perturbação. 
O modelo procedimental contém os passos (os caminhos) utilizados pelo estudante na resolução de um determinado problema sugerido pelo sistema (Figura 5). Para tornar possível uma avaliação do estudante pelo sistema, são incorporadas no módulo do domínio algumas técnicas especiais que possibilitam ao sistema imitar o modo pelo qual o estudante soluciona seus problemas.

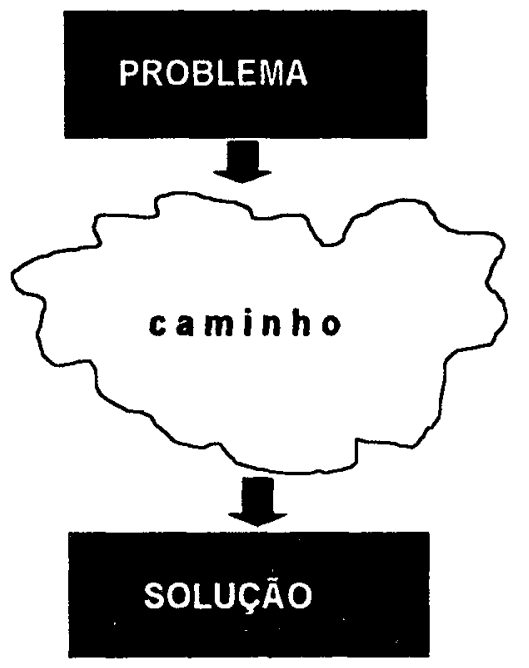

Figura 5: Modelo procedimental.

O modelo diferencial faz uso das comparações entre as respostas dadas pelo estudante, quando resolve um determinado problema, e a respectiva resposta dada por um especialista neste domínio. $O$ modelo do estudante é construído com base na análise das diferenças entre estas duas respostas, conforme apresenta a Figura 6. Um exemplo de sistema que utiliza este modelo é o WEST [BUR82a].

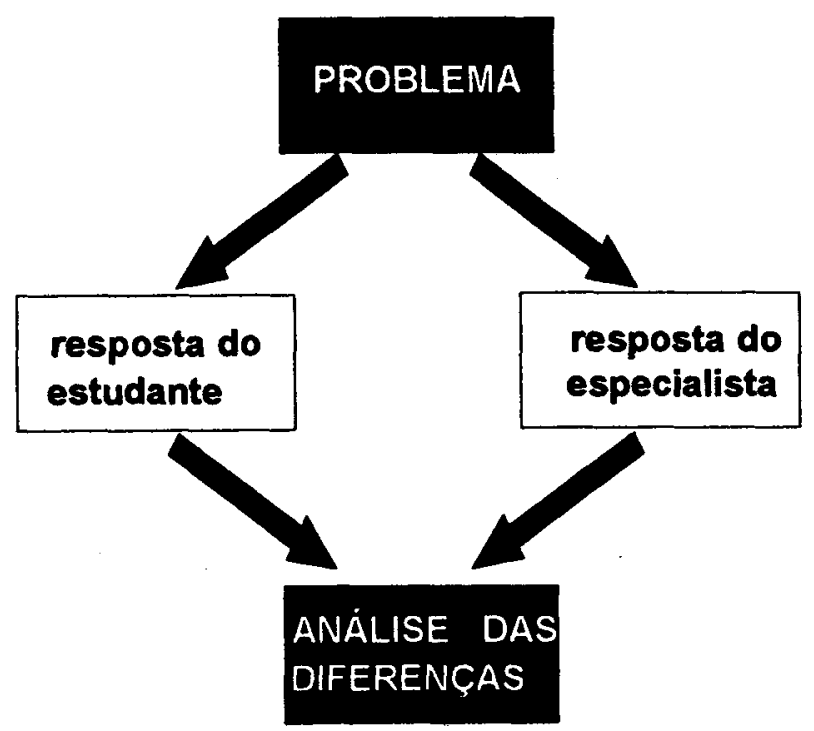

Figura 6: Modelo diferencial. 
A aplicação de técnicas de aprendizagem de máquina (Machine Learning*) para desenvolver e manter dinamicamente modelos individuais de estudantes está sendo muito pesquisada [GIL88]. Arun Kumar et al., em [ARU92], apresentam uma arquitetura de um sistema de aprendizagem de máquina integrado (Integrated Machine Learning System, IMLS) para gerar um STI, enfatizando, principalmente, a modelagem do estudante.

\subsubsection{O módulo tutorial}

O módulo tutorial (também chamado de módulo pedagógico ou módulo de estratégias de ensino) é o componente do STI que planeja e governa a interação com o estudante. Contém estratégias e técnicas de ensino que são selecionadas e combinadas dinamicamente de acordo com as reações dos estudantes. Este módulo é fonte e administrador de todas as intervenções pedagógicas feitas pelo sistema.

Uma estratégia de ensino pode ser vista como um plano, ou seja, uma estrutura de ações que visa atingir determinados objetivos. As estratégias constituem o conhecimento sobre como ensinar [VIC90] [VIC92]. Para um bom desempenho do STI, o módulo tutorial tem que verificar o modelo do estudante e avaliá-lo de forma a obter informações de como apresentar com sucesso um determinado tópico a um determinado estudante .

É um dos objetivos dos STIs representar explicitamente o conhecimento contido no módulo tutorial. Isto possibilita ao sistema adaptar-se e melhorar suas estratégias de ensino com o passar do tempo (self-improving tutors). Também possibilita que algumas estratégias sejam reutilizadas em outros domínios. Segundo Kearsley [KEA87b], é de fundamental importância para um STI adaptar suas estratégias de ensino a um determinado estudante.

Muitos STIs representam suas estratégias de ensino (regras tutoriais) através de regras de produção. Esta representação facilita a modificação do conhecimento, visto que a inclusão, remoção e alteração das regras tutorais é, de certo modo, simples [RIC89].

Segundo Wenger [WEN87] e Breuker [BRE88], as estratégias definidas no módulo tutorial abordam, principalmente:

a) a forma de divisão do controle, ou seja, como é realizado o gerenciamento da iniciativa no controle do aprendizado. Esta decisão pode ser classificada em:

- controle total do sistema sobre a forma de aprendizagem. $\mathrm{O}$ sistema monitora todas as atividades realizadas pelo estudante, o qual apenas responde às questões formuladas pelo sistema;

- controle do aprendizado é balanceado entre o sistema e o estudante (controle de iniciativa mista). Ambos podem perguntar e responder questões, $\mathbf{e}$ 
- controle total do estudante sobre a aprendizagem. $\mathbf{O}$ estudante tem a possibilidade de controlar totalmente o sistema. Este controle está presente, por exemplo, em sistemas de treinamento (Coach Systems*);

b) os critérios de quando interromper o estudante e $o$ quê dizer. Esta questão desdobra-se em:

- seleção dos tópicos a serem apresentados;

- ordenação dos tópicos, se houver mais que um, e

c) quais os critérios de avaliação do estudante quanto ao conteúdo do assunto a ser explorado.

Portanto, independentemente do tipo de controle, o módulo tutorial é responsável por definir quando e o quê deve ser apresentado ao estudante. No caso do controle baseado na iniciativa mista, o módulo tutorial deve ainda definir quando interromper, ou seja, que razões justificam interromper o raciocínio ou aprendizagem do estudante. $O$ como apresentar o material instrucional é de responsabilidade de outro módulo da arquitetura (módulo de comunicação) discutido a seguir.

\subsubsection{O módulo de comunicação}

O papel da interface na interação usuário-computador vem ganhando importância significativa desde a última década. Pode-se dizer que, independentemente de sua funcionalidade, um sistema interativo terá sucesso ou não dependendo da qualidade e usabilidade de sua interface com o usuário. STIs não constituem uma exceção. Pelo contrário, sendo seu principal objetivo auxiliar a aprendizagem, é fundamental que a comunicação com o estudante seja construída de uma maneira que o estimule. Quanto mais o estudante se sentir inserido no seu ambiente de aprendizagem, mais rica e interessante será a sua experiência.

De acordo com alguns autores (Frye et al. [FRY88]; Winkels [WIN89]; Barnard et al. [BAR90]), para que um STI tenha uma interação flexível com o estudante, é essencial possuir um módulo específico que controle esta interação, denominado módulo de comunicação.

Enquanto o módulo tutorial decide, essencialmente, o conteúdo do material instrucional a ser apresentado para o estudante, o módulo de comunicação deve se preocupar com a forma final da apresentação deste material ao estudante. Assim, este módulo é considerado o componente de comunicação de um STI que controla a interação tanto entre o sistema e o estudante, quanto entre o sistema e o professor.

O estudante não é o único a interagir com o STI; o professor é um usuário cuja interação é igualmente importante e geralmente é esquecido pelos projetistas. Ter um professor como usuário de um STI não é um objetivo nos projetos atuais destes sistemas. A interação entre professor e STI difere substancialmente daquela entre estudante e STI. Na interação com o professor o compromisso do sistema não é ensinar, mas sim, expor e explicar de diversas maneiras o funcionamento e a estrutura do sistema, 
além de prover dados sobre o desempenho dos estudantes que com ele interagem. Devese ressaltar que não se trata de um professor atuando como um estudante, mas sim de uma interação projetada especialmente para um professor. Desta forma, a interação com um professor tem duas funções principais:

a) validar o sistema: por validação do sistema entende-se o acesso do professor às bases de conhecimento (domínio, estudante, tutorial) e às regras que controlam uma seção especial com o professor. Ele pode questionar o sistema a fim de obter uma "radiografia" deste. Assim, o tutor, por ser uma ferramenta dinâmica, pode ser constantemente atualizado, melhorado e corrigido pelo professor. Para isto, é necessário que o sistema se "mostre" ao professor, apontando os pontos possiveis de alteração e a forma (explicação) de como isso pode ser realizado, e

b) avaliar o estudante: o sistema pode servir como fonte ao professor para avaliar a atuação dos estudantes. A partir das informações do estudante, presentes no modelo do estudante (representadas através de gráficos, tabelas, textos, etc.), o professor tem meios de avaliar o desempenho do usuário durante a interação com o sistema.

Segundo Hoog et al. [HOO91] e Viccari e Oliveira [VIC92], outros objetivos a serem cumpridos pelo módulo de comunicação podem ser:

a) evitar que o estudante se entedie, ou seja, é preciso possibilitar que a comunicação aconteça numa linguagem compreensível ao estudante. Para isto, é necessário utilizar vários recursos que apresentem o material instrucional, diversificando os meios de apresentação e, conseqüentemente, permitindo ao estudante uma experiência de aprendizagem mais rica. Segundo Edwards 1 , as pessoas retêm aproximadamente $25 \%$ do que escutam, $45 \%$ do que vêem e escutam, e $70 \%$ do que vêem, escutam e fazem. Desta forma, pode-se concluir que as informações são melhor absorvidas se o estudante for um participante ativo no processo de aprendizado, e se a apresentação envolver vários dos sentidos do estudante;

b) facilitar o diálogo, ou seja, possibilitar ao estudante intervir facilmente no discurso com o tutor e vice-versa;

c) manter o tempo de resposta do sistema dentro de limites aceitáveis, e

d) realizar a monitoração do estudante o máximo possível em background, não sobrecarregando o estudante com questionários excessivos.

Deste modo, o estudante poderá se sentir inserido no seu ambiente de aprendizagem o que, por sua vez, poderá, mais facilmente, estimular a assimilação do assunto ensinado pelo sistema.

1 EDWARDS, M. The Mercedes Bens of interactive video. Hardcopy, v.14, n.5. p.74-80. may 1985. apud [RIC89]. 
O progresso em tecnologia de mídia tem fornecido novas ferramentas para a construção de interfaces que possibilitem uma comunicação sistema/usuário mais eficiente. Por exemplo, hipertexto e hipermídia são tecnologias emergentes que têm grande potencial para facilitar a interação das pessoas com o mundo da informação em que vivem, podendo enriquecer, e muito, o processo de ensino-aprendizagem [RUS87] [DUC90] [JON90] [LEG90] [NUN93b].

Enfim, pesquisas em interfaces para STIs são recentes, tanto que muitos não consideram o módulo de comunicação como um componente distinto da arquitetura, e ainda não existe uma teoria coerente e útil sobre como desenvolver interfaces eficientes num contexto instrucional [MIL88] [HOO91].

\subsection{Sistemas tutores para o ensino da Matemática}

Como descrito anteriormente, tanto os computadores como os STIs não podem ser vistos como uma panacéia para resolver todos os problemas educacionais. Esta seção discute algumas vantagens e desvantagens do uso de STIs para auxiliar o processo de ensino-aprendizagem em geral e especificamente no domínio da Matemática.

\subsubsection{Vantagens e desvantagens}

O uso de STIs para auxiliar o processo de ensino e aprendizagem apresenta, de acordo com a literatura, algumas vantagens e desvantagens.

Segundo Lovell2, a área da Matemática tem um papel fundamental na transição de CAI para STI. As duas principais razões são:

a) A Matemática é altamente estruturada e seus algoritmos são bem definidos.

b) A Matemática é uma área educacional importante, pois sustenta muitas outras ciências e engenharias.

Além das discutidas até agora, Ridgway, em [RID88,p.29], aponta algumas vantagens de sistemas computacionais de auxílio ao ensino:

" $A$ idéia de introduzir inteligência dentro de sistemas de aprendizagem parece ser uma proposta promissora. É plausivel pensar que a adaptação às necessidades do estudante seja benéfica para a Educação;

- A pesquisa em STI é muito excitante, oferecendo grandes desafios intelectuais para os pesquisadores, independentemente da utilidade educacional desses desafios, $e$

2 LOVELL, K. Intelligent teaching systems and the teaching of mathematics. AISB Quartely, 38, p.2630, 1980. apud [NWA88]. 
- A interdisciplinaridade oferecida pelos STIs, por exemplo, a grande influência nas áreas de Psicologia e Ciência da Computação, tem encorajado pesquisadores a construirem modelos de como o ser humano raciocina ou resolve determinados tipos de problemas."

Por outro lado, Ridgway também destaca que muitos dos STIs existentes atendem apenas a função de expor o material instrucional de diversas maneiras e fixar/praticar habilidades. Porém, isto já é predominante nas atividades de salas de aula, não apresentando vantagem significativa. De acordo com Ridgway, em [RID88,p.30]:

“...os STIs têm sido utilizados para fins equivocados, podendo se tornar uma barreira ao invés de uma inovação, no sentido de melhorar o ensino da Matemática. Os STIs atuais são deficientes quanto às suposições pedagógicas e epistemológicas implicitamente presentes. Os professores e estudantes necessitam se conscientizar de questóes epistemológicas, refletir sobre seus próprios conhecimentos e maneiras de como adquirir outros conhecimentos."

Segundo Rosenberg [ROS87], Nwana e Coxhead [NWA88] e Ridgway [RID88], algumas críticas feitas com relação aos vários STIs no processo de ensino-aprendizagem são:

a) o desenvolvimento de STIs enfatiza o trabalho individual, ou seja, um estudante interagindo isoladamente com uma máquina. Isto tem muitas desvantagens, pois no processo de resolução de problemas há muita necessidade de trabalho cooperativo;

b) a tarefa de correção dos problemas deveria ser de responsabilidade do estudante e não do sistema. $O$ sistema não tem acesso ao processo de explicação do raciocínio dos estudantes sobre o respectivo método usado para resolver os problemas. Isto é considerado um aspecto essencial para o aprendizado;

c) se o usuário (estudante) tiver que dar detalhes sobre como está resolvendo o problema, fatalmente enfrentará efeitos negativos. Perguntar a ele pode ser inócuo: ele pode fazer coisas sem saber explicar ou descrever como o fez. Diálogos livres com a máquina estão distantes e não substituem, por exemplo, um trabalho em grupo com outros colegas;

d) o sistema separa os conceitos das possíveis aplicações do seu mundo, como por exemplo os conceitos do mundo da Matemática. Um determinado conceito não deveria ser visto como um tópico separado do pensamento matemático. $\mathrm{O}$ uso de algoritmos em situações reais é de um valor pedagógico indiscutível;

e) os STIs não possuem dentro da sua arquitetura um modelo verdadeiro destinado à aprendizagem dos estudantes. Sua construção é mais motivada pela disponibilidade tecnológica (o uso de computadores na 
educação) do que pelas necessidades educacionais de um bom ensino. 0 modelo deveria coletar dados sobre situações atuais e reais de ensino. Deveria investir um grande tempo com os especialistas (professores) e com os usuários (estudantes). 0 modelo deveria ser validado por professores e estudantes que utilizam o sistema. Porém, muitos pesquisadores não parecem preocupados com estas idéias;

f) o conhecimento envolvido nos algoritmos de depuração dos erros do estudante revelam uma rica interconexão entre diferentes domínios da Matemática. Isto restringe o valor de escolher domínios simples para serem ensinados, $\mathrm{e}$

g) há ainda uma grande porcentagem de erros de estudante não explicados (30 a 40\%) em muitos sistemas tutores.

Segundo Gilmore e Self [GIL88], para um STI alcançar um ensino mais individualizado é necessário compreender e classificar os métodos de raciocínio utilizados pelos estudantes, ou mesmo aprender um novo método de raciocínio. Porém, os estudantes têm métodos idiossincráticos de solução de problemas e mesmo sistemas sofisticados, conhecedores de vários métodos, não podem compreender todas as possibilidades. Enquanto os professores são capazes de aprender os métodos de raciocínio através do diálogo com os estudantes, a capacidade da máquina para essa tarefa está ainda em estágio primitivo [RID88].

Todas estas críticas feitas com relação ao uso de STIs no processo de ensinoaprendizagem são de fundamental importância. Isto mostra que esta área é muito polêmica e que é necessário ter cuidado quando se comentam os objetivos pelos quais os STIs são constrúdos. $O$ objetivo não é o de substituir o professor em uma sala de aula por um ou vários computadores, enfatizando somente o trabalho individual máquinaestudante. Pelo contrário, deseja-se que o computador fique disponivel no ambiente de sala de aula para ser uma ferramenta de auxilio, complementação, aperfeiçoamento e de possível melhoria na qualidade do ensino. Epstein e Hillegeist, em [EPS90,p.13], confirmam esta idéia comentando que:

“... a chave do sucesso usando computadores no ensino é clarear os papéis dos estudantes, do professor, do computador e a interação entre estes. Estudantes e professores devem ver o computador como uma ferramenta útil, não como uma ameaça ou um impedimento para um bom ensino."

Com o uso do computador, os estudantes poderiam questionar mais, querer saber quais as possíveis ligações com alguns conceitos e suas aplicações no mundo real. Assim, o professor não teria mais o papel de ser considerado o dono da verdade; teria um papel de facilitador da aprendizagem dos estudantes. Os professores poderiam expor aos estudantes as várias situações práticas onde ocorrem alguns problemas; poderiam estimular os algoritmos próprios dos estudantes e pedir-lhes explicações de como e porque eles funcionam; estimular o trabalho em grupo (trabalho cooperativo); deixar que os estudantes identifiquem e corrijam seus próprios erros, entre outras possibilidades. 


\subsubsection{Exemplos de sistemas}

Alguns sistemas tutores destinados a explorar conceitos matemáticos são apresentados no apêndice II. Nesta seção são descritos, para efeito de ilustração, mais detalhadamente três sistemas: WEST, SORT EQUIVALENT FRACTIONS e GREEN GLOBS.

\subsubsection{WEST}

Desenvolvido por Burton e Brown [BUR82a], WEST é um jogo de computador que foi criado originalmente pelo projeto PLATO $^{3}$, para oferecer ao estudante treinamento e prática em conceitos relacionados à aritmética. $\mathrm{O}$ jogo é composto por uma trilha que possui 70 posições. Cada jogador recebe três números (spinner). Estes devem ser empregados em uma expressão aritmética utilizando as operações de adição, subtração, multiplicação e divisão, e mais os parênteses. Uma única condição é que os operadores ou os números não podem ser usados na expressão mais de uma vez. $O$ valor da expressão é o número de posições que o estudante usa para se movimentar ao longo da trilha. $O$ objetivo do jogo é fazer com que um dos jogadores desembarque primeiro na posição 70 .

Para tornar a tarefa do estudante mais complicada, existem alguns grupos de movimentos especiais. Há cidades a cada 10 posições. $O$ estudante que desembarca em uma delas avança até a próxima cidade, dando 10 posições a mais. Existem também os atalhos. $\mathrm{O}$ estudante que desembarca no início de um atalho avança para o fim do atalho, ganhando algumas posições. Se o estudante desembarca na posição que seu oponente está ocupando, este é obrigado a retroceder duas cidades, a menos que já esteja em uma cidade.

No WEST, existem três niveis a focalizar. No 10 nivel estão as habilidades básicas de Matemática que o estudante deseja praticar. No sistema isto inclui o uso dos parênteses, dos operadores aritméticos e a maneira como o estudante faz os movimentos de acordo com a expressão. 020 nivel contém as habilidades necessárias para jogar o WEST, que inclui os movimentos especiais, a direção de um movimento e o desenvolvimento da estratégia para escolher um movimento. 030 nível compreende as habilidades gerais da jogada. Uma habilidade geral é a estratégia de vigiar seu oponente, a fim de aprender com seus movimentos.

O WEST foi um dos primeiros sistemas tutores a utilizar o modelo diferencial para modelar o estudante, isto é, ele interpreta as diferenças entre a resposta do especialista e a do estudante para construir o modelo do estudante. Se o estudante emprega uma estratégia diferente da usada pelo especialista, o modelador deve ser capaz de detectar quando isto ocorre e caracterizar precisamente qual é esta estratégia.

3 O jogo PLATO foi desenvolvido por Bonnie Anderson no Projeto "Dr. Robert Davis's Elementary Mathematic". DUGDALE, S. \& KIBBEY, D. Elementary Mathematics with PLATO. Urbana, University of Illinois (Computer-based Education Research Laboratory), july 1977. apud [BUR82a]. 


\subsubsection{SORT EQUIVALENT FRACTIONS}

O SORT é um sistema destinado a ensinar os estudantes a classificarem frações eqüivalentes, dentro de alguns conjuntos definidos pelo sistema [DUG92]. $O$ sistema apresenta aos estudantes uma coleção de frações e o estudante tem a tarefa de classificálas dentro de seus correspondentes conjuntos de eqüivalência, conforme apresenta a Figura 7. Para movimentar uma fração para dentro de um conjunto ou entre os conjuntos, seleciona-se a fração e depois insere-a na posição desejada na tela.

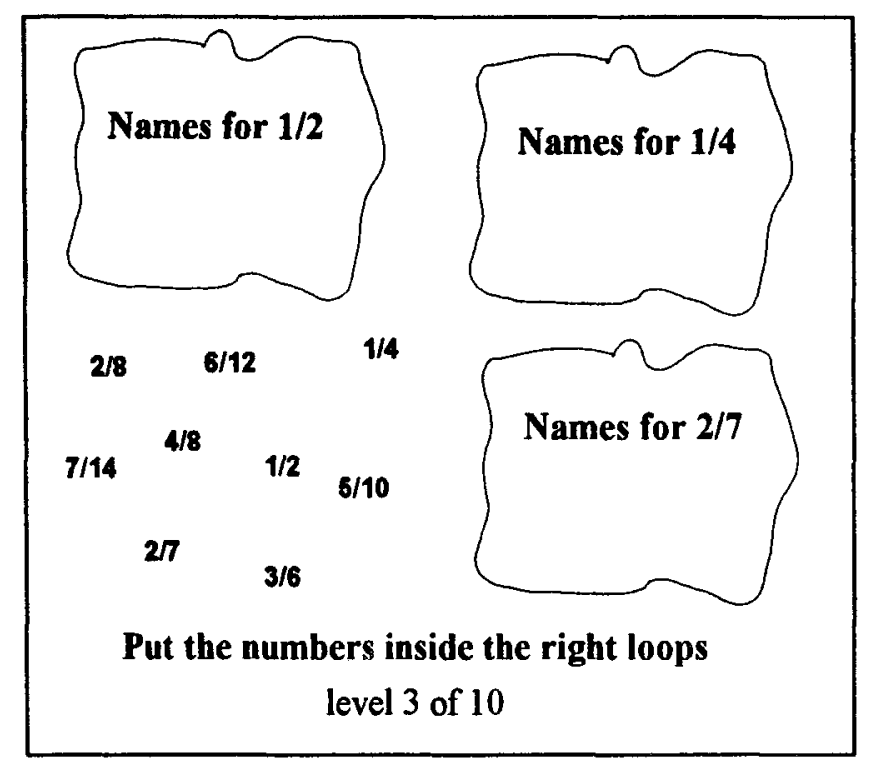

Figura 7: Tela inicial de SORT [DUG92,p.17].

Após todas as frações terem sido colocadas nos conjuntos, o estudante informa que terminou o exercício. Então, o sistema verifica as frações que são eqüivalentes em cada conjunto e fornece ao estudante um feedback informando que existem frações não corretamente classificadas, ou que ele acertou. A Figura 8 apresenta a classificação das frações feita pelo estudante em que o sistema responde que uma fração está no conjunto errado. Na Figura 9 o estudante movimentou a fração que estava no conjunto errado para o seu respectivo conjunto.

O sistema contém diferentes tipos de exercícios para serem realizados pelo estudante. Cada exercício está associado a um nível de dificuldade, mostrado na parte inferior da tela. $O$ sistema ajusta os exercícios de acordo com o desempenho do estudante, variando a dificuldade, como: aumenta ou diminui o número de frações a serem classificadas e o número de conjuntos, entre outros.

Um aspecto que fez com que este sistema promovesse uma rica experiência para os estudantes foi a forma pela qual ele fornece o feedback aos erros cometidos pelos estudantes. $O$ sistema simplesmente comenta que existem frações não corretamente classificadas nos conjuntos. Assim, é deixada aos estudantes a tarefa de diagnosticar seus próprios erros. Como e que tipo de feedback fornecer aos estudantes são aspectos importantes explorados neste sistema. Observações feitas pelos estudantes indicam que o 
passo de diagnóstico dos erros é importante para encorajar a olhar o problema de uma maneira menos mecânica [DUG80 $]^{4}$.

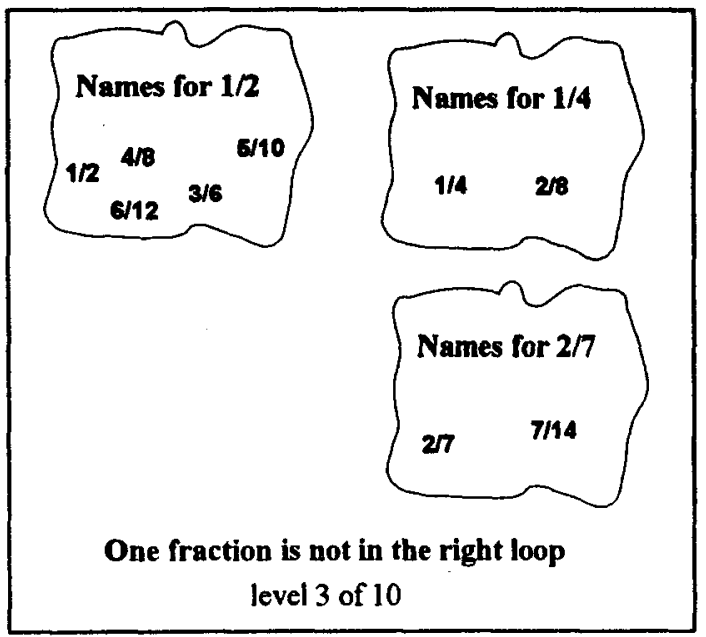

Figura 8: Classificação das frações [DUG92,p.17]

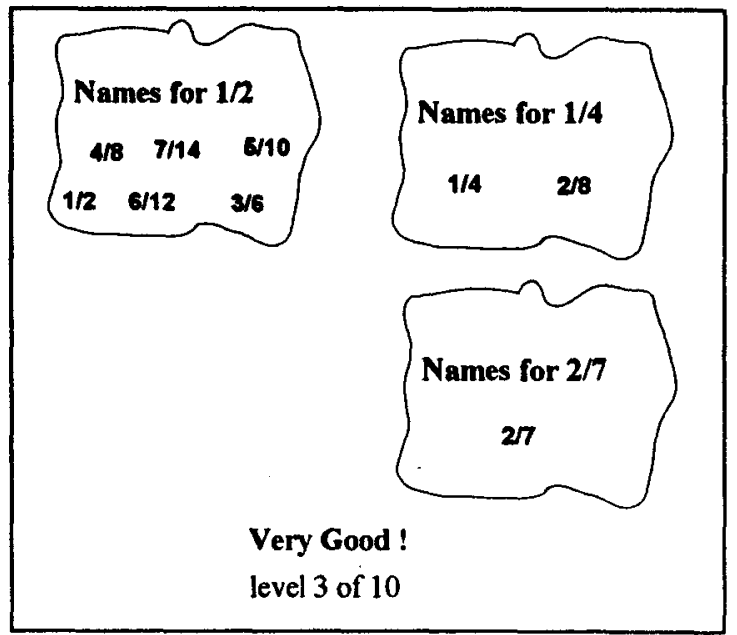

Figura 9: Exercicio feito corretamente [DUG92,p.18].

\subsubsection{GREEEN GLOBS}

Este sistema fornece aos estudantes uma oportunidade para usar e desenvolver seus conhecimentos sobre equações e suas representações gráficas. Inicialmente, o sistema exibe o eixo de coordenadas $(\mathrm{x}, \mathrm{y})$ com 13 círculos verdes distribuídos aleatoriamente (Figura 10). Este sistema pode ser considerado como um jogo, cujo objetivo é acertar todos os círculos com seus respectivos gráficos, especificados pelas equações escolhidas. Quando um círculo é acertado, ele explode e desaparece. Quando o estudante escolhe uma equação errada, o sistema exibe informações sobre os gráficos para que ele possa diagnosticar seus erros, tais como: "talvez o gráfico esteja muito largo ou estreito", "a curvatura esteja muito fechada ou aberta", entre outras. Através deste sistema observou-se que estudantes com diferentes níveis de conhecimento sobre equações desenvolvem várias estratégias e aumentam sua facilidade para manipular equações e representações gráficas [DUG82] 5 .

O algoritmo de pontuação encoraja os estudantes a acertarem tantos círculos quanto possível em cada escolha. Para cada escolha, o primeiro círculo acertado vale 1 ponto, o segundo vale 2 pontos, o terceiro vale 4 pontos, e assim por diante. Por exemplo, o score de um estudante na quinta escolha correta é $1+2+4+8+16=31$ pontos.

\footnotetext{
4 [DUG80] DUGDALE, S. \& KIBBEY, D. The fractions curriculum of the PLATO elementary school mathematics project (2d Ed.). Urbana, IL: University of Illinois, Computer-Based Education Research Laboratory, CERL Publications, 1980. apud [DUG92].

5 [DUG82] DUGDALE, S. Green globs: a microcomputer application for graphing of equations. Mathematics teacher, march 1982. apud [DUG92].
} 
Uma seqüência de telas exibida pelo sistema é mostrada nas Figuras 10 e 11 . Inicialmente, tem-se 13 círculos verdes distribuídos no eixo de coordenadas (x,y), e o sistema espera uma equação. $O$ estudante entra com a equação e o sistema automaticamente gera seu gráfico no eixo $(x, y)$. Os círculos verdes explodem quando o estudante acerta os gráficos. 0 jogo termina quando o estudante desiste ou os 13 círculos são atingidos.

Existem dois aspectos importantes neste sistema:

a) o feedback aos erros do estudante é fornecido pelo sistema, graficamente, comentando seus erros, $\mathrm{e}$

b) o sistema fornece uma assistência apropriada à sintaxe das equações, como o uso de parênteses em argumentos de função. Por exemplo, se o estudante entra com um argumento de uma função sem parênteses, o sistema não somente o lembra de que o argumento deve ser colocado entre parênteses, como também pode, por si mesmo, inserí-los de modo apropriado e seguir a interação com o estudante [DUG92].

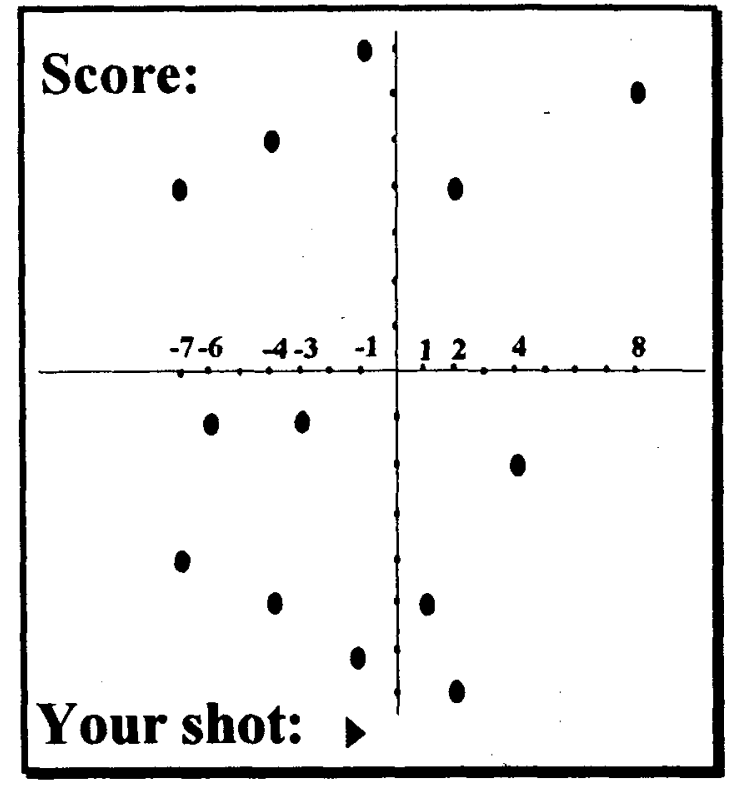

Figura 10: Tela inicial do jogo Green Globs [DUG92,p.29].

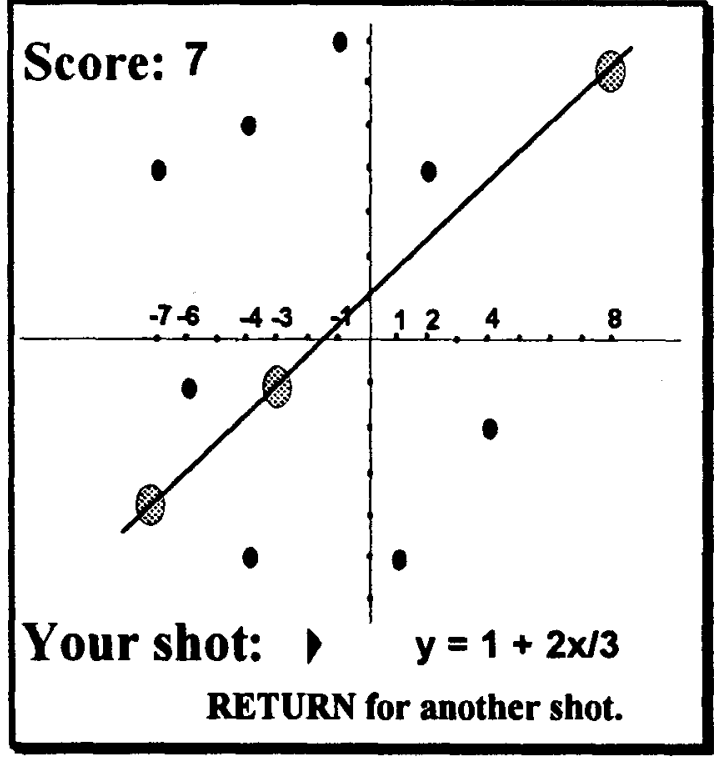

Figura 11: Exemplo de uma segunda tela do jogo Green Globs [DUG92,p.29].

\subsection{Consideraçס̋es finais}

Neste capítulo foi apresentada uma revisão bibliográfica sobre STIs. De uma maneira geral, os STIs são programas computacionais de auxílio ao processo de ensinoaprendizagem projetados para incorporar técnicas de IA, de modo a fazê-los capazes de saber o quê ensinam, a quem ensinam e como devem ensinar. 
Elsom-Cook ${ }^{6}$ observa que assim como a IA tenta reproduzir no computador um comportamento que, se realizado por um ser humano, seria considerado "inteligente", os STIs tentam reproduzir um comportamento no computador que, se realizado por um ser humano (professor), seria descrito como o de um "bom ensino".

Este capítulo apresentou, também, a arquitetura básica para os STIs. Através do conhecimento presente no módulo do domínio e das informações do modelo do estudante, o módulo tutorial é capaz de decidir o quê e quando se deve apresentar o material instrucional para um determinado estudante. $O$ módulo de comunicação, a partir de informações do módulo tutorial sobre o material instrucional a ser apresentado e do modelo do estudante, decide como, ou seja, qual a forma final da apresentação do material para o estudante. Algumas vezes estes componentes mínimos não aparecem tão explicitamente na arquitetura, o que nos faz detectar modelos razoavelmente distintos da arquitetura básica.

No próximo capítulo será apresentado o Tangram e como ele pode ser utilizado para explorar conceitos relacionados à Geometria, escolhida como domínio a ser ensinado pelo sistema TEGRAM. A arquitetura do sistema TEGRAM será apresentada no capítulo quatro e possui algumas características de STIs que foram discutidas neste capítulo.

6 ELSOM-COOK, M. Intelligent Computer-aided instruction research at the Open University. Technical Report, n.63. Computer-Assisted Learning Research Group, The Open University, Milton Keynes, 1987. apud [NWA90]. 


\section{CAPÍTULO 3}

O USO DO TANGRAM NO ENSINO DE CONCEITOS GEOMÉTRICOS
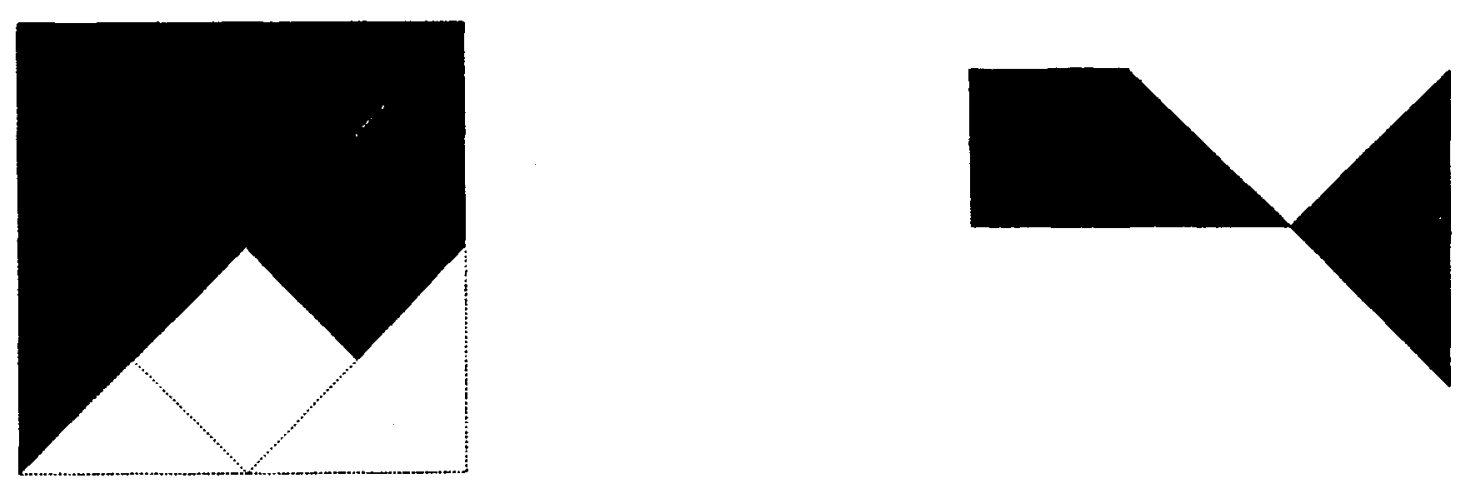


\subsection{O Tangram: definição e construção}

Tangram ${ }^{1}$ é um material didático que pode ser usado para facilitar ao estudante a observação, visualização e uma melhor compreensão de alguns conceitos matemáticos. Esta observação, durante o manuseio do material, pode possibilitar a formulação de problemas e hipóteses, tornando possível ao estudante construir, pela sua própria experiência, conceitos sobre um determinado assunto. $\mathrm{O}$ Tangram também pode ser utilizado como um jogo recreativo ou quebra-cabeça para aguçar a curiosidade, estimular a criatividade e levar à descoberta de novos conceitos.

O Tangram foi inventado pelos chineses há centenas de anos. É formado por sete peças que têm formas geométricas bastante conhecidas: cinco triângulos, um quadrado e um paralelogramo. Todas estas peças são originadas da decomposição de um quadrado ABCD, conforme apresenta a Figura 12 [SAN87] [GAR88a] [GAR88b].

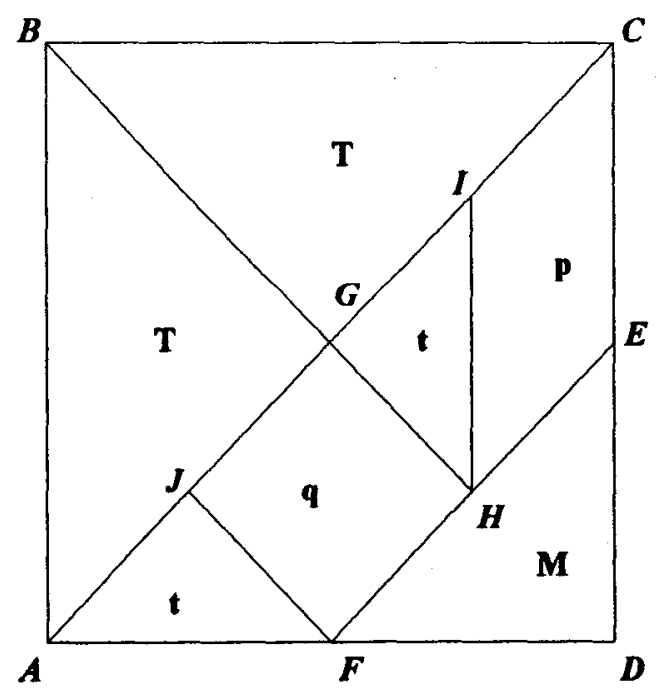

Figura 12: As sete peças que formam o Tangram.

1 Os chineses o conhecem por "Tch'i Tch'lao pan", que significa "As sete tábuas da argúcia (habilidade)" [SAN87]. 
As sete peças do Tangram são obtidas da seguinte forma:

a) $\overline{A C}$ é diagonal.

b) E é ponto médio de $\overline{C D}$.

c) F é ponto médio de $\overline{A D}$.

d) $\overline{E F}$ é paralelo a $\overline{A C}$.

e) $\overline{B H}$ é segmento da diagonal $\overline{B D}$.

f) $\overline{H I}$ é paralelo a $\overline{C D}$.

g) $\overline{F J}$ é perpendicular a $\overline{A C}$.

Assim, as peças obtidas do Tangram são: cinco triângulos (dois $\mathbf{T}$, dois $\mathbf{t}$ e um $\mathbf{M}$ ), um quadrado (q) e um paralelogramo (p). Os cinco triângulos são retângulos $e$ isósceles. Os dois triângulos menores $\mathbf{t}$ são denominados triângulos básicos, pois todas as outras peças do Tangram são composições deles.

\subsection{O Tangram como um recurso didático}

Nas aulas de Matemática o Tangram pode ser utilizado como um recurso didático bastante rico, possibilitando desenvolver atividades envolventes e desafiadoras. Muitas das atividades trabalhadas com este jogo não exigem uma resposta padrão bem definida e única, o que estimula a busca de novas soluções pelos estudantes. Isto pode levá-los à descoberta das várias maneiras de realizar uma determinada atividade, o que favorece, principalmente, a construção do conhecimento matemático pela criança.

$\mathrm{O}$ grande atrativo que os estudantes vêem no Tangram, muitas vezes, se deve ao fato de ser uma espécie de quebra-cabeça livre, sem soluções previamente estabelecidas. Possibilita a formação de 1.600 figuras com apenas um conjunto de sete peças. Desta maneira, podem ser estimuladas a imaginação e a criatividade dos estudantes na solução dos problemas.

Para mostrar que não é tão simples formar certas figuras, Güngordü e Oflazer [GUN91] desenvolveram um sistema para o usuário contruir figuras com o quebracabeça formado pelas sete peças do Tangram. Este sistema utiliza técnicas e métodos de IA (heurísticas e resolução de problemas - solving problems) e geometria computacional (algoritmos de intersecção de retas, etc.).

Segundo Negrete [NEG92], o Tangram pode ser visto como uma metáfora da ciência computacional para ensinar determinados conceitos aos estudantes. É importante porque possibilita à criança trabalhar com símbolos fisicos (peças). Desta forma, a criança pode, além de criar modelos de como seriam determinadas figuras ou conceitos, visualizar e manipular estes símbolos com determinados objetivos.

O material instrucional produzido pelo Tangram pode ser explorado por crianças e estudantes de diferentes idades e niveis escolares. Nas primeiras séries espera-se que as crianças apenas brinquem, manuseando as peças individualmente ou em grupo, para formar figuras (desenhos) como gato, cisne, pato, galinha, canguru, um chinês, entre outros. Este estágio é muito importante para que elas se familiarizem com as peças e 
percebam algumas relações, como: identificar formas e figuras, contar o número de lados, "pontas" e ângulos, comparar ângulos e comprimentos, etc. Segundo Santos e Imenes [SAN87] o resultado desta etapa, muitas vezes, pode auxiliar também na alfabetização da criança.

À medida que as crianças vão avançando, o objetivo é realçar as características geométricas das peças e chegar às suas definições e propriedades. Desta maneira são desenvolvidas noções relativas às figuras geométricas planas, como área e perimetro. É possivel também explorar o conceito de congruência e semelhança entre figuras geométricas, noções de razão, proporção, frações e até o Teorema de Pitágoras.

\subsection{Atividades com o Tangram}

Esta seção apresenta alguns exemplos de atividades propostas na literatura, utilizando as peças do Tangram. Muitas delas possuem uma certa sequiência, ou seja, uma certa dependência entre os conceitos envolvidos, em ordem crescente de dificuldade. Todas as atividades descritas trabalham com figuras geométricas planas, porém extensões podem ser feitas para trabalhar com figuras geométricas no espaço.

Ao usar as peças do Tangram para ensinar algum conceito matemático, deve-se valorizar o raciocinio utilizado pelo estudante, confrontar as soluções e discutir com a classe as diferentes idéias que sempre acabam surgindo. De acordo com Santos e Imenes, em [SAN87,p.47]:

"... nestas atividades o processo para se chegar a um determinado resultado é muito mais importante que o próprio resultado."

O caminho percorrido pelo estudante ao realizar uma determinada tarefa é essencial para que o professor faça uma boa avaliação do processo de aprendizagem. A seqüência de ações que o estudante percorre, muitas vezes, é o espelho que reflete o seu conhecimento sobre um determinado assunto e o seu estilo de pensamento. Isto, quando usado como objeto de reflexão, torna-se uma poderosa fonte de aprendizagem tanto para o professor como para o sistema tutor sobre o desempenho do estudante em relação a um determinado assunto [PAP80].

Um grupo de professores, utilizando o Tangram como material didático, observou que as crianças ao realizarem atividades com as peças do Tangram espontaneamente expressam algumas relações em sua linguagem verbal. Por exemplo, "Dois triângulos pequenos fazem um quadrado", "Essa peça cabe aqui" e "Esta figura vale tantos triângulos pequenos". Assim, além de descobrir as várias maneiras de solucionar um determinado problema, as crianças vão construindo conhecimentos subjacentes à atividade [SEM].

Nesta seção, o objetivo é ilustrar os tipos e finalidades de algumas possíveis atividades apoiadas no Tangram, antecipando algumas características utilizadas no sistema desenvolvido neste trabalho. Além disto, são apresentados também alguns conceitos matemáticos que podem ser explorados utilizando o Tangram. 


\subsubsection{Atividades lúdicas - Jogo Chinês}

O objetivo desta atividade é formar figuras mais complexas (ou desenhos) a partir das peças do Tangram, permitindo à criança familiarizar-se com as peças e com o jogo. Isto propicia situações que permitam ao estudante trabalhar com alguns conceitos matemáticos (por exemplo, reconhecer formas, comparar ângulos e comprimentos de lados de figuras geométricas), despertando a imaginação e a criatividade através da construção de silhuetas de animais, figuras humanas e alguns tipos de objetos.

O grande desafio do jogo é formar certas figuras obedecendo às seguintes regras:

a) 1a regra: é necessário, em cada figura, usar sempre todas as sete peças (nenhuma peça pode ficar de fora).

b) 2a regra: as figuras formadas são planas, isto é, as sete peças devem repousar sobre uma superficie plana.

c) 3a regra: não é permitido sobrepor peças.

Para melhor compreender esta atividade (ou jogo), um exemplo é: dado o contorno de uma figura, preenchê-la com as peças do Tangram, seguindo as regras acima. A Figura 13 mostra como as sete peças poderiam ser encaixadas para representar um gato e um chinês (dos quais teria sido apresentado apenas o contorno).

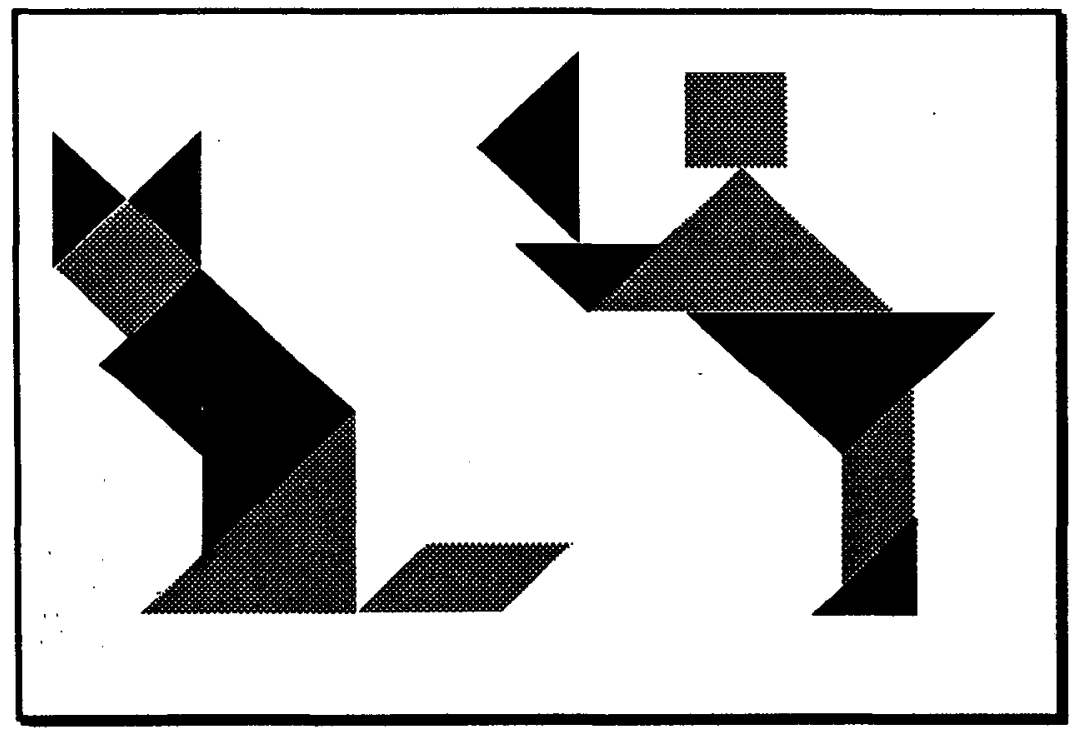

Figura 13: Representação de um gato e um chinês.

Esta atividade pode ser utilizada por estudantes mais avançados como uma forma de entretenimento após a realização de outras atividades. Ou ainda, como uma atividade pedagógica no caso de crianças em idade pré-escolar.

Além do Jogo Chinês, novas atividades lúdicas podem ser construídas [JAM89]. Estas atividades são de fundamental importância para 0 processo de ensinoaprendizagem. Elas devem preceder as atividades que tenham como objetivo ensinar 
algum conceito matemático e/ou auxiliar na alfabetização da criança, por favorecer a familiaridade com as peças e o seu reconhecimento.

\subsubsection{Atividades envolvendo conceitos matemáticos}

O uso pedagógico do material produzido pelo Tangram nas aulas de Matemática pode ser muito relevante, pois introduz e/ou utiliza conceitos como os ilustrados a seguir:

a) Relações entre as peças do Tangram: manuseando as peças isoladamente ou compondo/decompondo as peças, o estudante percebe algumas relações e características geométricas, tais como:

- os triângulos indicados com a letra T (triângulo maior) são congruentes e suas hipotenusas têm o comprimento igual aos lados do quadrado original (quadrado maior). Seus catetos têm comprimento igual à metade da diagonal do quadrado maior;

- o triângulo indicado com a letra $\mathbf{M}$ (triângulo médio) tem catetos de comprimento igual à metade do lado do quadrado maior. Sua hipotenusa mede metade da diagonal do quadrado maior;

- os triângulos indicados com a letra t (triângulo menor) são congruentes e suas hipotenusas têm comprimento igual à metade do lado do quadrado maior. Cada um dos seus catetos tem medida igual à quarta parte da diagonal do quadrado maior;

- o lado do quadrado q tem medida igual à quarta parte da diagonal do quadrado maior, e

- um dos lados do paralelogramo $\mathbf{p}$ tem medida igual à metade do lado do quadrado maior, e o outro igual à quarta parte da diagonal do quadrado maior.

b) Construção de figuras geométricas: ao trabalhar com as peças do Tangram, o estudante pode formar figuras geométricas (quadrado, paralelogramo, triângulo, retângulo, entre outras), usando um número limitado de peças. Por exemplo, pode-se pedir a construção de um quadrado utilizando um determinado número de peças (de 2 a 7 peças). Para cada quadrado construído é interessante analisar as possíveis soluções diferentes. Duas soluções são diferentes se os quadrados obtidos forem diferentes ou, então, se os quadrados obtidos forem iguais, mas formados por peças diferentes.

Por exemplo, o problema "formar um quadrado escolhendo $D U A S$ das sete peças do Tangram" tem duas soluções, e os quadrados obtidos são diferentes, como mostra a Figura 14. Já com TRESS peças, há apenas uma solução (Figura 15).

Há três soluções no caso de $Q U A T R O$ peças, e os quadrados obtidos são iguais em tamanho, porém formados por peças diferentes (Figura 16).

No caso de CINCO peças tem-se apenas uma solução (Figura 17). No entanto com SEIS peças é impossível construir um quadrado. É interessante notar que esta situação é muito intrigante para o estudante, pois uma vez que é possível resolver o problema com duas, três, quatro e cinco peças, espera-se conseguir solução também com seis peças, o que não ocorre. A discussão sobre esta questão, esclarecendo o porquê 
deste problema ser impossivel, constitui uma abordagem distinta das demais atividades, que é interessante ser apresentada a estudantes mais avançados.

Com SETE peças a solução é única e o quadrado obtido é o próprio Tangram (Figura 12).
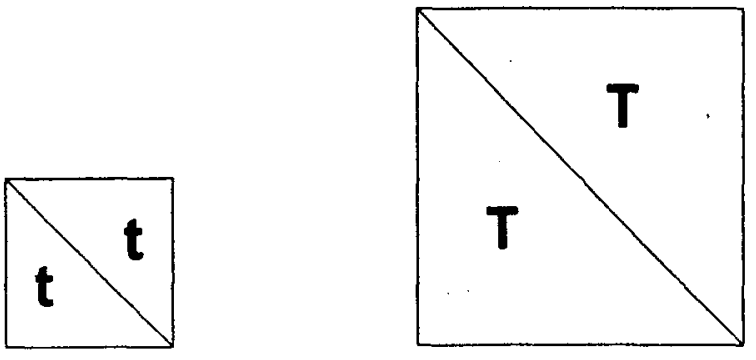

Figura 14: Quadrado com duas peças.
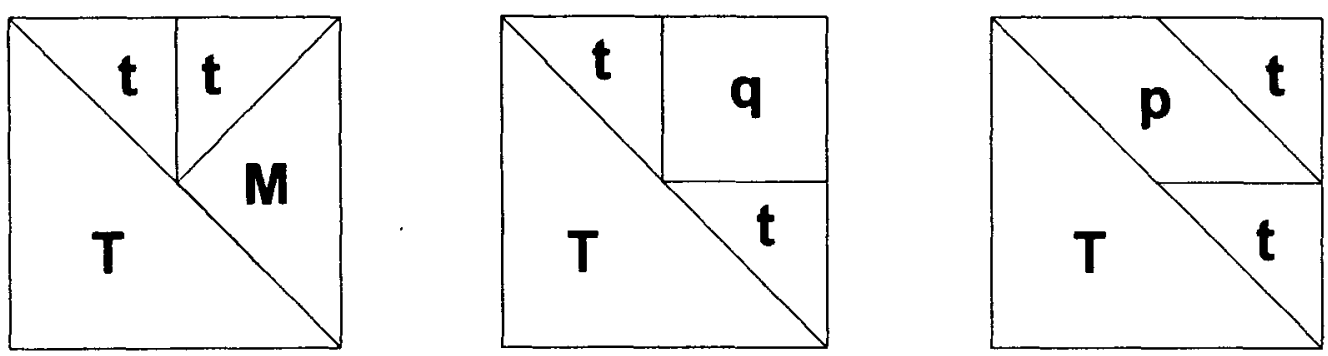

Figura 15: Quadrado com três peças.

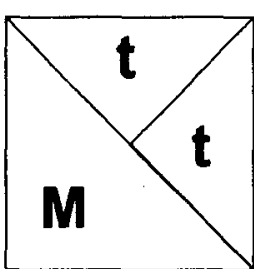$$
\text { tres peças. }
$$

Figura 16: Quadrado com quatro peças.

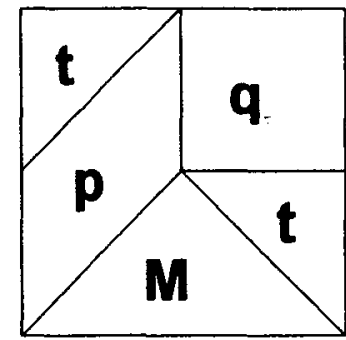


Atividades análogas a esta podem ser propostas, sugerindo que os estudantes construam triângulos, retângulos, paralelogramos, trapézios, usando só duas peças, só três e assim por adiante.

c) Classificação de figuras geométricas planas: trabalhando com as peças do Tangram o estudante pode conhecer as figuras geométricas originais (quadrado, triângulo e paralelogramo) e outras figuras que podem ser compostas com suas peças (trapézio, losango, retângulo, hexágono, etc.). Para conseguir classificar corretamente as figuras geométricas planas, os estudantes têm que saber identificar as figuras, medindo e contando os lados, pontas (bicos) e ângulos.

d) Congruência entre figuras geométricas: a partir de dois triângulos $\mathbf{t} e$ do paralelogramo $\mathbf{p}$ ou de dois triângulos $\mathbf{t}$ e do triângulo $\mathbf{M}$ pode-se formar um triângulo maior T (Figura 18). Desta forma, pode-se explorar com o conceito de congruência entre lados e ângulos de diferentes figuras para formar o mesmo triângulo $\mathbf{T}$. A idéia de congruência pode ser explorada através de outras figuras geométricas, como por exemplo, as apresentadas na Figura 16.
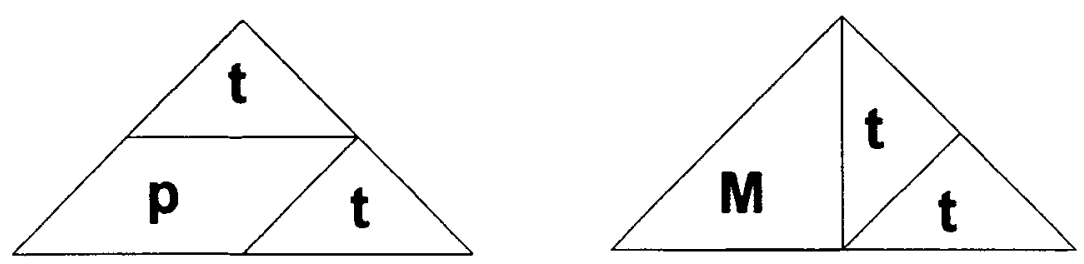

Figura 18: Congruência entre figuras.

e) Semelhança entre figuras geométricas: com os dois triângulos maiores $\mathbf{T}$ pode-se formar um paralelogramo, como mostrado na Figura 19, semelhante a outro formado pelos dois triângulos $t$, ambos semelhantes ao paralelogramo $p$ original do Tangram. Comparando os dois paralelogramos, verifica-se que os ângulos são iguais e os lados são proporcionais. É natural trabalhar a noção de semelhança entre figuras usando, principalmente, os triângulos do Tangram, pois eles têm ângulos iguais e lados de diferentes tamanhos, entre os quais se pode estabelecer uma constante de proporcionalidade (ou também outros conceitos e relações exploradas em atividades anteriores).
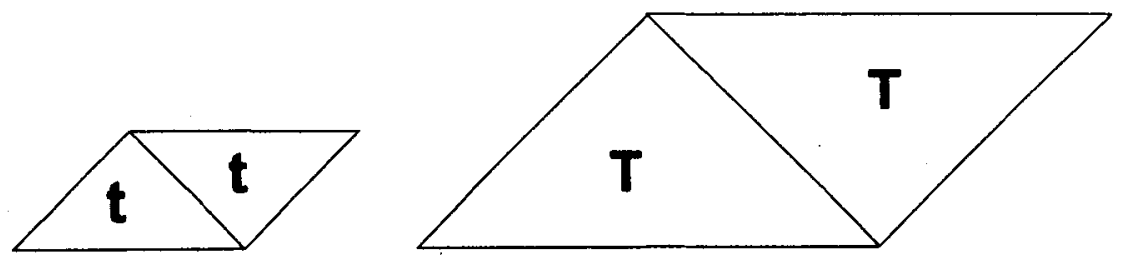

Figura 19: Semelhança entre dois paralelogramos. 
f) Área: através da composição e decomposição das peças do Tangram, o estudante poderá compreender o significado de área de uma determinada figura. Também pode ser explorada a equivalência de áreas entre figuras de formas diferentes, ou seja, quando o estudante descobre que com dois triângulos menores $t$ pode-se formar um paralelogramo, um quadrado ou outro triângulo, conforme mostra a Figura 20. Conseqüentemente se verifica que as áreas das três figuras formadas pelos dois triângulos ( $t$ ) são eqüivalentes independentemente da forma das três figuras. A área é a mesma, pois são formadas pelas mesmas peças. De importância fundamental para o estudante compreender este conceito é o princípio de conservação da área, ou seja, "o todo é a soma de suas partes, independente de sua configuração" [MEN89].

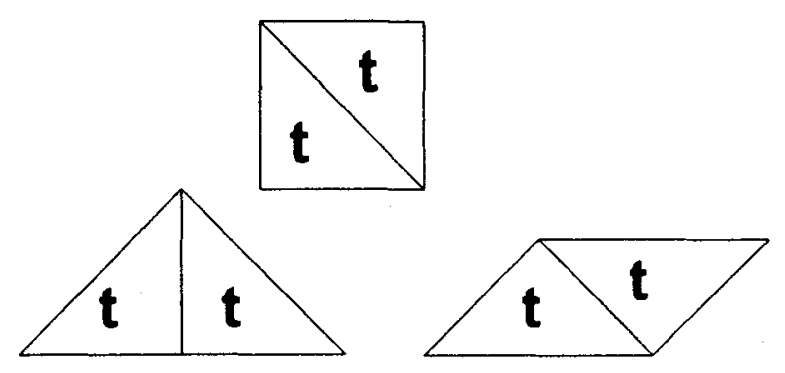

Figura 20: Eqüivalência de áreas.

g) Cálculo da área de figuras: para se obter a área de alguma peça do Tangram é necessário cómpará-la com um padrão. Então supõe-se que o quadrado q seja este padrão e tenha área unitária, o que permite calcular as áreas das demais peças que formam o Tangram. É importante propor como regra, nesta atividade, que sejam feitas composições e decomposições de peças em vez de usar fórmulas matemáticas para o cálculo das áreas e que é possivel a superposição de peças. Como ilustra a Figura 21, as possíveis soluções para este problema são:

Dois triângulos $t$ formam o quadrado $q$, logo a área de $t$ é $1 / 2$.

$\mathbf{O}$ triângulo $M$ pode ser decomposto em dois triângulos $\mathbf{t}$, logo sua área é 1 . Combinando ainda dois triângulos $t$ obtemos o paralelogramo $\mathbf{p}$ que também tem área 1 . Então, confirma-se que $M, p$ e q têm áreas iguais. $O$ triângulo $T$, por outro lado, pode ser composto (ou decomposto) de várias maneiras. Sua área é igual a 2. 


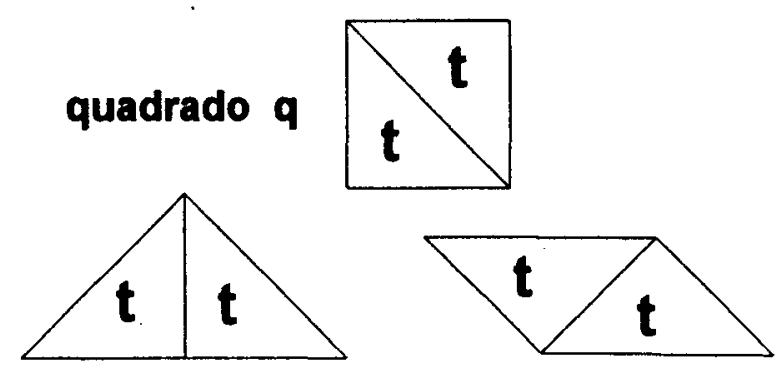

triângulo $\mathrm{M}$

paralelogramo $p$
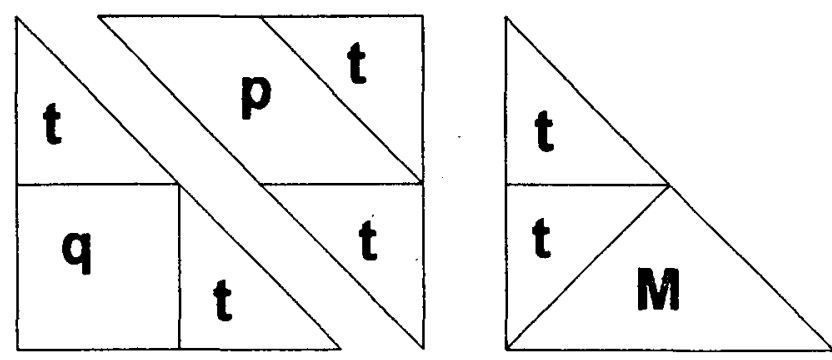

\section{triângulo T}

Figura 21: Composição das peças para cálculo das áreas.

Alguns conceitos considerados como pré-requisitos para esta atividade envolvem noções de área de figuras geométricas e composição e decomposição de figuras. Um conceito que esta atividade pode reforçar e explorar, em especial para crianças, é o princípio de conservação da área.

Esta atividade pode ser ampliada calculando a área de cada um dos quadrados construídos no item b). É interessante que, supondo a área do quadrado q igual a 1 , os estudantes concluam que qualquer figura obtida a partir das peças do Tangram possui área, no máximo, igual a 8 , e no mínimo, igual a $1 / 2$.

De acordo com uma pesquisa realizada por professores em sala de aula, publicada em [SEM], observou-se que estudantes que utilizam as peças do Tangram para explorar/calcular área de figuras geométricas utilizam diferentes procedimentos, como por exemplo:

- Os estudantes calculam a área da figura comparando-a com a área das peças do Tangram. Por exemplo, se a área do triângulo pequeno é 0.5 então a área do quadrado (q) é 1 .

- Os estudantes contam o número de triângulos pequenos que cabem em cada figura. Por exemplo, “... para construir um quadrado preciso de dois triângulos pequenos, logo a área do quadrado é o dobro da área do triângulo pequeno...".

- Os estudantes sobrepõem as peças do Tangram na figura, e então calculam sua área. 
h) Sistemas de equações: com tantas relações existentes entre as peças do Tangram é possivel construir, por exemplo, sistemas de equaç̃es para calcular as áreas destas peças. De acordo com a Figura 18, pode-se escrever a seguinte equação:

$$
\begin{aligned}
& \text { - } p+2 t=T \\
& \text { - } M+2 t=T
\end{aligned}
$$

Assim, p é igual a $\mathbf{M}$, ou seja, a área de $\mathbf{p}$ é igual a área de $\mathbf{M}$.

i) Perímetro: é possivel desenvolver a noção de perímetro usando as peças do Tangram. $O$ perímetro de qualquer figura é a soma das medidas de todos os seus lados. A Figura 22 mostra um exemplo do cálculo do perímetro de uma determinada peça.

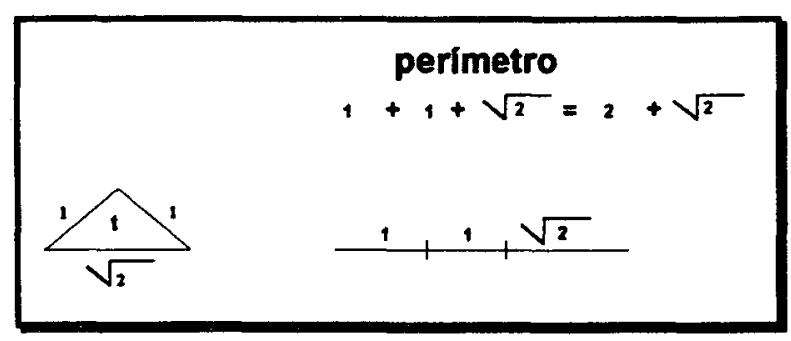

Figura 22: Perímetro da peça t.

j) Teorema de Pitágoras: com o Tangram é possivel fazer uma interpretação geométrica do Teorema de Pitágoras, como é apresentada na Figura 23. Para fazer esta interpretação geométrica, inicialmente seleciona-se o triângulo menor $\mathbf{t} \mathbf{e}$ com as peças originais do Tangram (podendo repetí-las) forma-se um quadrado em cada um dos lados (cateto e hipotenusa) do triângulo $t$. A soma das áreas dos quadrados menores (a.a + b.b) é eqüivalente à área do quadrado maior (c.c), ou seja, a soma dos quadrados dos catetos é igual ao quadrado da hipotenusa, o que se conclui através, por exemplo, de resolução de sistemas de equações como mostrado no item $h$ ).

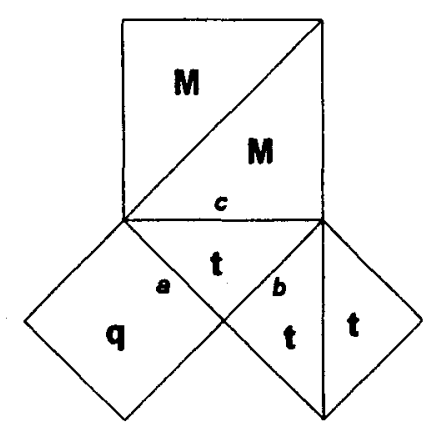

Figura 23: Interpretação geométrica do Teorema de Pitágoras.

1) Comprimento dos lados das figuras: dado que o quadrado $q$ tem área igual a 1 , seu lado também tem comprimento igual a 1 . 0 problema é calcular as medidas dos lados das figuras T, t, M, p (Figura 24) e do quadrado maior (que dá origem ao Tangram). Uma solução para este problema é apresentada a seguir. 
Comparando as peças, nota-se que os catetos de $\mathbf{t}$ são iguais ao lado do quadrado q, isto é, iguais a 1. Para calcular a medida de sua hipotenusa (x), aplica-se o Teorema de Pitágoras: $x^{2}=1^{2}+1^{2}--->x=\sqrt{2}$ (Figura 25)

Os catetos de $\mathbf{M}$, por sua vez, são iguais à hipotenusa de $\mathbf{t}$. Portanto, iguais a $\sqrt{2}$. Sua hipotenusa é o dobro do lado do quadrado q. Logo, igual a 2 (Figura 25). De maneira análoga calculam-se os lados do quadrado maior, de $\mathbf{T}$ e p.
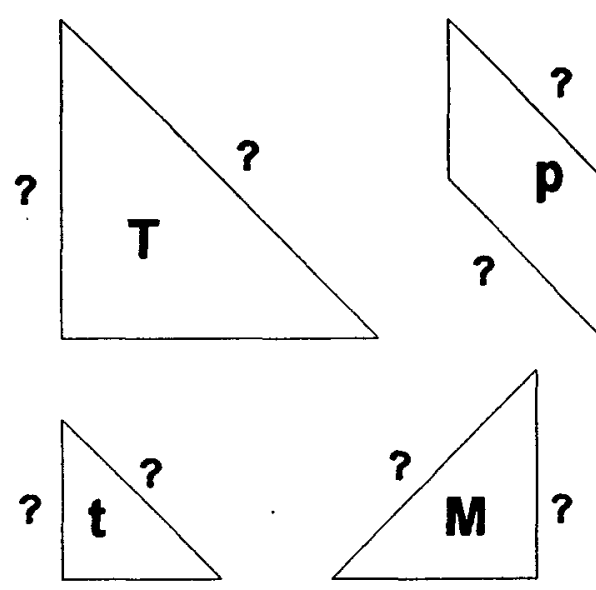

Figura 24: Lados das peças a serem calculados.
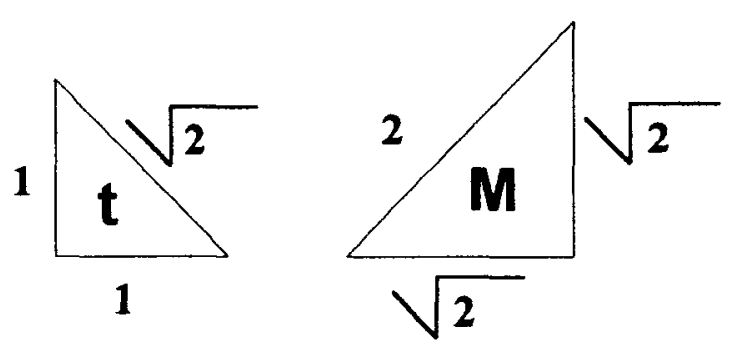

Figura 25: Medida dos lados dos triângulos $\mathrm{t}$ e M.

Esta atividade trabalha, essencialmente, com as relações entre as peças do Tangram. Um conceito importante que pode ser amplamente explorado é o Teorema de Pitágoras.

m) Relação entre área e perímetro de figuras: outra atividade propõe ao estudante formar diferentes figuras (por exemplo, triângulo, retângulo e um quadrado, conforme mostra a Figura 26) através da composição das sete peças do Tangram. $O$ objetivo desta atividade é mostrar a relação existente entre os perímetros de figuras que têm a mesma área e formas diferentes.

Após construídas as figuras, a tarefa consiste em calcular suas áreas e perímetros. Todas elas são construídas com as mesmas peças. Logo, considerando a área do quadrado q igual a 1, a área das figuras construídas é igual a 8, ou seja, é igual à soma de todas as áreas das sete peças que formam o Tangram. Calculando o perímetro das três figuras, tem-se:

- perímetro do triângulo $=8+4 \sqrt{2}$;

- perímetro do retângulo $=12, \mathrm{e}$

- perímetro do quadrado maior $=8 \sqrt{2}$. 

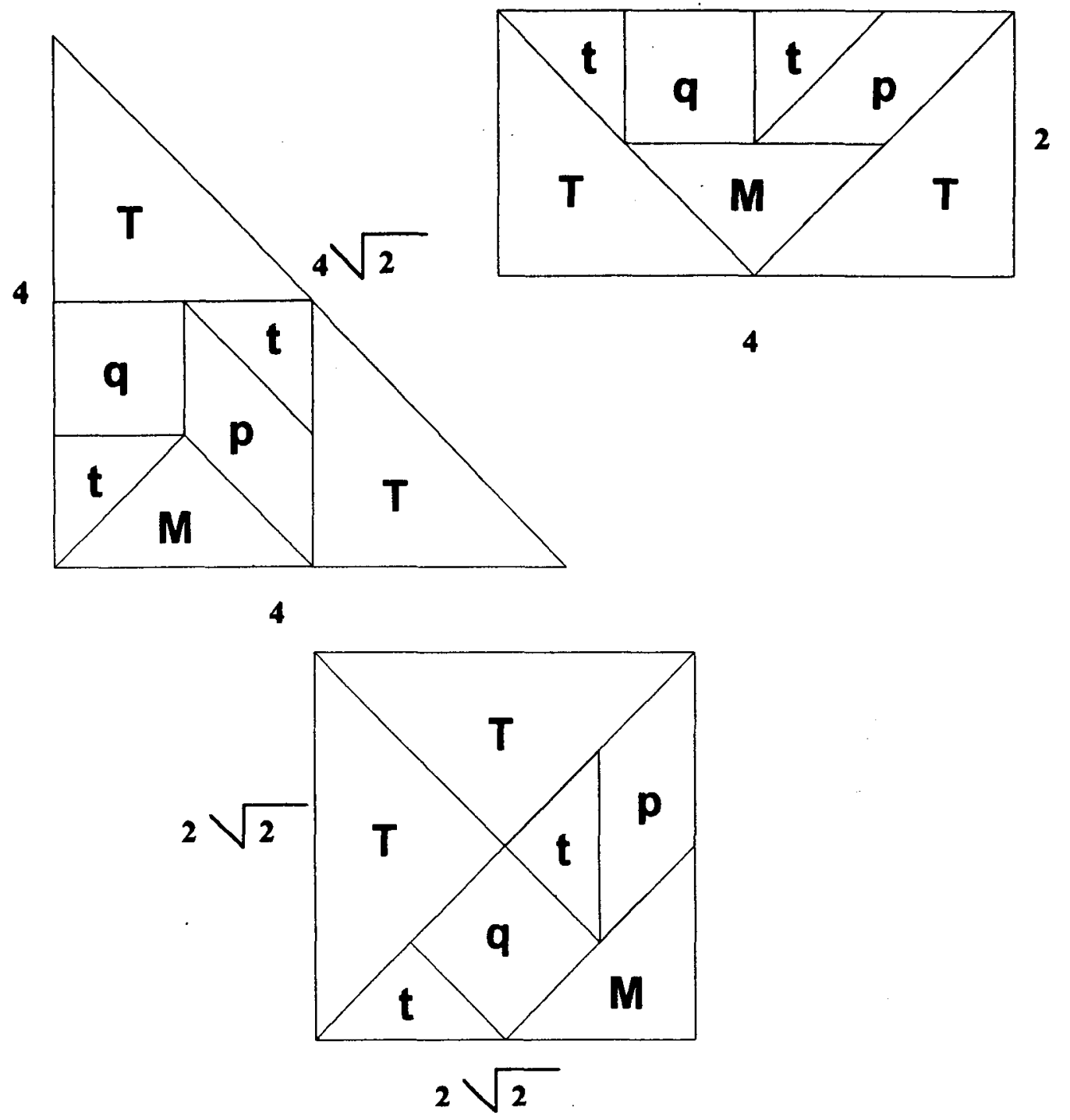

Figura 26: Triângulo, retângulo e quadrado formados com as sete peças.

Estes resultados mostram que estas três figuras têm perimetros diferentes, embora tenham áreas iguais, ou seja, não existe uma relação de eqüivalência entre os perímetros de figuras que têm áreas iguais (e vice-versa). Outras atividades podem ser propostas com o objetivo de explorar estas relações.

n) Frações e eqüivalência de frações: considerando o quadrado maior como um inteiro, pode-se concluir que um $T$ representa $1 / 4$ do total. Também se observa que $o$ quadrado $q$, o triângulo médio $M$ e o paralelogramo $p$ correspondem a 1/8 cada e que os demais triângulos $t$ eqüivalem a 1/16 cada um. Todas estas relações devem ser exploradas através de atividades que permitam à criança tirar suas conclusões. 
o) Simetria: a simetria como relação matemática também deve ser explorada, tanto nas peças do jogo, quanto no contorno das figuras construídas. As atividades de simetria relacionam-se com as atividades que exploram os conceitos de semelhança e congruência.

\subsection{Considerações finais}

Neste capítulo apresentamos uma definição do Tangram e os passos necessários para construí-lo. Como pode ser observado neste capitulo, o Tangram é um material didático muito rico e que pode ser utilizado para motivar os estudantes a descobrirem ou deduzirem vários conceitos matemáticos. Através do Tangram podem ser desenvolvidas atividades lúdicas que despertam a curiosidade do estudante e ao mesmo tempo ajudam a estimular a descoberta de novos conceitos.

Todas as atividades didáticas propostas pelo sistema TEGRAM, descritas no capítulo cinco, são baseadas no Tangram. As atividades implementadas exploram somente alguns dos conceitos matemáticos discutidos neste capítulo. Existem outros conceitos matemáticos que podem ser explorados com o Tangram, além dos aqui apresentados. Para cada um dos conceitos discutidos, várias atividades podem ser propostas para serem realizadas por estudantes de diferentes faixas etárias.

No capítulo seguinte será apresentado o sistema TEGRAM e sua arquitetura, com a descrição da estrutura e a função de cada um dos módulos que a compõem. 


\section{CAPÍTULO 4}

\section{O SISTEMA TEGRAM}
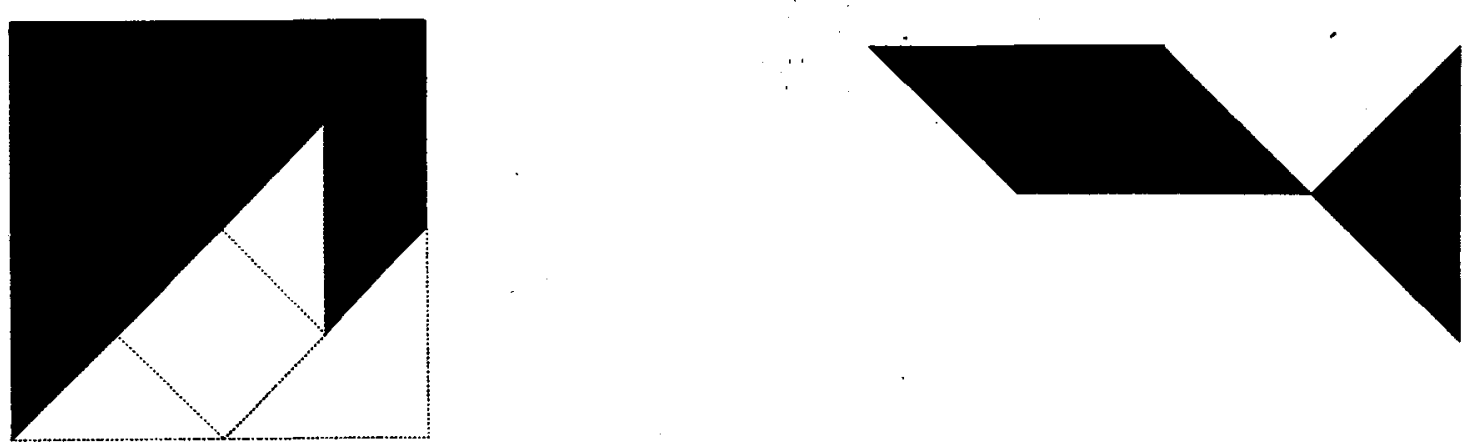


\subsection{Consideraçס̃es iniciais}

nalisando os principais temas de atividades matemáticas (Sistema de
Numeração Decimal, Adição, Subtração, Multiplicação, Divisão, Seqüência,
Classificação, Geometria e Medidas) abordados na série de livros intitulada "Atividades Matemáticas" [AMA83a] [AMA83b] [AMA84] [AMA86] [AMA91], notase que o ensino de Geometria é um dos temas fundamentais.

Com base na importância da Geometria na Matemática, este trabalho apresenta uma ferramenta útil para auxiliar o processo de ensino-aprendizagem nesta área. Em particular, este trabalho tem por objetivo planejar e implementar um protótipo do sistema TEGRAM - um sistema tutor destinado a ensinar conceitos relacionados à Geometria Plana para estudantes do 10 grau. Para despertar a curiosidade e o interesse dos estudantes em relação aos conceitos matemáticos propostos pelo sistema, todas as atividades didáticas são baseadas no Tangram. Como visto no capítulo três, o Tangram é um material que pode ser utilizado como um recurso didático bastante rico nas aulas de Matemática, fornecendo um grande número de atividades que estimula os estudantes na assimilação de conceitos de Geometria Plana, além de envolvê-los com atividades lúdicas.

A construção de um sistema tutor que seja modular é um dos principais objetivos, pois tal abordagem permite o acréscimo, com o tempo, de novos conceitos, atividades e materiais para auxiliarem o processo de ensino-aprendizagem. Isto viabiliza $o$ crescimento do sistema e aumenta a flexibilidade para futuras manutenções.

O sistema TEGRAM introduz e/ou utiliza alguns conceitos matemáticos descritos no capítulo três, tais como: classificação e construção de figuras geométricas planas, congruência e semelhança entre figuras geométricas, exploração do conceito de área e perimetro e suas relações, entre outros. A idéia básica é que o estudante assimile estes conceitos de uma forma intuitiva, através da realização de atividades monitoradas pelo sistema. A formalização destes conceitos é realizada somente a posteriori.

Como o sistema está projetado modularmente, outros tópicos mais avançados de área, perímetro, cálculo do comprimento dos lados das figuras, construção de desenhos com as peças do Tangram, construção de sistemas de equação, Teorema de Pitágoras, entre outros, poderão ser desenvolvidos futuramente.

Este capítulo apresenta a forma como o sịstema TEGRAM está organizado a fim de alcançar os seus objetivos. 


\subsection{Arquitetura do sistema TEGRAM}

A arquitetura do sistema TEGRAM é formada por quatro componentes:

- Módulo do domínio.

- Modelo do estudante.

- Módulo tutorial.

- Módulo de comunicação de atividades.

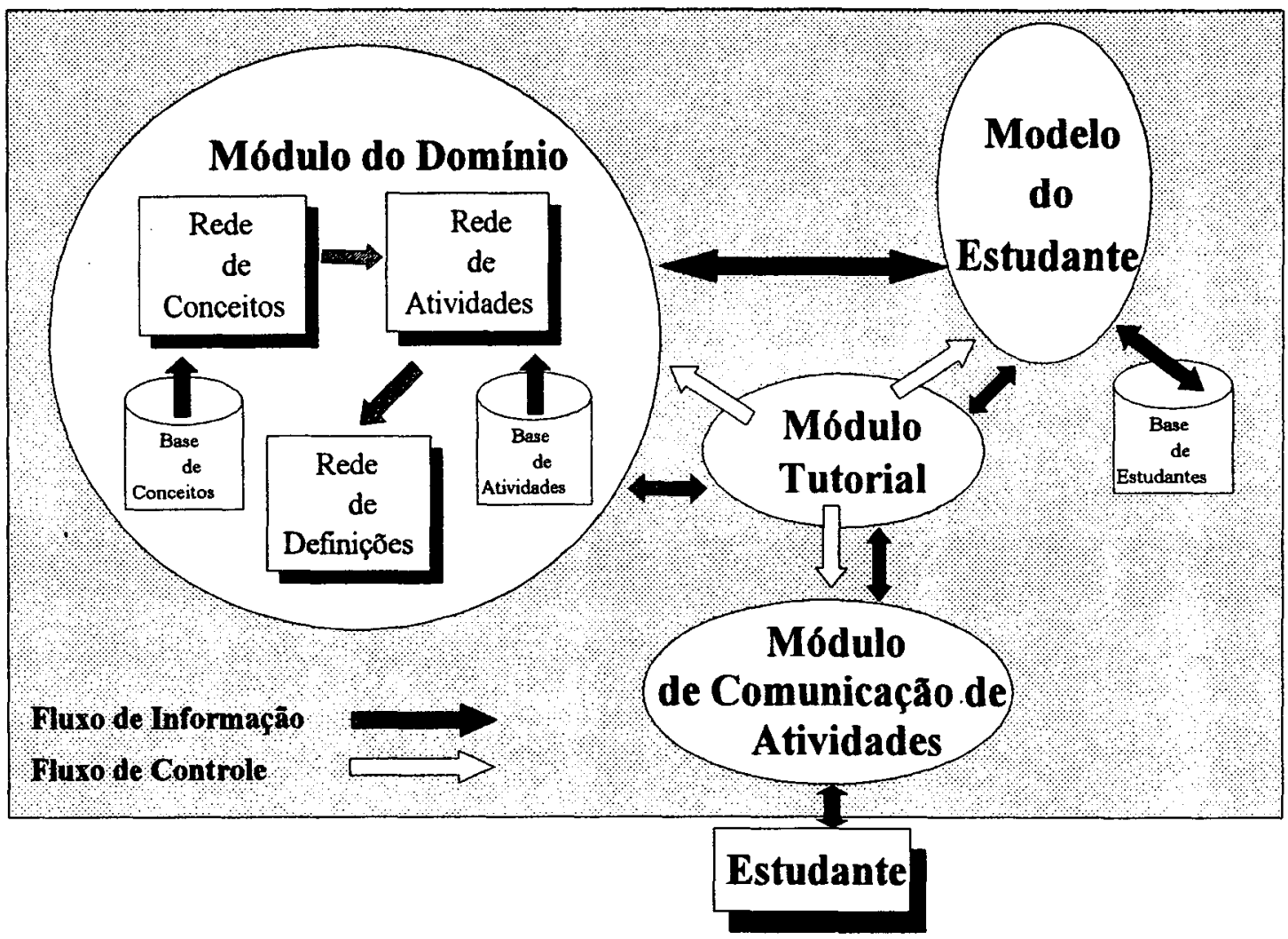

Figura 27: Arquitetura do sistema TEGRAM.

A Figura 27 apresenta os componentes da arquitetura do sistema TEGRAM. De uma maneira geral, o módulo do domínio é formado por três módulos (rede de conceitos, rede de atividades e rede de definições) e por duas bases de conhecimento (base de conceitos e base de atividades). A rede de conceitos é construída a partir da base de conceitos. Para explorar cada conceito, armazenado na rede de conceitos, existe uma rede de atividades. Esta rede de atividades é construida a partir da base de atividades. Para avaliar o que o estudante fez na atividade, o sistema utiliza procedimentos da rede de definições. $\mathbf{O}$ modelo do estudante contém informações do estudante que está interagindo com o sistema, e no final da sessão elas são armazenadas na base de estudantes. 
O terceiro módulo da arquitetura do sistema TEGRAM apresentado na Figura 27 é o módulo tutorial. Este módulo contém as decisões tutoriais (estratégias de ensino) necessárias para guiar a interação com o estudante. Passa ordens (fluxo de controle) para o módulo do domínio, modelo do estudante e para o módulo de comunicação de atividades. Por último, o módulo de comunicação de atividades controla a interação sistema/estudante.

Nas próximas seções, estes quatro componentes são discutidos mais detalhadamente.

\subsubsection{Módulo do domínio}

O módulo do dominio contém o conhecimento sobre os conceitos de Geometria Plana que serão ensinados para o estudante e mais o conhecimento das atividades didáticas que exploram tais conceitos, servindo como um padrão para avaliar o desempenho geral do estudante nas atividades propostas pelo sistema. O módulo do domínio é composto por três módulos: rede de conceitos, rede de atividades e rede de definições. Estes três submódulos são descritos a seguir.

\subsubsection{Rede de conceitos e atividades}

O submódulo rede de conceitos contém todos os conceitos matemáticos a serem ensinados pelo sistema a um determinado estudante. Esta rede é representada na forma de um grafo direcionado (dígrafo). Existem muitos conceitos matemáticos relacionados à Geometria Plana, porém o sistema TEGRAM abrange apenas alguns deles.

O conhecimento sobre os conceitos matemáticos explorados pelo sistema está armazenado e representado explicitamente em uma "base de conceitos". Esta base faz parte do módulo do domínio e é construída e atualizada somente pelo projetista e/ou professor responsável pelo sistema. $O$ estudante não tem acesso direto a esta base.

Internamente na rede de conceitos, os conceitos matemáticos são classificados em dois grandes grupos: os conceitos nucleares (CNs) e os conceitos satélites (CSs). De acordo com a Figura 28, um conceito matemático pode ser um conceito nuclear ou um conceito satélite, dependendo do nível de conhecimento do estudante que está utilizando o sistema.

Os conceitos mucleares correspondem aos conceitos matemáticos que o sistema está habilitado a ensinar. Os conceitos satélites correspondem aos conceitos que o sistema pressupõe conhecidos pelo estudante para entender um determinado CN. Os CSs são considerados os conceitos pré-requisitos para explorar as atividades relacionadas aos CNs. Na base de conceitos não está explícita uma classificação em CN ou CS. A partir da interação com o estudante, o sistema realiza esta classificação, a fim de explorar os conceitos supostamente adequados para o nivel de conhecimento do estudante. Um conceito pode ser CN para um estudante e CS para outro. 


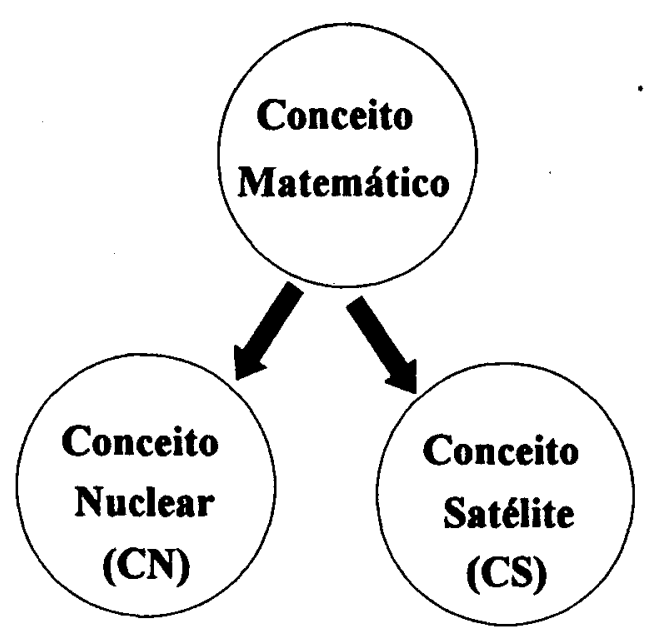

Figura 28: Classificação dos conceitos matemáticos.

A Figura 29 apresenta uma rede de conceitos dos quais três são nucleares e quatro satélites. Os conceitos nucleares são $\mathrm{C} 01, \mathrm{C} 02$ e $\mathrm{C} 03$. Eles definem entre si uma relação de precedência: o $\mathrm{C} 01$ tem que ser explorado antes do $\mathrm{C} 02$, e o $\mathrm{C02}$ é precede o $\mathrm{C} 03$. As atividades que exploram o conceito $\mathrm{C} 01$ têm como satélites $\mathrm{C} 04$ e $\mathrm{C} 05$. Os conceitos C05 e C06 são satélites das atividades que exploram o C02, e o conceito $\mathrm{C03}$ tem como satélites $\mathrm{C} 04$ e C07. Assim, os nós do digrafo (rede de conceitos) são os conceitos matemáticos. Os arcos entre os conceitos nucleares definem as relações de precedência entre eles. $\mathbf{O}$ arco existente entre um conceito nuclear e um satélite não define nenhuma relação.

Por exemplo, se o conceito nuclear é a noção de área de figuras geométricas, existem alguns conceitos geométricos considerados fundamentais, que podem ser chamados de satélites. Supondo que o estudante esteja fazendo uma atividade para calcular a área do quadrado pequeno (q) do Tangram, os três conceitos seguintes podem ser considerados satélites:

- Classificação das peças do Tangram.

- Reconhecimento da forma de um quadrado.

- Congruência de figuras geométricas.

Para ensinar um determinado $\mathrm{CN}$, existe um conjunto de atividades associadas a ele, formando uma rede de atividades. As atividades são submetidas ao estudante em uma ordem crescente de dificuldade. Dependendo do desempenho do estudante durante a atividade, o sistema pode sugerir novas atividades, indicar alguma revisão, ou propor outra atividade que explore alguns problemas detectados pelo sistema.

O sistema TEGRAM é destinado a estudantes dos mais variados níveis de conhecimento e estilos de aprendizagem. Assim, é importante que o sistema tenha várias atividades diferentes para ensinar cada conceito. Esta é uma condição de grande importância para que o processo de ensino-aprendizagem aconteça de forma significativa e agradável. 


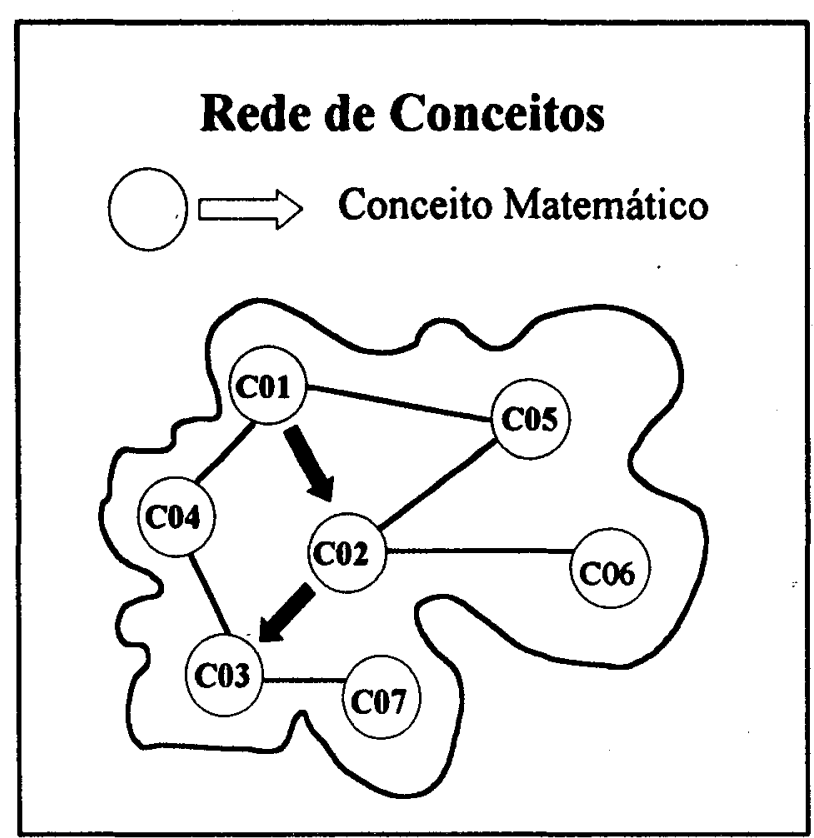

Figura 29: Exemplo de uma rede de conceitos.

A Figura 30 apresenta a rede de atividades do conceito nuclear C01. Esta rede é formada pelas atividades A01, A02, A03 e A04. Estas atividades definem entre si uma relação de dificuldade. De acordo com a Figura 30, a atividade A04 é a mais dificil, as atividades A01 e A02 são básicas e a atividade A03 é intermediária.

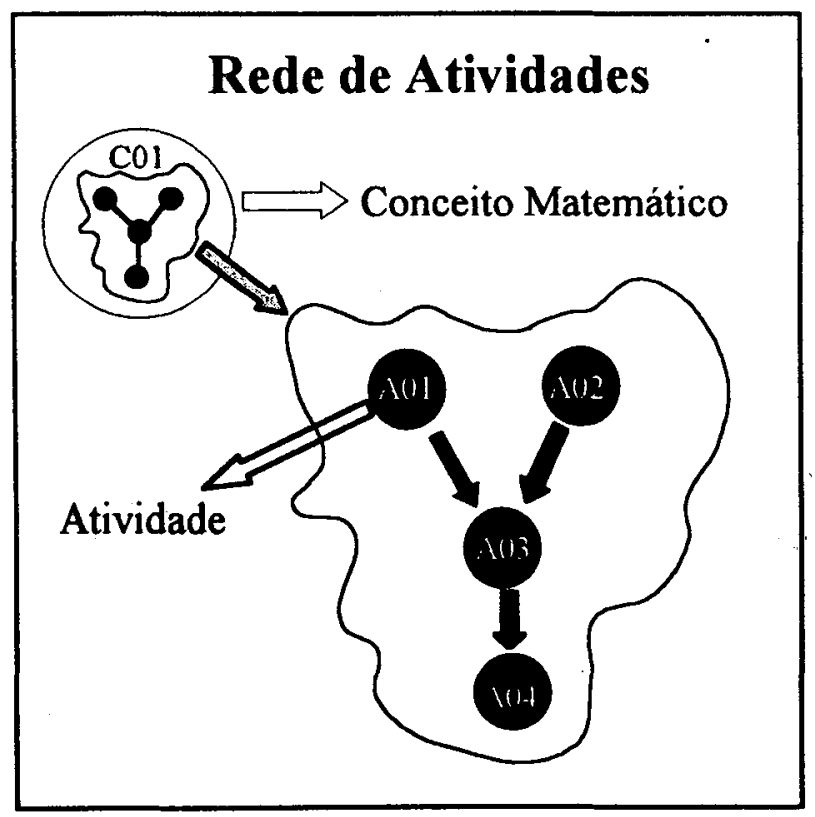

Figura 30: Rede de atividades do conceito $\mathrm{C} 01$.

De maneira análoga aos conceitos matemáticos, o sistema também possui uma "base de atividades", que contém o conhecimento de todas as atividades utilizadas pelo sistema TEGRAM, representado explicitamente. 
A estrutura de dados das atividades, utilizada pelo sistema TEGRAM, possui vários slots, descritos abaixo:

- Slot 1: Identificação da atividade.

- Slot 2: Nome da atividade.

- Slot 3: O nível de dificuldade para realizar a atividade. Por exemplo, a atividade "construir um quadrado com duas peças" é mais fácil do que a "construir um quadrado com três peças".

- Slot 4: Uma lista de conceitos satélites relacionados a esta atividade. Cada atividade explora um $\mathrm{CN}$ especial e conseqüentemente tem um número limitado de conceitos pré-requisitos (CS) para ser realizada com sucesso.

Um exemplo de como uma atividade é armazenada no sistema é mostrado a seguir:

- Slot 1: A23

- Slot 2: IDENTIFICAR_QUADRADO

- Slot 3: 1

- Slot 4: [C01, C03]

Os slots acima mostram que a atividade A23 de nome IDENTIFICAR_QUADRADO tem um nível de dificuldade básico (nível 1) e possui como conceitos satélites $\mathrm{C} 01$ e $\mathrm{C} 03$.

Internamente, a estrutura dos conceitos matemáticos utilizada pelo sistema TEGRAM contém os seguintes slots:

- Slot 1: Identificação do conceito matemático.

- Slot 2: Nome do conceito matemático.

- Slot 3: Uma lista das séries escolares apropriadas para ensinar este conceito.

- Slot 4: Uma atividade que contém a definição (teoria) deste conceito matemático. Este dado é importante, pois quando este conceito for satélite, o sistema apresenta a atividade presente neste slot. Nesta atividade, o sistema apresenta somente a definição do conceito matemático, não propondo problema a ser realizado pelo estudante.

- Slot 5: Uma lista de atividade/série proposta para explorar este conceito.

- Slot 6: Uma lista de conceitos sucessores deste conceito. Nela estão pressupostas as relações de precedência entre os conceitos matemáticos (prérequisitos). 
O exemplo abaixo mostra como um conceito matemático é armazenado na base de conceitos do sistema:

- Slot 1: C01

- Slot 2: POLÍGONO

- Slot 3: $[1,2,3]$

- Slot 4: D01

- Slot 5:[[A01,1][A23,1][A25,1][A05,2][A35,2][A36,2][A02,3][A10,3][A40,3]]

- Slot 6: [C02,C03,C04,C05,C06]

Os seis slots descritos acima mostram que o nome do conceito C01 é POLÍGONO e será ensinado para estudantes da primeira, segunda e terceira séries. A atividade que contém a definição deste conceito matemático é D01. As atividades A01, A23 e A25 são apropriadas para estudantes da primeira série. As atividades A05, A35 e A36 para os de segunda série e A02, A10 e A40 para os de terceira série. Os conceitos sucessores de C01 são C02, C03, C04, C05 e C06.

Quando o estudante utiliza o sistema pela primeira vez, o sistema constrói uma rede de conceitos. Esta rede é específica para o estudante que está interagindo com o sistema, e é construída a partir de sua série escolar (nível de conhecimento do estudante sobre o assunto que será ensinado). $O$ capítulo cinco tem uma explicação mais detalhada de como esta rede de conceitos é construída e como o sistema monitora a interação sistema/estudante.

Construída a rede de conceitos, o sistema vai ensinar cada um dos conceitos nucleares (CNs) da rede, em uma determinada ordem. $O$ estudante interage com $o$ sistema através das atividades relacionadas com seus respectivos $\mathrm{CNs}$. Caso ele tenha alguma dúvida durante a realização de uma determinada atividade, pode recorrer aos CSs desta atividade (Slot 4 da estrutura das atividades).

Deste modo, o estudante pode adaptar-se às atividades que lhe pareçam mais adequadas ao seu ambiente de aprendizagem. Se encontrar dificuldades na realização de alguma atividade, ele pode pedir ajuda ao sistema, que o aconselhará a ver alguns CSs ou fazer/refazer alguma atividade, com base nas informações que já tem sobre ele. Ou então, o estudante pode, por si mesmo, escolher seu próximo passo (por exemplo, pode ver alguns CSs ou realizar outras atividades relacionadas ao $\mathrm{CN}$ sendo explorado).

\subsubsection{Rede de definições}

O submódulo rede de definições contém o conhecimento sobre as peças que fazem parte do Tangram (quadrado, paralelogramo, triângulo) e as possíveis combinações destas peças que formam novas figuras geométricas (retângulo, trapézio isósceles e retângulo, losango e hexágono, entre outras), a fim de avaliar o que o estudante faz nas atividades. $\mathbf{O}$ conhecimento presente neste módulo é representado via procedimentos. 
Assim, além de reconhecer as peças do Tangram, este submódulo é projetado para ter procedimentos para reconhecer outras figuras geométricas construídas a partir das peças do Tangram, tornando o sistema mais expert (por exemplo, reconhecer um quadrado formado por duas, três, quatro, cinco, seis e sete peças do Tangram). Alguns destes procedimentos já foram construídos para verificar o quão complexo é reconhecer as diferentes figuras geométricas compostas pelas peças do Tangram. Para facilitar este reconhecimento, todos os procedimentos foram construidos modularmente. Por exemplo, quando o sistema reconhece que existem dois triângulos bem próximos, ele ativa um procedimento com o objetivo de verificar se o estudante formou com estes dois triângulos um trapézio, um quadrado, um triângulo ou um paralelogramo.

Os procedimentos que foram desenvolvidos e que fazem parte do submódulo rede de definições são descritos a seguir:

- formou_quadrado2(índice1, indice2): este procedimeto reconhece se o estudante formou um quadrado utilizando duas peças do Tangram. Cada peça do Tangram possui um identificador (indice), que serve para identificar a peça. - formou triângulo2(indice 1, indice2): reconhece um triângulo formado com duas peças do Tangram.

- formou paralelogramo2(indice1, indice2): reconhece se o estudante formou um paralelogramo utilizando duas peças do Tangram

- formou_trapézio_isósceles2(índice1, indice2): verifica se o estudante formou um trapézio isósceles a partir de duas peças do Tangram.

- formou_trapézio_retângulo2(índice1, indice2): reconhece um trapézio retângulo formado com duas peças.

- formou_quadrado3(índice1, indice2, indice3): reconhece um quadrado formado com três peças do Tangram.

- formou_triângulo3(indice 1, indice2, indice3): verifica se o estudante formou um triângulo com três peças.

- formou paralelogramo3(indice1, indice2, indice3): reconhece um paralelogramo com três peças.

- formou_retângulo3(índice 1, indice2, indice3): reconhece um retângulo formado com três peças do Tangram.

- formou_trapézio_isósceles3(indice1, indice2, indice3): reconhece um trapézio isósceles formado com três peças.

- formou_trapézio_retângulo3(índice1, indice2, índice3): verifica se 0 estudante formou um trapézio retângulo utilizando três peças do Tangram.

Para implementar os procedimentos citados acima, foi necessário utilizar recursos da Matemática. Um exemplo da utilização destes recursos é: "Há situações em que o sistema não pode permitir que o estudante sobreponha peças. Deste modo, é necessário que o sistema verifique se as peças estão sobrepostas ou não". Para resolver tal problema, foi construído o procedimento sobreposta(peçal, peça2) que verifica se as 
peças (peçal e peça2) estão sobrepostas. A Figura 31 apresenta dois casos diferentes de sobreposição da peçal e peça2. Inicialmente, o sistema TEGRAM verifica se uma determinada peça (peçal) tem algum vértice contido na outra peça (peça2) e vice-versa. Se tem algum vértice contido, estas peças estão sobrepostas. Caso contrário, verifica-se se alguma reta da peçal intercepta alguma reta da peça2 (algoritmo de intersecção de retas). Em caso positivo, as peças estão sobrepostas. Caso contrário, não há sobreposição de peças.
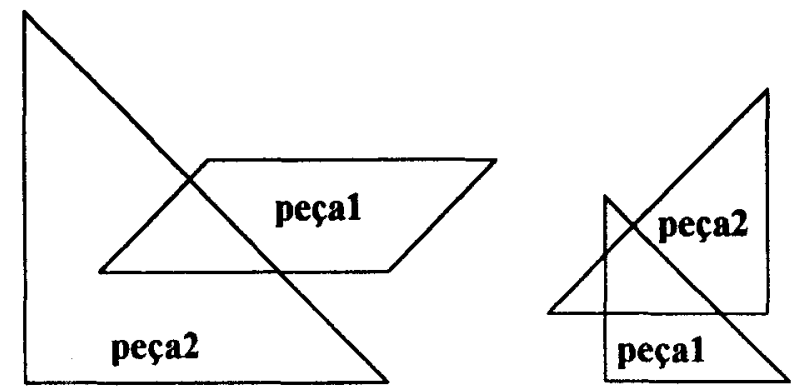

Figura 31: Exemplos de sobreposição de peças

\subsubsection{Modelo do estudante}

No sistema TEGRAM, o modelo do estudante é construído com o objetivo de representar o conhecimento do estudante sobre o assunto que está sendo explorado, além de possuir outras informações sobre o estudante. Este modelo é construído e atualizado dinamicamente pelo sistema durante cada interação.

Como descrito no capítulo dois, este modelo é fundamental para o sistema alcançar um ensino mais individualizado e um comportamento mais inteligente. Sua construção, porém, não é uma questão simples. Neste trabalho, tivemos dificuldades para projetar as informações que o modelo do estudante deveria ter. A quantidade de informações possíveis de serem capturadas é volumosa e quase impraticável.

Diante desta dificuldade, recorreu-se à análise de modelos de estudante de alguns outros sistemas tutores, como: Geometric Tutor, Lisp Tutor e PROUST, por exemplo. A partir desta análise, pudemos constatar que a natureza do conhecimento do estudante e as regras para a manipulação desse conhecimento são ainda grandes problemas para o projetista do sistema tutor. Os sistemas tutores, em sua maioria, ainda usam medidas muito incipientes do conhecimento do estudante.

Deste modo, foi projetado um modelo de estudante para o sistema TEGRAM, consistindo basicamente de um conjunto de parâmetros quantitativos capazes de fornecer um "retrato" de um determinado estudante durante uma sessão com o sistema. Nosso objetivo não foi construir um modelo ideal neste protótipo, mas sim um modelo a ser testado e avaliado para verificar a sua adequação. Tal modelo é construído com base na história do diálogo entre o sistema e o estudante, e com algumas informações sobre o desempenho do estudante na resolução das atividades. 
Dentre os vários tipos de modelo do estudante descritos no capitulo dois (seção 2.2.2.), o construído no sistema TEGRAM pode ser classificado como overlay. Além de o estudante ser representado como um subconjunto da base de conhecimento do módulo do domínio (base de conceitos e atividades), o modelo do estudante possui, na sua estrutura de dados, informações coletadas a partir da interação sistema/estudante, como: nome, senha, série escolar do estudante, entre outras descritas abaixo.

É de grande importância detectar os erros cometidos pelo estudante e os motivos que o levaram a errar. Alguns erros cometidos pelo estudante nas atividades realizadas são representados no seu modelo. Porém, os motivos que o levaram a errar não são tão simples de serem detectados e representados pelo sistema. Como o objetivo deste trabalhonão é deixar o professor isolado, caberá a ele analisar o modelo do estudante e inferir algumas informações que levaram o usuário a errar ou a tomar certas decisões. Assim, para o professor poder analisar o desempenho do estudante nas atividades realizadas, o sistema TEGRAM armazena o modelo de todos os estudantes que utilizaram o sistema em uma "base de estudantes".

A estrutura de dados do modelo do estudante utilizada pelo sistema TEGRAM possui os seguintes slots:

- Slot 1: O nome do estudante que utilizou o sistema ou que está utilizando.

- Slot 2: A senha do estudante para utilizar o sistema.

- Slot 3: A série escolar do estudante.

- Slot 4: A data da primeira sessão em que o estudante utilizou o sistema.

- Slot 5: A data da última sessão em que o estudante utilizou o sistema.

- Slot 6: O número de vezes que o estudante utilizou o sistema.

- Slot 7: Uma lista de conceitos nucleares a serem explorados pelo estudante.

- Slot 8: Uma lista de conceitos supostamente aprendidos pelo estudante.

- Slot 9: Uma estrutura que contém as seguintes informações relativas às atividades realizadas pelo estudante:

a) Qual a atividade realizada (identificação da atividade).

b) Data da realização da atividade.

c) Número de vezes que o estudante realizou esta atividade.

d) Desempenho do estudante durante a realização da atividade.

e) Uma lista com todas as soluções encontradas pelo estudante na atividade

A partir destes dados, o sistema poderá determinar o perfil do estudante, auxiliando na busca de um processo de ensino mais individualizado. Isto não significa que os dados do modelo descritos acima sejam absolutos. Cáso a utilização do sistema aponte a necessidade de alterar o modelo do estudante, isto será possível e desejável, desde que se mantenha a consistência entre ele e os demais componentes do sistema. A importância de cada uma das informações contidas no modelo do estudante é apresentada a seguir: 
O Slot 1 contém o nome do estudante que utilizou ou que está utilizando o sistema. Esta é uma das informações que o sistema utiliza para armazenar e recuperar o modelo do estudante da base de estudantes. Ela serve para que o sistema verifique se o estudante é novato ou não. Um estudante é considerado novato se está utilizando o sistema pela primeira vez. Além disso, o sistema TEGRAM ușa esta informação para se comunicar de forma personalizada com o estudante, enriquecendo o feedback.

O Slot 2 é utilizado em conjunto com o Slot 1 para identificar corretamente o estudante. Um estudante não novato só utilizará novamente o sistema se digitar o nome e a senha corretos. A existência deste slot é importante, pois evita que outros estudantes entrem em "áreas" não permitidas, ou seja, impede que um estudante altere o modelo de outros (questão de segurança).

O Slot 3 contém a série escolar que o estudante está cursando. Esta informação é muito importante para o sistema, pois é o ponto de partida para iniciar o processo de individualização, propondo atividades que explore os conceitos adequados a um determinado estudante . Este slot é inicializado na primeira sessão com o sistema. $\dot{E}$ atualizado internamente pelo sistema, assim que todos os conceitos nucleares (Slot 7 do modelo do estudante) relativos ao nível de conhecimento do estudante estejam supostamente aprendidos. Se isto acontecer, o estudante passa para um nivel de conhecimento mais avançado no sistema.

o Slot 4 contém a data da primeira sessão em que o estudante utilizou o sistema. Esta informação ainda não está sendo utilizada de forma ampla. Este slot será útil futuramente quando existir um módulo de avaliação da evolução do estudante desde que este interagiu com o sistema pela primeira vez. Neste protótipo esta informação está sendo utilizada somente para se obter um histórico do estudante, servindo para ele e/ou para o professor.

O Slot 5 contém a data da última sessão do estudante com o sistema. Esta informação também não está ainda sendo utilizada de forma ampla. Ela será utilizada futuramente pelo módulo de avaliação da evolução do estudante. Ela também pode estar vinculada à seguinte decisão tutorial: "Se faz muito tempo que o estudante não utiliza o sistema, então devem-se propor os conceitos vistos na data da última sessão, para depois explorar os novos conceitos". Desta maneira, o sistema pode propor algumas atividades para revisão. Apesar de não estar sendo muito utilizada neste protótipo, o professor pode utilizar esta informação para avaliar o desempenho do estudante desde a primeira sessão.

O Slot 6 contém o número de vezes que o estudante utilizou o sistema. Esta informação serve como um parâmetro a mais no histórico do estudante.

O Slot 7 contém a lista dos conceitos nucleares que o sistema vai explorar, ou seja, os conceitos matemáticos (CNs) a serem ensinados para um determinado estudante com um determinado nível de conhecimento (por exemplo, os conceitos matemáticos para um estudante da primeira série). Esta lista é inicializada na primeira sessão (estudante novato). Ela é formada a partir de uma ordenação topológica da rede de conceitos do estudante em questão (ordenada pelo Slot 6 da estrutura dos conceitos). Todos os conceitos desta lista pertencem à base de conceitos do sistema. A partir desta lista, o 
sistema apresenta os conceitos matemáticos pertinentes para o nivel do estudante. Quando o sistema explorar todos os conceitos desta lista, ele aumenta o nivel de conhecimento do estudante, constrói novamente a rede de conceitos e atualiza esta lista com novos conceitos.

O Slot 8 contém a lista de conceitos que o sistema considera supostamente aprendidos pelo estudante. Esta lista é construída a partir da lista de conceitos nucleares a serem explorados (Slot 7 do modelo do estudante). Mas, o que seria um conceito supostamente aprendido? No sistema TEGRAM, se o estudante tem um desempenho satisfatório nas atividades que foram realizadas para explorar tal conceito, eset passa a ser supostamente aprendido. $\mathbf{O}$ conceito é, então, eliminado da lista do Slot 7 e inserido, de uma maneira ordenada, na lista do Slot 8. Esta lista será utilizada pelo sistema para propor a revisão de alguns conceitos, para apresentar os conceitos vistos e, mais importante, para auxiliar o sistema a descobrir qual conceito foi visto e ainda não está bem fixado pelo estudante.

O Slot 9 possui as informações sobre todas as atividades realizadas pelo estudante. Este slot está relacionado diretamente com o Slot 8, pois todos os conceitos supostamente aprendidos têm associado consigo algumas atividades. Todas as atividades realizadas pelo estudante estão representadas neste slot. As informações presentes neste slot são:

a) Um identificador que revela qual atividade realizada pelo estudante. Este identificador é o mesmo do Slot 1 da estrutura de atividades.

b) A data da realização da atividade, que serve para o sistema propor uma revisão.

c) O número de vezes que o estudante realizou esta atividade. Esta informação ainda não está sendo utilizada pelo sistema, mas será útil para avaliar a evolução do estudante na atividade. Junto com outras informações, auxiliará o sistema a esboçar o perfil do estudante.

d) O desempenho do estudante na atividade é uma medida quantitativa de enorme importância no sistema. Através do desempenho das atividades relacionadas com 0 conceito explorado, o sistema verifica se este conceito será considerado supostamente aprendido ou não. Esta informação permite ao sistema apresentar novos conceitos matemáticos, explorando a lista de conceitos nuclerares (Slot 7 do modelo do estudante).

O sistema TEGRAM possui uma função "desempenho" que avalia as atividades realizadas pelo estudante. A funcionalidade desta função desempenho será discutida a partir dos testes a serem realizados em um próxima fase experimental, envolvendo estudantes de diferentes faixas etárias.

O desempenho do estudante em uma atividade, denominado DA, está sendo calculado da seguinte maneira:

$D A_{i}=S E N S$, onde

- $S E$ é o número de soluções corretas encontradas pelo estudante durante a realização da atividade $A_{\mathbf{i}}$.

- NS é o número total de soluções da atividade $\mathrm{A}_{\mathbf{j}}$. 
Fica evidente que esta proposta é uma função heuristica e poderá ser aprimorada. Para realizar esta mudança, é necessário um estudo mais aprofundado para verificar quais fatores refletem realmente no desempenho da atividade, não utilizando somente seu número de soluções.

e) Por último, o Slot 9 possui uma lista com todas as soluções encontradas pelo estudante na atividade. Esta lista de soluções é formada por um par de valores: um valor que indica se o estudante encontrou ou não a solução correspondente ( 1 ou 0 ) e o número de tentativas em que o estudante encontrou a solução. Cada uma das atividades presentes na base de atividades possui uma lista de soluções. Esta lista é atualizada durante a interação do estudante com a atividade. A rede de definições, do módulo do domínio, possui os procedimentos necessários para interpretar cada uma destas listas, ou seja, a rede de definições tem um conhecimento implícito da estrutura da lista de soluções da atividade realizada.

Por exemplo, todas as atividades que têm o objetivo de construir figuras geométricas com duas peças do Tangram possuem uma lista de soluções formada por 16 elementos, com a seguinte estrutura:

lista_soluções $=[[$ Campo0,n_tentativa] $[$ Campol,n_tentativa $] ..$ [Campo15,n_tentativa], onde:

- Campo0: indica se o estudante construiu na Janela B um quadrado compondo os dois triângulos $\mathbf{T}$. Se construiu então Campo0 é igual a 1, caso contrário Campo0 é igual a 0 . A Janela $B$ contém a resposta do estudante na atividade, e será explicada mais detalhadamente no capítulo cinco.

- Campo1: indica se o estudante construiu na Janela B um triângulo compondo dois triângulos $\mathbf{T}$.

- Campo2: indica se o estudante construiu na Janela B um paralelogramo compondo dois triângulos $\mathbf{T}$.

- Campo3: indica se o estudante não formou nada na Janela B com dois triângulos T.

- Campo4: indica se o estudante construiu na Janela B um quadrado compondo dois triângulos $\mathbf{t}$.

- Campo5: indica se o estudante construiu na Janela B um triângulo compondo dois triângulos t.

- Campo6: indica se o estudante construiu na Janela B um paralelogramo compondo dois triângulos $\mathbf{t}$.

- Campo7: indica se o estudante não formou nada com dois triângulos t na Janela B.

- Campo8: indica se o estudante construiu na Janela B um trapézio compondo o paralelogramo p mais o triângulo $\mathbf{M}$.

- Campo9: indica se o estudante construiu na Janela B um trapézio compondo o paralelogramo p mais o triângulo $t$ de cor vermelha.

- Campo10: indica se o estudante construiu na Janela B um trapézio compondo o paralelogramo p mais o triângulo $t$ de cor rosa. 
- Campo11: indica se o estudante construiu na Janela B um trapézio compondo o quadrado $q$ mais o triângulo $t$ de cor vermelha.

- Campo12 indica se o estudante construiu na Janela B um trapézio compondo o quadrado q mais o triângulo $t$ de cor rosa.

- Campo 13: indica se o estudante movimentou para a Janela B o quadrado q.

- Campo14: indica se o estudante construiu na Janela B um trapézio compondo o triângulo $\mathbf{t}$ de cor vermelha mais o triângulo $\mathbf{M}$.

- Campo15: indica se o estudante construiu na Janela B um trapézio compondo o triângulo $\mathrm{t}$ de cor rosa mais o triângulo $\mathbf{M}$.

O valor n_tentativa corresponde ao número de tentativas (número de Prontos) em que o estudante encontrou a solução de um determinado campo da lista de soluções da atividade. Algumas atividades implementadas no sistema possuem na "janela da atividade" o button Pronto, que é utilizado toda vez que o estudante tem uma resposta para o exercício proposto e quer um feedback do sistema (no capítulo cinco apresentamos mais detalhadamente o que é a janela da atividade e do que ela é formada). Esta informação (n_tentativa) é importante para o sistema e/ou professor analisar o caminho pelo qual estudante começou a resolver o problema, qual foi a primeira solução encontrada e quantas tentativas foram necessárias para encontrar a solução correta.

Por exemplo, se o estudante está realizando a atividade "construir todos os quadrados possiveis com duas das sete peças do Tangram", a lista de soluções é a mesma apresentada acima. Inicialmente, se o estudante forma um quadrado compondo dois triângulos t e clica o button Pronto, o sistema atualiza o par [Campo4,n_tentativa] com os valores $[1,1]$. O Campo 4 vale 1 porque o estudante construiu um quadrado utilizando dois triângulos $\mathbf{t}$, e o n_tentativa vale 1 porque a solução foi encontrada na primeira tentativa (o button Pronto foi acionado só uma vez). Se o estudante clica mais quatro vezes o button Pronto, o sistema atualiza o número de tentativas (n_tentativa = 5). Agora, se o estudante forma um novo quadrado com dois triângulos $\mathbf{T}$ e clica 0 button Pronto, o par [Campol, n_tentativa] é igual a [1,6].

Os dados abaixo mostram que o modelo apresentado é do estudante "Moreira Xavier da Silva" (nome completo) e a sua senha de acesso ao sistema é "Abracadabra". Possui nível de conhecimento de um estudante de primeira série. Ele utilizou cinco vezes o sistema, sendo a data da primeira sessão 09/06/1994 e a da última sessão 27/07/1994. Os cinco conceitos matemáticos (conceitos nucleares) que o sistema terá que explorar são $\mathrm{C02}, \mathrm{C03}, \mathrm{C04}, \mathrm{C} 05$ e C06. Então, o próximo conceito a ser proposto, na próxima sessão, é $\mathrm{C} 02$. O estudante já explorou o conceito $\mathrm{C} 01$. As três atividades realizadas pelo estudante que exploram o conceito $\mathrm{C} 01$ são $\mathrm{A} 01, \mathrm{~A} 02$ e A03. Ele realizou a atividade A01 duas vezes, sendo a última no dia 15/06/1994. O seu desempenho nesta atividade foi considerado satisfatório, tendo recebido nota 10 . Por último, a lista que contém todas as soluções do estudante na atividade A01 é apresentada. A mesma interpretação é feita para as atividades A02 e A03. 
Um exemplo fictício de instanciação do modelo do estudante no sistema TEGRAM é apresentado a seguir.

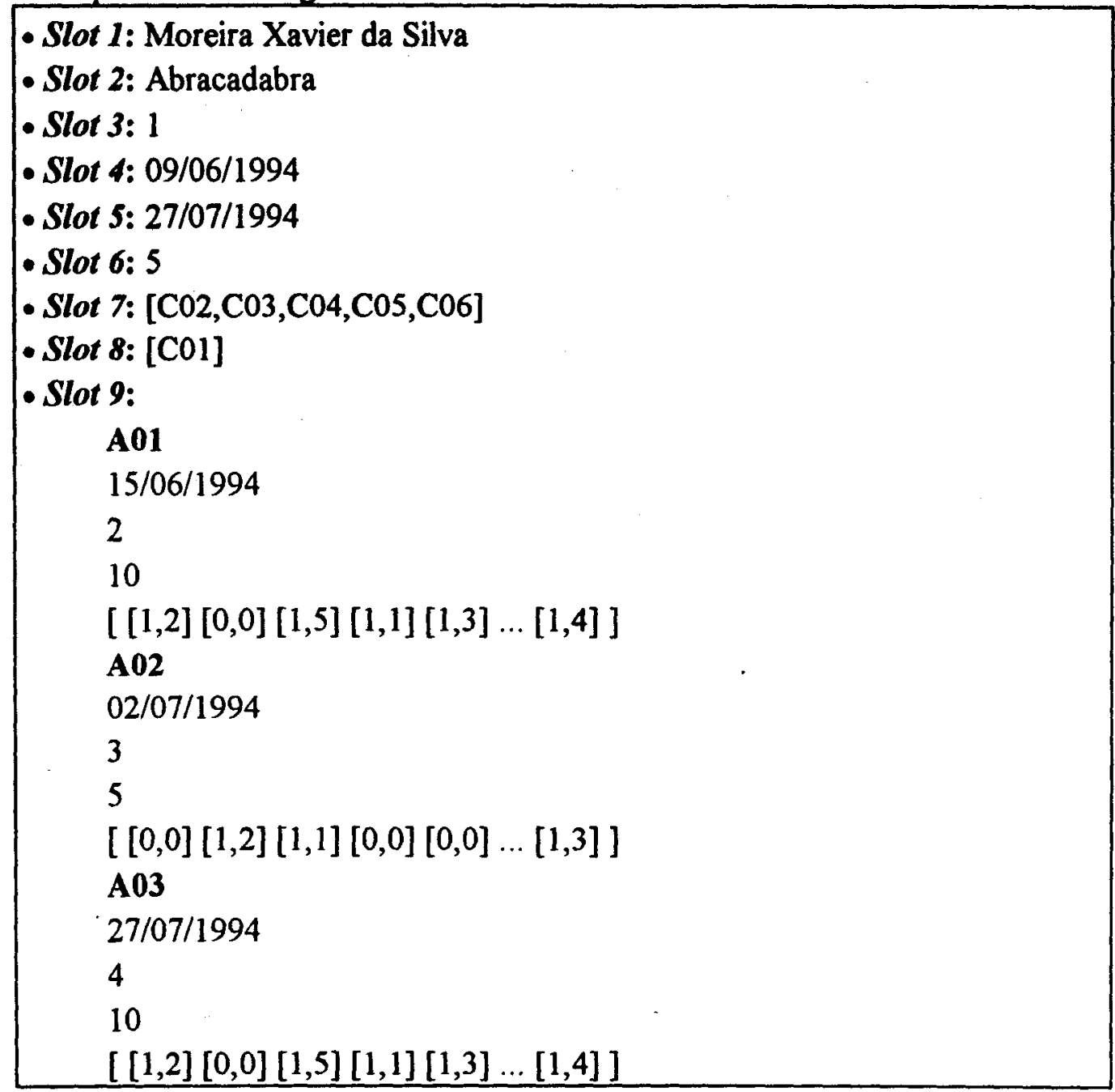

\subsubsection{Modulo tutorial}

A fim de que o sistema não seja um mero "expositor eletrônico" e/ou dificulte a aprendizagem dos estudantes, é necessária a existência de algumas estratégias que visem facilitar a assimilação dos conceitos subjacentes às atividades. Estas estratégias são denominadas no sistema TEGRAM de decisões tutoriais.

O módulo tutorial contém as estratégias e técnicas de ensino que são selecionadas e combinadas dinamicamente de acordo com as reações do estudante. Como mostra a Figura 27, este módulo ativa ordens (pelos fluxos de controle) para os outros módulos da arquitetura: módulo do domínio, modelo do estudante e módulo de comunicação de atividades.

As decisões tutoriais presentes no módulo tutorial são ativadas a fim de decidir por qual caminho o sistema guiará a interação com o estudante. Algumas decisões tutoriais presentes no sistema TEGRAM são: identificar se um estudante é novato; o que fazer quando ele é novato ou não novato; selecionar o material instrucional que deve ser 
apresentado; selecionar os conceitos matemáticos considerados nucleares; determinar quando apresentar uma atividade; determinar como deve ser o feedback fornecido ao estudante; quando apresentar as informações sobre help no sistema; quando atualizar o modelo do estudante, entre outras. Desta forma, estas decisões são acionadas para dar continuidade à sessão em curso. Algumas destas decisões tutoriais são discutidas mais detalhadamente no próximo capítulo, onde será apresentada a interação do sistema TEGRAM com um determinado estudante.

O sistema TEGRAM não possui uma representação explícita do conhecimento presente no módulo tutorial. Todas as decisões tutoriais estão representadas implicitamente no sistema através de procedimentos, que combinam o conhecimento do módulo do domínio e do modelo do estudante para selecionar o material a ser apresentado e para conduzir a interação sistema/estudante de uma maneira mais estimulante e produtiva. A meta principal deste módulo e do sistema TEGRAM é orientar o estudante através de atividades que the possam proporcionar a formulação de um determinado conceito.

Como este sistema também tem por objetivo encorajar os estudantes a tornarem-se aprendizes ativos e criativos, o sistema dará oportunidades para que eles explorem livremente as atividades a serem realizadas. A forma pela qual o sistema informa ao estudante seus erros tem grande influência no seu processo de aprendizagem. Como, quando e que tipo de feedback fornecer ao estudante são pontos importantes aos quais o módulo tutorial se preocupa. O sistema TEGRAM tenta fornecer feedback ao estudante de modo a levá-lo a diagnosticar seus próprios erros através da reavaliação da atividade realizada. Caso não consiga progredir na procura e correção do erro, o sistema pode ajudá-lo mostrando um possivel caminho para descobrir e corrigir tal erro.

\subsubsection{Módulo de comunicação de atividades}

O módulo de comunicação de atividades é o componente responsável pelo gerenciamento dos conceitos e atividades que serão propostos pelo sistema. A partir de informações do módulo do dominio e do modelo do estudante, filtradas pelas decisões tutoriais encontradas no módulo tutorial, o módulo de comunicação de atividades tem como objetivo controlar a interação sistema/estudante, apresentando as informações pertinentes a cada estudante.

Por exemplo, quando o sistema reconhece que um estudante é novato no sistema, através de algumas decisões tutoriais, o módulo tutorial ativa um procedimento (uma ordem) para o módulo de comunicação de atividades apresentar uma janela explicando $o$ que é e como é possível construir o Tangram. A Figura 32 mostra a janela do sistema TEGRAM que define o Tangram.

Além de apresentar a "janela de definição" do Tangram, e fornecer helps do sistema TEGRAM, este módulo é responsável, principalmente, por construir dinamicamente, durante a interação com o sistema, o menu de atividades a serem realizadas pelo estudante. A Figura 33 apresenta a "janela principal" do sistema 
TEGRAM, contendo o menu de atividades representado pela opcão "Âtividades". Através destas atividades, que exploram somente um $\mathrm{CN}$ por vez, o estudante pode assimilar os conceitos propostos pelo sistema. Ambas as janelas do sistema TEGRAM, "janela de definição" do Tangram e a "janela principal", serão apresentadas mais detalhadamente no capítulo cinco.

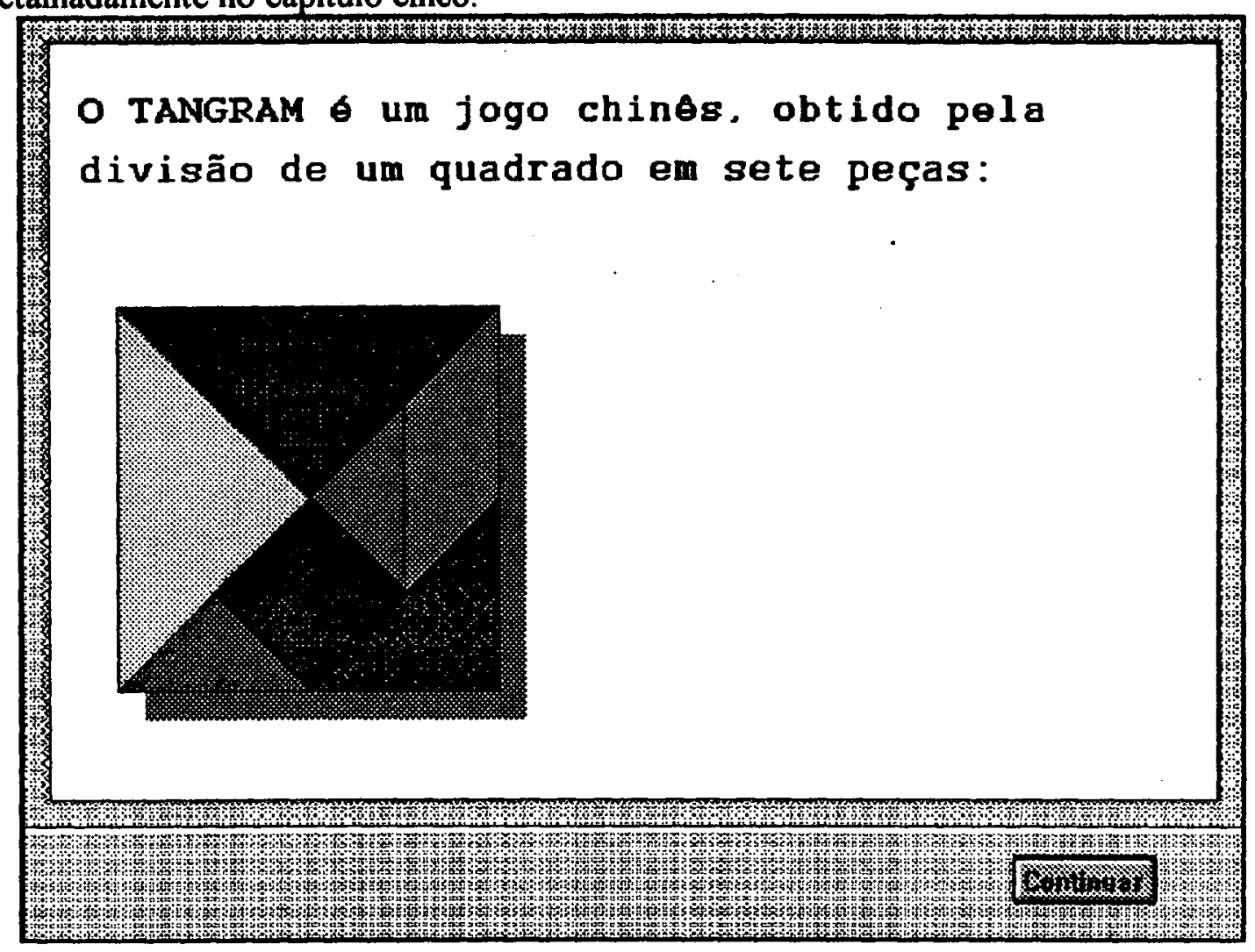

Figura 32: Janela de definição do Tangram.

Além do menu de atividades, este módulo é também responsável por construir dinamicamente o menu de conceitos vistos pelo estudante. Este menu é apresentado na Figura 33 através da opção "Ćnceitos Vistos". Este menu é construído e/ou atualizado toda vez que o estudante avança um nivel de conhecimento sobre $o$ assunto que está sendo ensinado, ou seja, quando o estudante supostamente aprendeu todos os conceitos nucleares relativos ao seu nível de conhecimento (Slot 7 do modelo do estudante). $\mathrm{O}$ menu contém todos os conceitos vistos pelo estudante até o momento. Cada conceito contém as suas atividades relacionadas. Todas as atividades relacionadas com o conceito estão presentes neste menu, independentemente do estudante ter ou não realizado a atividade. Este menu funciona como uma revisão/reforço ao qual o estudante pode recorrer quando sentir dificuldades.

Enfim, é importante ressaltar as facilidades gráficas deste módulo, uma vez que ele deve ser utilizado especialmente por crianças, e em um domínio como a Geometria. Cada atividade a ser proposta pelo sistema será apresentada de uma maneira que estimule o estudante, possuindo recursos gráficos que o fazem sentir-se inserido no seu ambiente de aprendizagem. Deste modo, espera-se que a experiência do estudante com o sistema seja rica e interessante. 


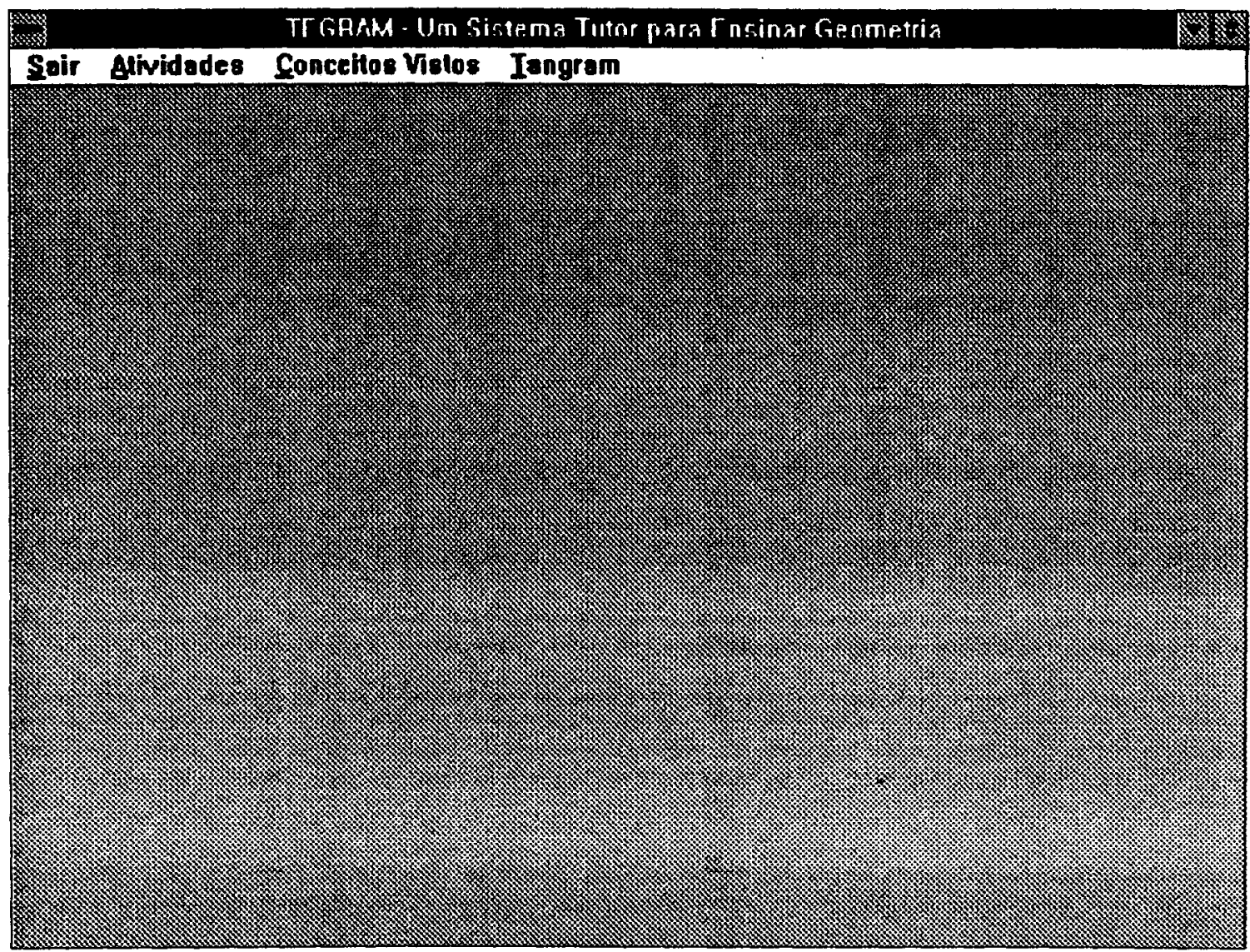

Figura 33: Janela principal do sistema TEGRAM.

\subsection{Ambiente de desenvolvimento}

Como faz parte de nossos objetivos que o sistema TEGRAM seja de utilidade prática em algumas escolas, auxiliando o estudante na complementação de conceitos vistos em sala de aula, tal sistema foi implementado num equipamento da linha IBM-PC (386, 486 e compatíveis).

Pesquisas foram realizadas para escolher qual ambiente de desenvolvimento seria utilizado para implementar o sistema TEGRAM. O ambiente escolhido foi o da "Borland C++ para Windows".

A utilização do paradigma de orientação a objetos, através da linguagem de programação $\mathrm{C}++$, possibilitou, entre outras coisas, a construção de um sistema modular. Como o sistema TEGRAM necessita de muitos recursos gráficos, o ambiente Windows facilitou a construção da interface gráfica. $O$ Windows fornece uma interface gráfica com o usuário que favorece a criação de sistemas interativos. Fornece um conjunto padrão de objetos de interface com o usuário tais como: janelas, menus, ícones e caixas de diálogo. Isto representa um aspecto consistente para todos os programas Windows, tornando-os fáceis de aprender e utilizar [MUR92] [NOR92] [PET92]. 


\subsection{Consideraçøes finais}

Neste capitulo apresentamos o sistema TEGRAM e a sua arquitetura. Com base na arquitetura básica dos STIs, o sistema TEGRAM possui uma arquitetura formada por quatro componentes: módulo do domínio, modelo do estudante, módulo tutorial e o módulo de comunicação de atividades.

No capítulo cinco serão apresentados os conceitos matemáticos que formam a base de conceitos do sistema TEGRAM e as atividades que foram implementadas para explorar tais conceitos. Para melhor visualizar o sistema TEGRAM, apresentamos, também, um exemplo da interação do sistema TEGRAM com um estudante novato e a seguir, com um não novato. 


\section{CAPÍTULO 5}

\section{INTERAC̣ÃO COM O SISTEMA TEGRAM}
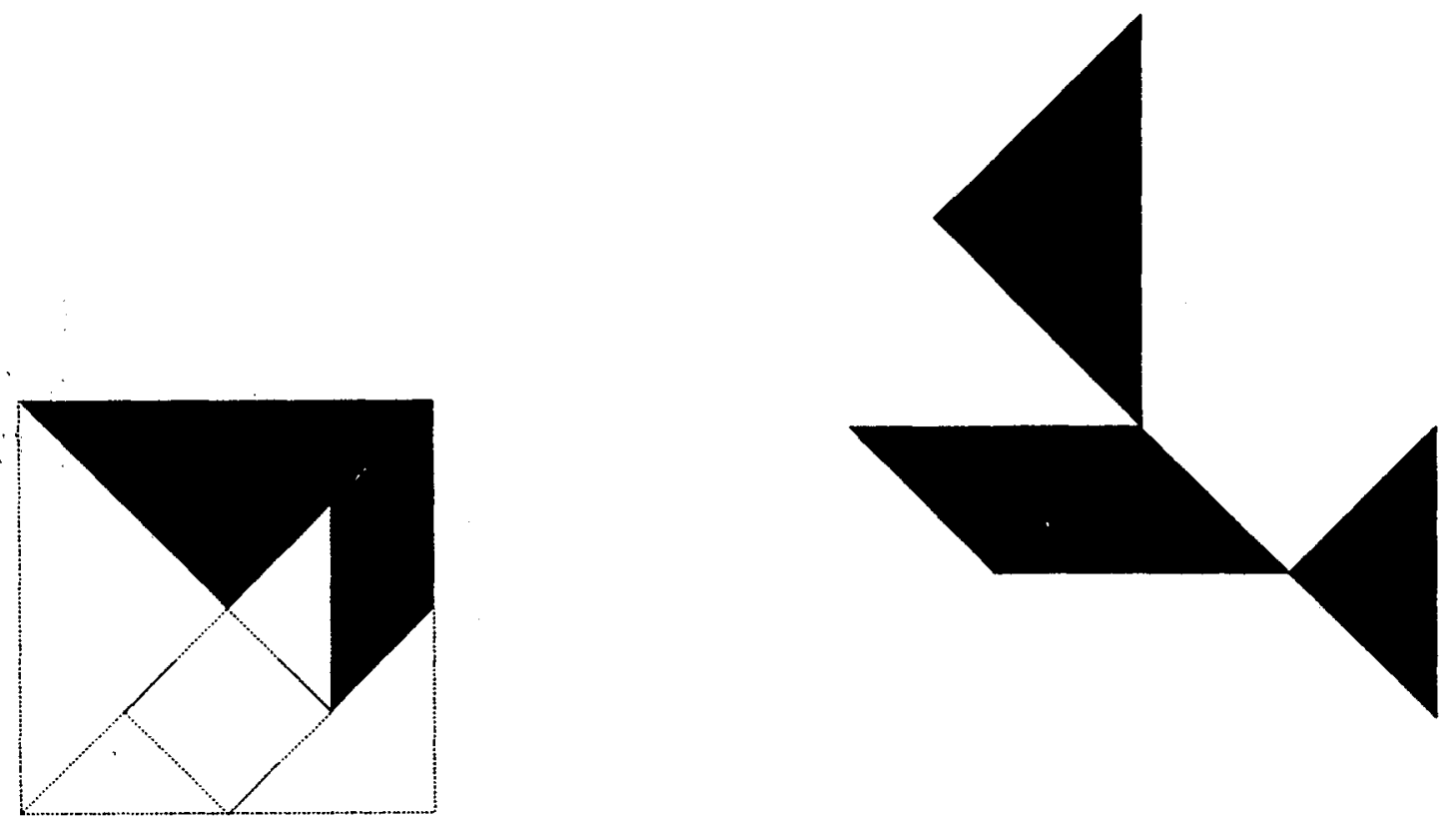


\subsection{Considerações iniciais}

ara visualizar melhor o sistema TEGRAM, é apreșentado neste capítulo um D exemplo de uma interação real entre o sistema e um determinado estudante. Para mostrar que um dos objetivos do sistema é tentar individualizar o processo de ensino-aprendizagem, apresentamos uma interação com um estudante novato e a seguir uma interação com um estudante não novato.

Antes de exemplificar as interações, são apresentados os conceitos matemáticos a serem explorados pelo sistema e as atividades que foram implementadas para explorar estes conceitos. $O$ objetivo de cada uma das atividades implementadas também é discutido neste capítulo.

Como visto no capítulo quatro, todos os conceitos matemáticos estão armazenados na base de conceitos e todas as atividades na base de atividades. Desta forma, para se ter uma melhor visão da relação existente entre os conceitos explorados pelo sistema TEGRAM, é apresentado um grafo direcionado (dígrafo) que contém todos estes conceitos, com suas respectivas relações de precedência.

\subsection{Base de conceitos}

Como visto no capítulo três, existem muitos conceitos matemáticos que podem ser explorados com o Tangram. Para escolher quais conceitos matemáticos o sistema inicialmente poderia ensinar, foi realizado um estudo junto com membros do grupo de Educação Matemática deste Instituto (ICMSC). A partir de várias reuniões, selecionamos alguns conceitos matemáticos considerados básicos e que estão relacionados com a Geometria:

a) Reconhecimento das figuras geométricas que fazem parte do Tangram. Por exemplo, dentre as peças do Tangram quais são os quadrados, triângulos e paralelogramos.

b) Composição e decomposição das peças do Tangram para formar figuras geométricas. Por exemplo, formar um quadrado através da composição de duas peças do Tangram, três peças do Tangram e assim por diante até sete peças. Além do quadrado, pode-se formar triângulos, paralelogramos, trapézios e retângulos.

c) Poligono.

d) Área de figuras geométricas.

e) Congruência entre figuras geométricas. 
f) Semelhança entre figuras geométricas.

g) Perímetro de figuras geométricas.

É importante ressaltar que a escolha dos conceitos a serem explorados e as relações entre eles devem ser mais pesquisadas, e novas propostas deverão surgir.

A Figura 34 apresenta um grafo direcionado (digrafo), formado por 13 conceitos matemáticos. Cada um destes conceitos possui associado um identificador (Slot 1 da estrutura dos conceitos matemáticos). Por exemplo, o conceito de nome QUADRADO possui o identificador $\mathrm{C01}$. O conceito $\mathrm{CO2}$ tem o nome de TRIÂNGULO, e assim por diante, conforme mostra a Figura 34. As relações de precedência entre os conceitos matemáticos encontradas na estrutura dos conceitos (Slot 6) são representadas pelos arcos entre os conceitos matemáticos.

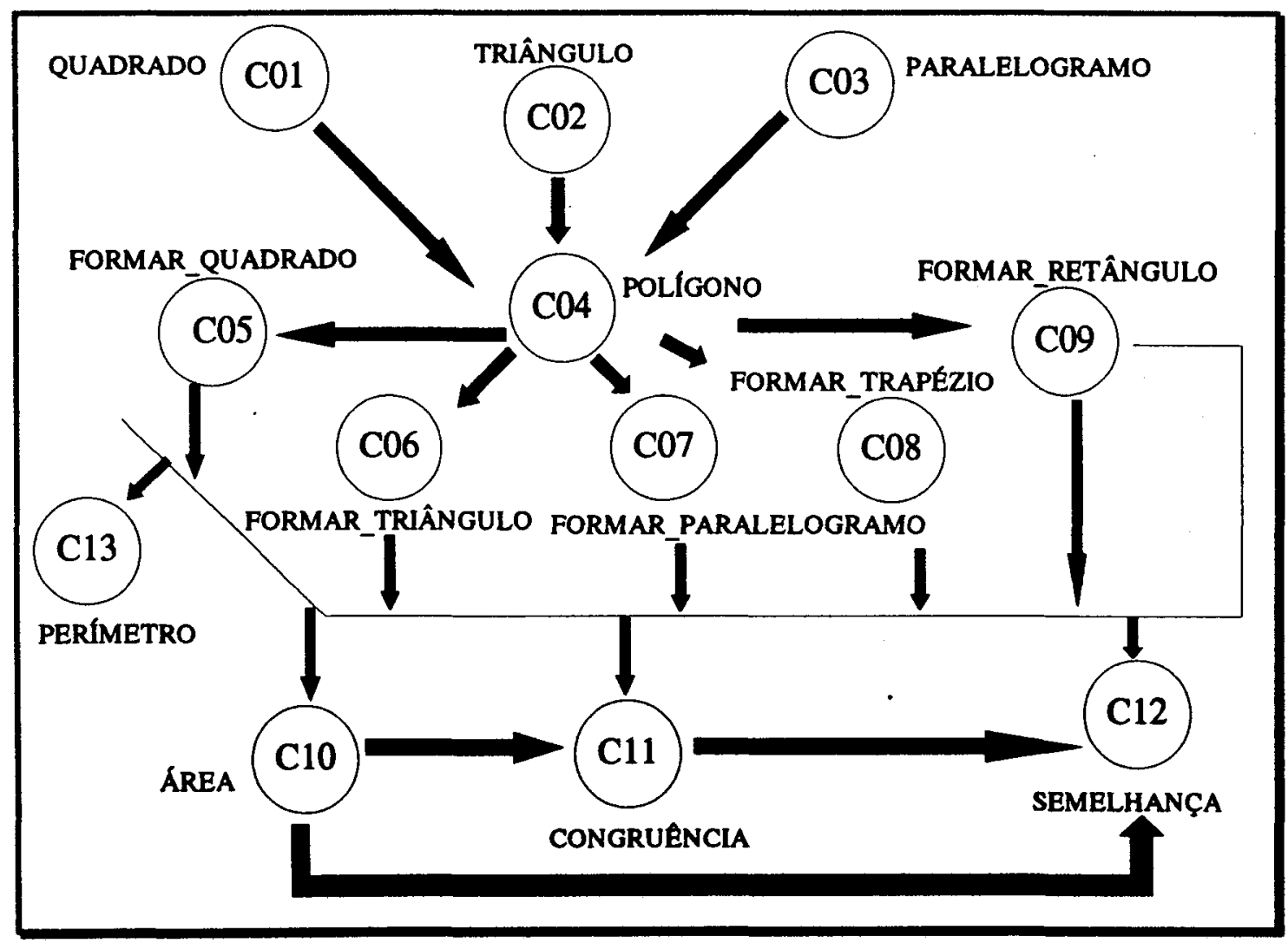

Figura 34: Dígrafo formado pelos conceitos matemáticos do sistema TEGRAM.

Os conceitos $\mathrm{C01}, \mathrm{CO2}$ e $\mathrm{C03}$ exploram o reconhecimento das figuras geométricas que fazem parte do Tangram: quadrado, triângulo e paralelogramo. São os conceitos básicos do sistema, e são destinados a estudantes de um primeiro nivel de conhecimento (estudantes da primeira série, por exemplo). O conceito C04 explora a noção de poligono e é destinado a estudantes com nível de conhecimento dois. Os conceitos C05, C06, C07 e C09 exploram a composição e decomposição de peças do Tangram a fim de 
construir figuras geométricas. Estes conceitos são destinados a estudantes com níveis de conhecimento dois, três e quatro. Já o conceito C08 é para estudantes com níveis três, quatro e cinco, assim como o conceito $\mathrm{C10}$, que explora a noção de área de uma figura geométrica. Os conceitos $\mathrm{C11}, \mathrm{C12}$ e $\mathrm{C13}$ exploram os conceitos de congruência, semelhança e perimetro, respectivamente. $\mathrm{O}$ conceito $\mathrm{C11}$ é apropriado a estudantes com nivel de conhecimento quatro, o $\mathrm{C12}$ a estudantes com nivel cinco e o $\mathrm{C13}$ a estudantes com niveis quatro e cinco.

\subsection{Base de atividades}

Para ensinar cada um dos conceitos matemáticos, existe um conjunto de atividades, ou seja, cada conceito possui associado a ele uma rede de atividades, onde cada atividade tem um nível de dificuldade associada.

Todas as atividades utilizadas pelo sistema TEGRAM estão armazenadas separadamente dos conceitos matemáticos. Como descrito no capítulo quatro, as informações relativas às atividades estão presentes na base de atividades.

\subsubsection{Descriçåo das atividades}

O sistema TEGRAM possui, até o momento, 10 atividades implementadas. Nem todos os conceitos matemáticos que formam o grafo de conceitos da Figura 34 possuem atividades implementadas. Por exemplo, os conceitos C04, C07, C08, C09, $\mathrm{C11}$ e $\mathrm{C12}$ ainda não têm atividades disponíveis. Entretanto, mesmo que estes conceitos não tenham atividades implementadas, o sistema apresenta várias propostas de atividades para explorá-los. Para estas atividades, o sistema não faz qualquer avaliação do que o estudante fez ou não. Elas servem para o estudante percorrer os conceitos matemáticos propostos pelo sistema e para o projetista e/ou professor avaliar como está a interação sistema/estudante.

As 10 atividades já implementadas no sistema TEGRAM são:

1) A atividade de nome IDENTIFICAR_QUADRADO explora o conceito C01. Esta atividade tem por objetivo fazer com que o estudante identifique dentre as peças do Tangram quais são os quadrados. Existe somente um quadrado entre elas.

2) A atividade de nome IDENTIFICAR_TRIÂNGULO explora o conceito C02. $O$ objetivo desta atividade é fazer com que o estudante reconheça os diferentes triângulos que formam o Tangram. $O$ Tangram possui cinco deles.

3) A atividade de nome IDENTIFICAR_PARALELOGRAMO explora o conceito C03. Através desta atividade o estudante pode reconhecer quais das peças do Tangram são paralelogramos. Existe somente um paralelogramo entre as peças do Tangram. 
4) A atividade de nome QUADRADO_2_PEÇAS explora o conceito C05. Esta atividade tem por objetivo fazer o estudante compor e decompor as sete peças do Tangram a fim de formar um quadrado usando duas delas. Esta atividade possui duas soluçðes diferentes que serão apresentadas na Figura 35. As soluções são diferentes se os quadrados obtidos forem de tamanhos diferentes ou se os quadrados obtidos forem do mesmo tamanho, mas formado por peças diferentes. Um quadrado é obtido compondo dois triângulos $\mathbf{t} \mathbf{e} \mathrm{O}$ outro através de dois triângulos $\mathbf{T}$.
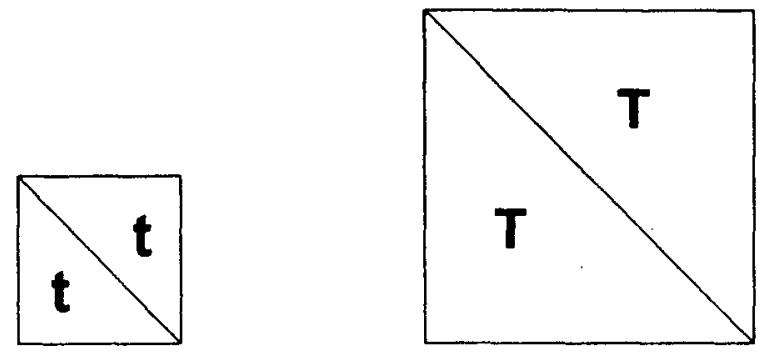

Figura 35: Quadrados possíveis com duas peças.

Além de reconhecer um quadrado com duas peças do Tangram, esta atividade reconhece outras figuras geométricas, tais como:

a) Os triângulos que são formados com duas peças, apresentados na Figura 36.

b) Os dois paralelogramos formados com duas peças, conforme a Figura 36 .

c) Alguns trapézios formados através da composição de duas peças. A Figura 36 apresenta, por exemplo, cinco trapézios que a atividade reconhece. Dentre estes estão os isósceles e os retângulos.

5) A atividade de nome TRIÂNGULO_2_PEÇAS explora o conceito C06. Esta atividade possibilita ao estudante compor e decompor as sete peças do Tangram a fim de formar um triângulo usando duas delas. Esta atividade possui duas soluções diferentes, conforme apresenta a Figura 36 (um triângulo é obtido compondo dois triângulos t e o outro através de dois triângulos $\mathbf{T}$ ).

6) A atividade de nome QUADRADO_3_PEÇAS explora o conceito C05. O objetivo desta atividade é proporcionar um ambiente para o estudante compor e decompor as sete peças do Tangram a fim de formar um quiadrado usando três delas. Esta atividade possui somente uma solução, que é apresentada na Figura 37. Um quadrado é obtido compondo dois triângulos $\mathbf{t}$ com o triângulo $\mathbf{M}$. 

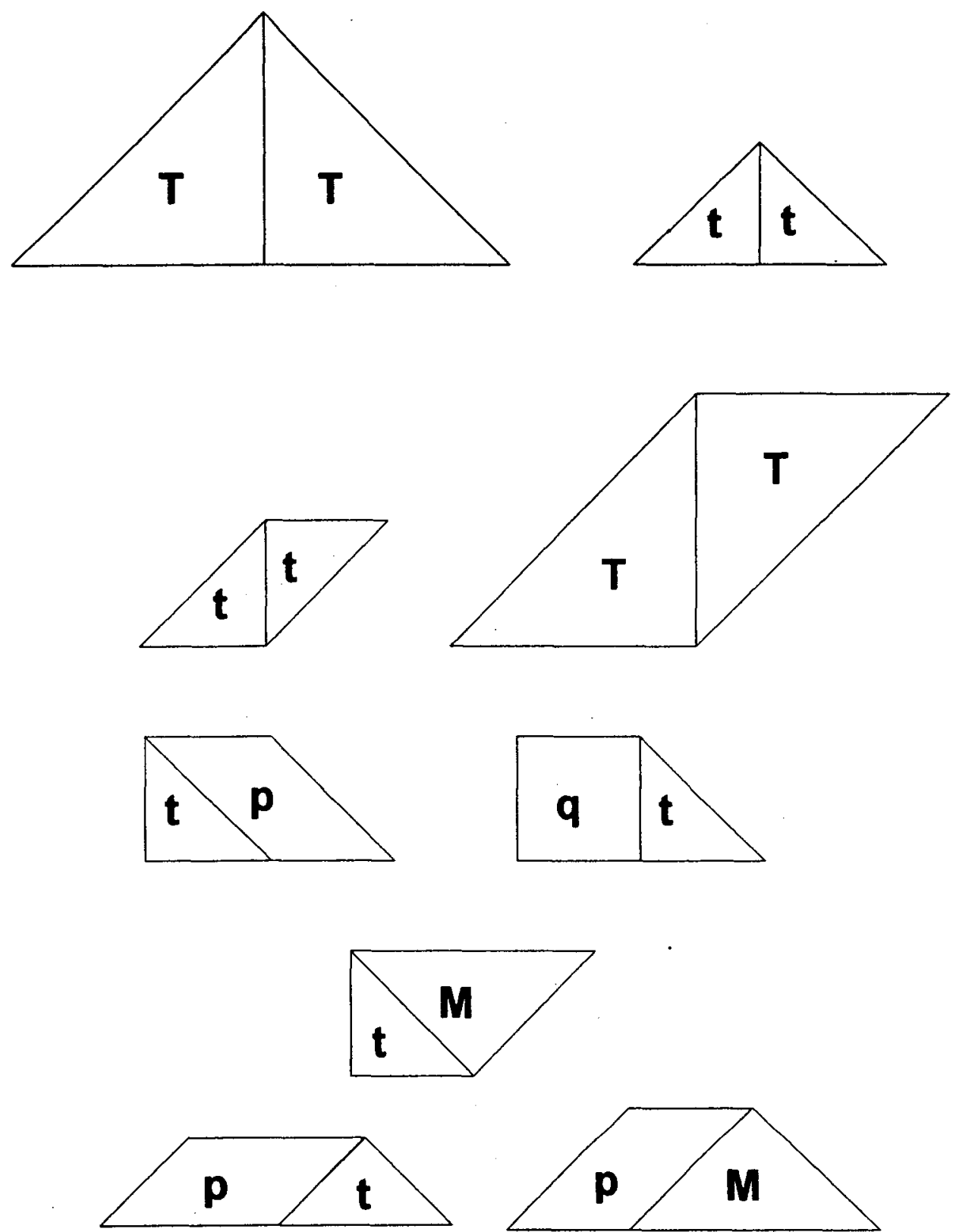

Figura 36: Triângulo, paralelogramo e trapézio formados com duas peças.

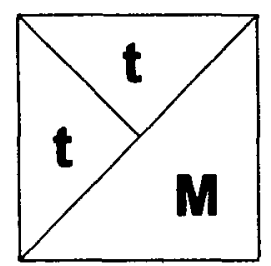

Figura 37: Quadrado com três peças. 
Além de reconhecer um quadrado com três peças do Tangram, esta atividade reconhece outras figuras geométricas, tais como:

a) Os triângulos que são formados com três peças. Os três triângulos obtidos são apresentados na figura abaixo.
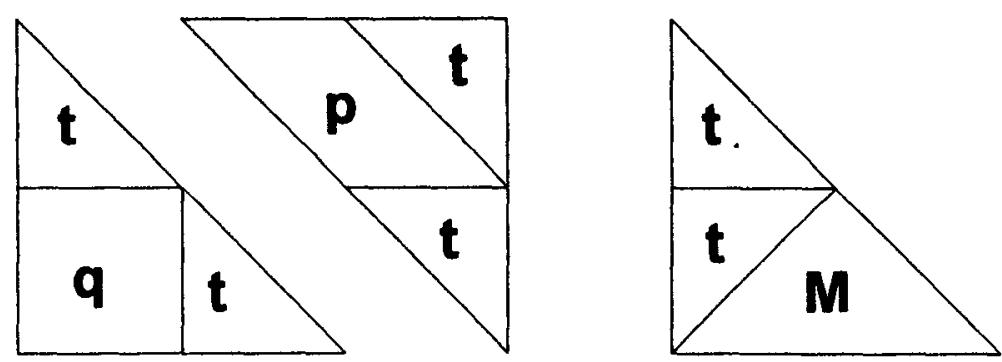

Figura 38: Triângulo com três peças.

b) Os cinco paralelogramos diferentes formados com três peças, conforme mostra a Figura 39.
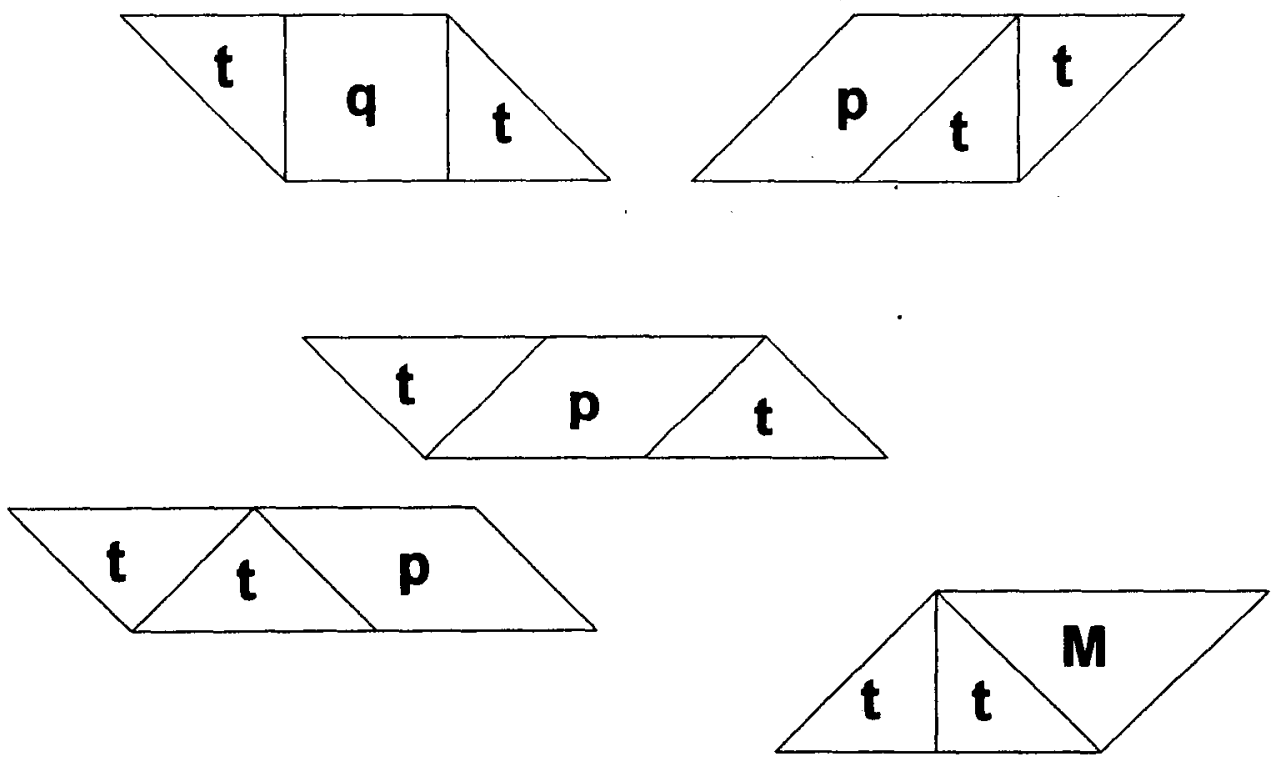

Figura 39: Paralelogramo com três peças.

c) Os sete trapézios diferentes formados através da composição de três peças, conforme mostra a Figura 40. Dentre estes trapézios estão os isósceles e os retângulos. 

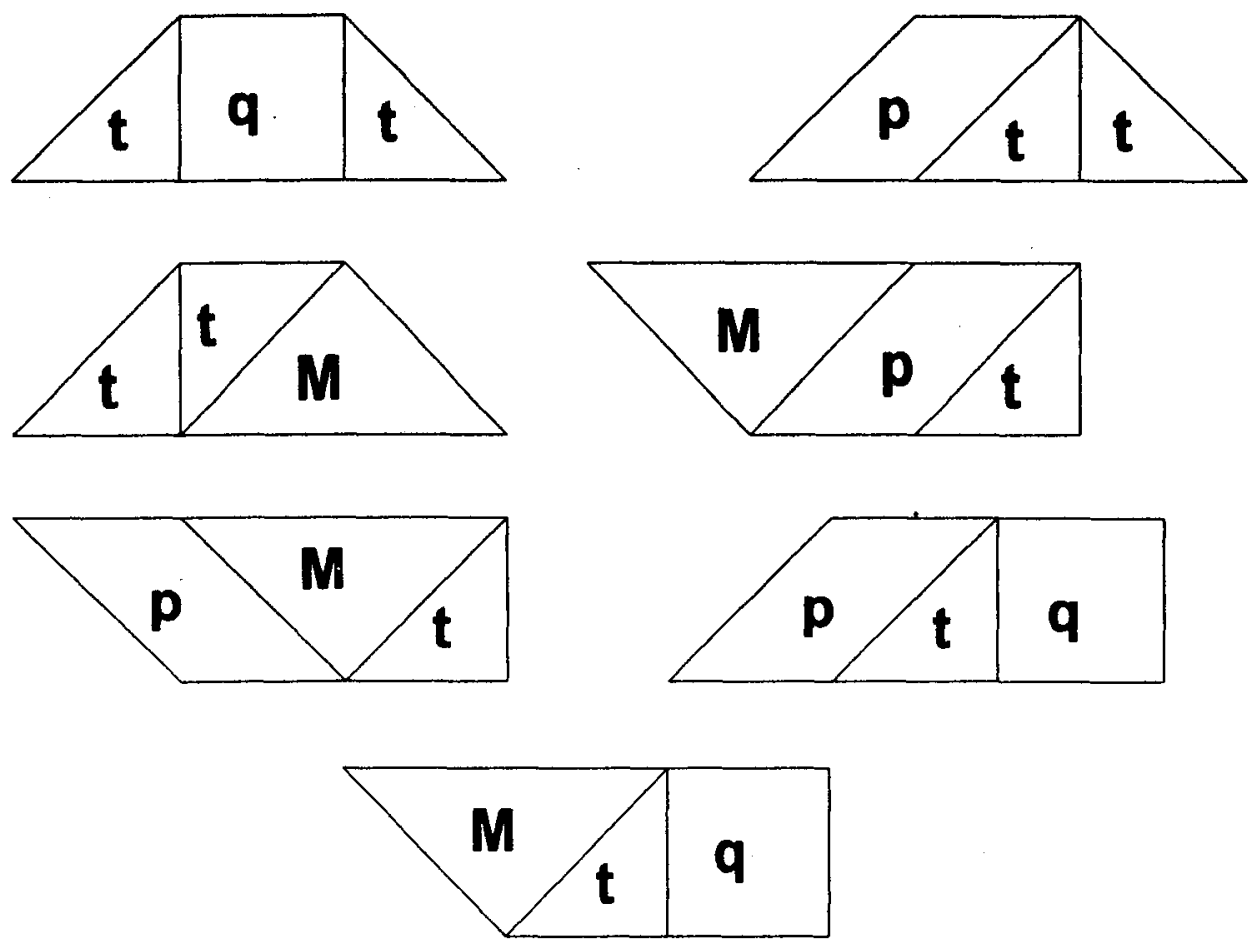

Figura 40: Trapézio com três peças.

d) Os três retângulos formados com três peças, conforme mostra a Figura 41 .
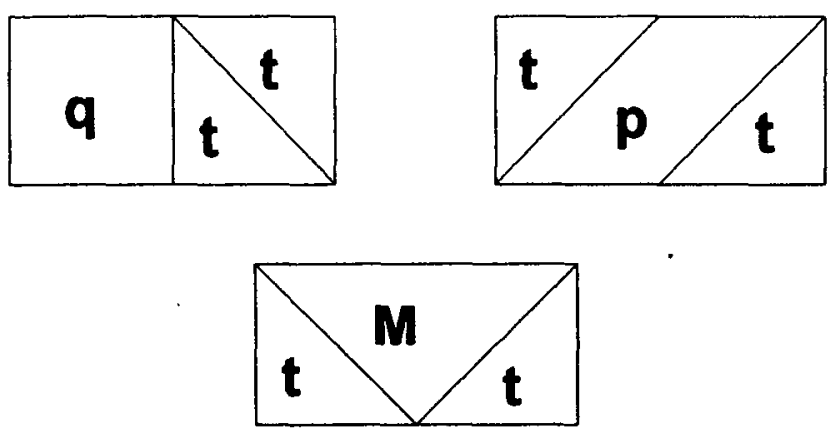

Figura 41: Retângulo com três peças.

7) A atividade de nome TRIÂNGULO_3_PEÇAS explora o conceito C06. Esta atividade possibilita ao estudante compor e decompor as sete peças do Tangram a fim de formar um triângulo usando três delas. Esta atividade possui três soluções diferentes que são apresentadas na Figura 38. Um triângulo é obtido compondo dois triângulos $t$ com o quadrado q. $O$ segundo triângulo é formado através de dois triângulos $t$ com 0 paralelogramo p e o terceiro com dois triângulos t e o triângulo $\mathbf{M}$.

8) A atividade de nome MEDIDA_TRIÂNGULO_VERMELHO é uma atividade inicial para o estudante explorar o conceito C10 (ÁREA). 0 objetivo desta atividade é introduzir o conceito de área de uma figura geométrica. A atividade não fala diretamente 
em calcular área e sim em calcular a medida da região ocupada pelas peças do Tangram. Esta atividade propõe ao estudante calcular a medida da região de seis peças do Tangram, supondo que a medida da região ocupada pelo triângulo vermelho $t$ seja 1 . Quando o estudante calcula a medida de todas as peças, o sistema informa que esta medida calculada tem o nome de área. Desta forma, o que ele calculou foi a área das peças do Tangram.

9) A atividade de nome ÁREA_QUADRADO explora também o conceito C10 (ÁREA). O objetivo desta atividade é trabalhar o conceito de área de uma figura geométrica supondo que o estudante já saiba o que é área (ao contrário da atividade anterior - MEDIDA_TRIÂNGULO_VERMELHO). Esta atividade pede para calcular a área de seis peças do Tangram, supondo que a área do quadrado $q$ vale 1 .

10) A última atividade possui o nome de PERÍMETRO_QUADRADO. Esta atividade explora o conceito $\mathbf{C 1 3}$, e tem como objetivo explorar o conceito de perimetro de uma figura geométrica. É destinada a estudantes com nível de conhecimento mais avançado, pois exige alguns conceitos satélites, tais como: Teorema de Pitágoras, Números Irracionais e Raiz Quadrada. A atividade propõe ao estudante calcular o perímetro das peças do Tangram, sabendo que o perímetro do quadrado (q) vale 4, por exemplo.

\subsubsection{Componentes da janela da atividade}

Internamente no sistema TEGRAM, cada atividade armazenada na base de atividades possui um "procedimento de janela" específico, que é gerenciado pelo módulo de comunicação de atividades. Este procedimento tem como objetivo construir a janela da atividade que será apresentada ao estudante. Esta janela contém- todas as informações relevantes da atividade. Por exemplo, todas as implementadas são compostas por duas outras janelas, como mostra a Figura 42 (atividade QUADRADO_3_PECAS). A primeira é denominada $T C A N V A S$ - é a principal e possui, entre outras informações, $o$ enunciado da atividade e as sete peças que formam o Tangram. A segunda é denominada TTOOLBAR - está localizada à esquerda da TCANVAS e é formada por um menu de ícones, sendo que cada ícone está relacionado com alguma das transformações geométricas oferecidas pelo sistema TEGRAM, tais como: rotação, translação e reflexão. Durante toda a dissertação usaremos o termo "janela da atividade" como sendo a primeira janela (TCANVAS).

A Figura 42 exemplifica uma das atividades que exploram o conceito QUADRADO. A janela TCANVAS contém o enunciado da atividade:"Movimente três peças da Janela A para a Janela $B$ a fim de formar um quadrado, sem que estas peças sejam sobrepostas. Sempre que encontrar uma solução clique o botão Pronto". Além disso esta janela está dividida em duas outras janelas: Janela A e Janela B. Existem atividades em que o "procedimento de janela" da atividade não divide a TCANVAS em duas outras, como por exemplo as atividades que exploram o conceito matemático ÁREA. Quando existir esta divisão, a Janela A terá o enunciado e as sete peças que 
formam o Tangram. A Janela B será reservada para o estudante resolver o problema proposto e também possui o menu da atividade formado pelos seguintes buttons: Pronto, Dicas, Conceitos, Sobre Botão e Sair.

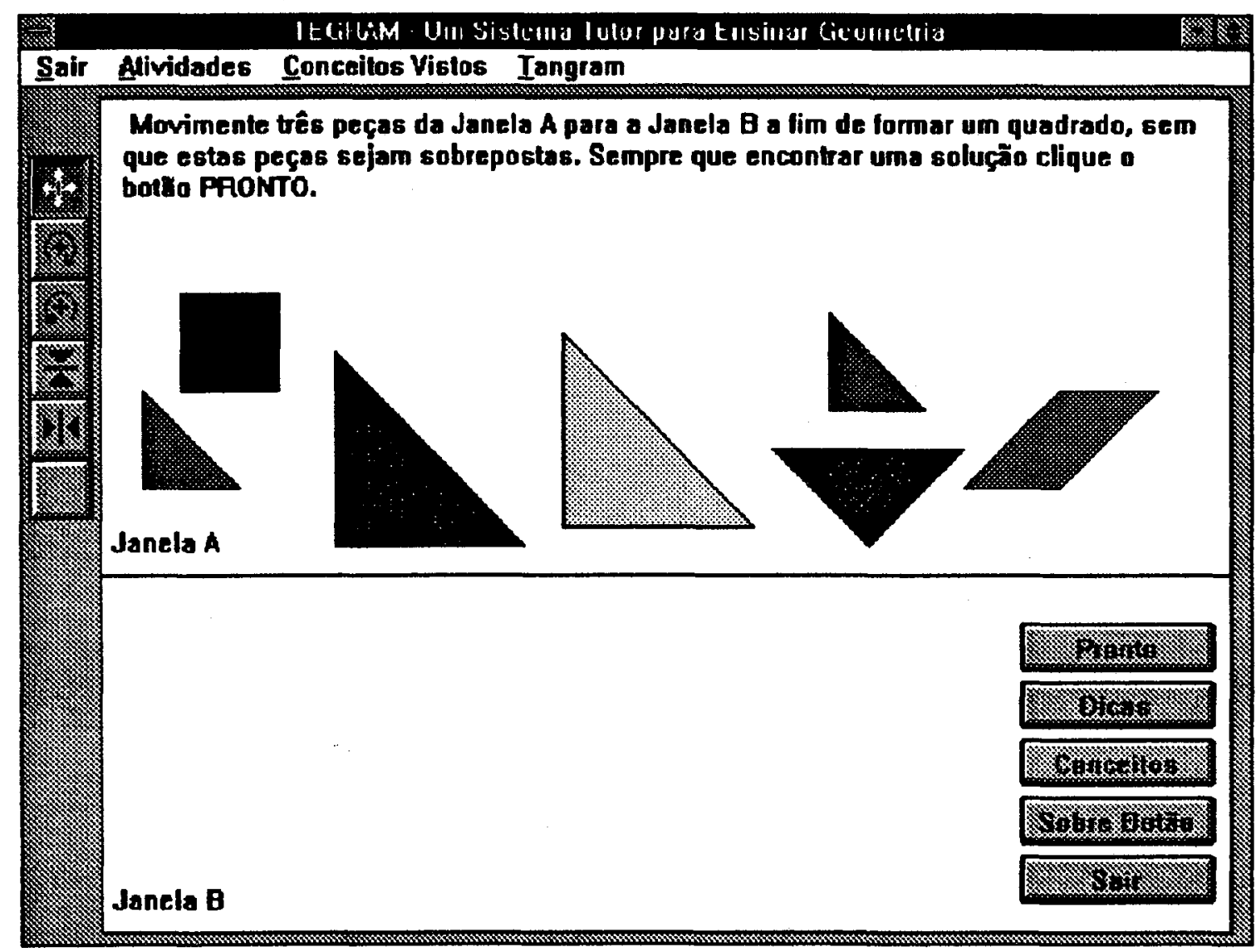

Figura 42: Janela da atividade QUADRADO_3_PEÇAS.

O button Pronto é utilizado pelo estudante toda vez que ele encontrou uma resposta na atividade e quer um feedback do sistema. Se o estudante clicar este button, o sistema avalia a solução dada e retorna um feedback. A Figura 43 mostra um exemplo de feedback fornecido pela atividade QUADRADO_3_PEÇAS. O estudante construiu um quadrado na Janela B compondo três das sete peças do Tangram presentes na Janela A, e clicou o button Pronto. 


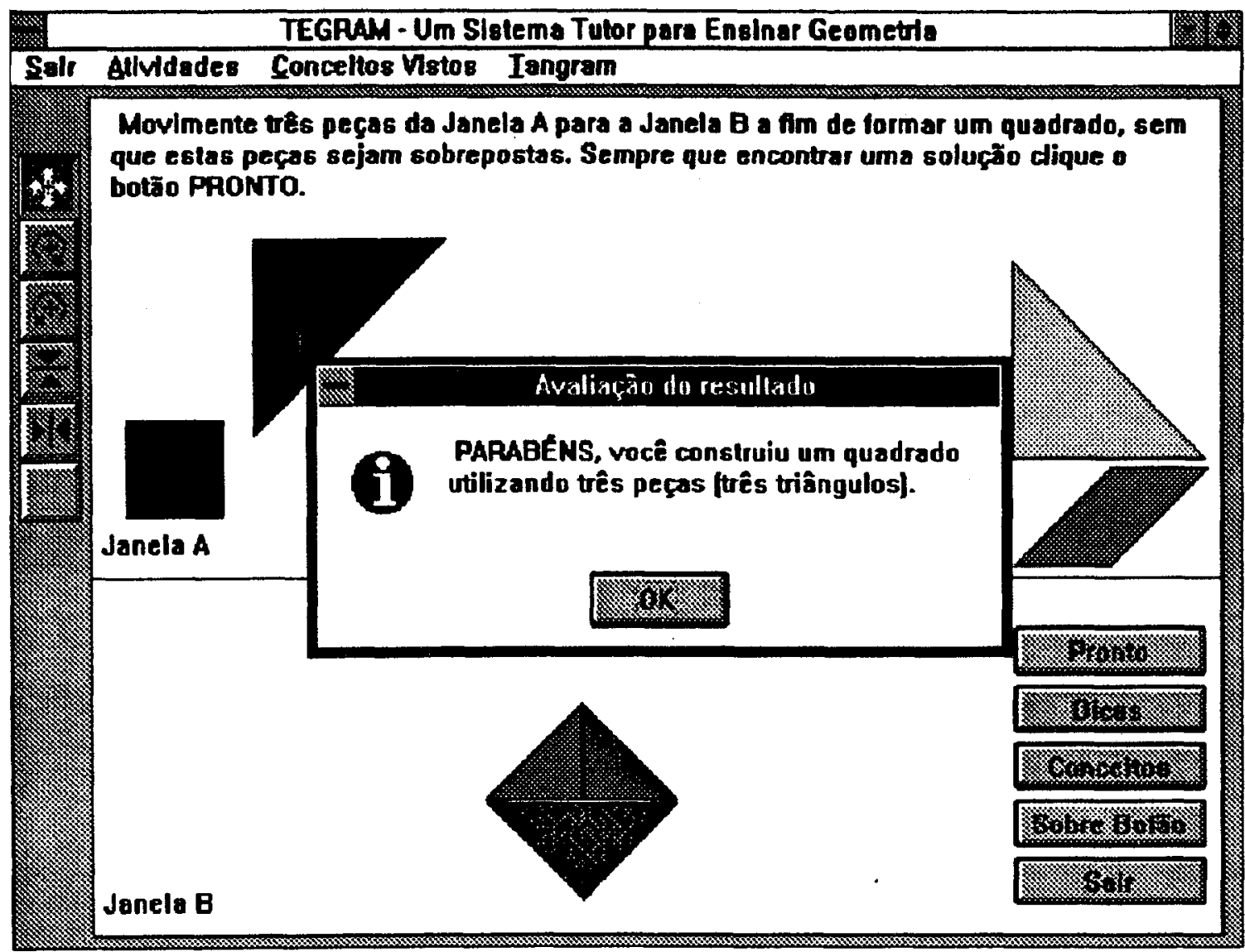

Figura 43: Estudante clicou o button Pronto da atividade QUADRADO_3_PEÇAS.

O button Dicas fornece algumas dicas para o estudante resolver o problema proposto pela atividade. Fornecer dicas para resolver um determinado problema é importante para mostrar alternativas ao estudante. Neste protótipo do sistema TEGRAM, as dicas fornecidas pelo sistema são limitadas. Trata-se de textos estáticos, ou seja, textos pré-armazenados no sistema pelo projetista. Estas dicas não levam em consideração as dificuldades encontradas pelo estudante durante a realização da atividade. Situação ideal seria aquela em que o sistema acompanhasse o estudante na resolução do problema e à medida que ele sentisse dificuldades, o sistema interromperia a atividade e proporia sugestões de como resolvê-lo.

O button Conceitos apresenta os conceitos satélites, ou seja, a teoria dos conceitos pré-requisitos da atividade que o estudante está realizando. Como visto no capítulo quatro, o Slot 4 da estrutura das atividades contém a lista dos conceitos satélites da atividade. Assim, quando o estudante tem alguma dificuldade, ele pode recorrer aos conceitos pré-requisitos da atividade ou, também, o sistema pode interromper a atividade e pedir ao estudante que veja os conceitos pré-requisitos da atividade.

Quando o estudante clica este button (Conceitos), o sistema busca as informações da atividade atual na base de atividades, e através do Slot 4, da estrutura das atividades, constrói um menu de conceitos pré-requisitos da atividade. A partir deste menu, 0 estudante pode escolher o conceito a ser revisado. Feito isto, o sistema busca na estrutura deste conceito qual é o procedimento a ser realizado. Através do Slot 4, da 
estrutura dos conceitos matemáticos, o sistema apresenta a janela da atividade que define este conceito matemático. 0 sistema TEGRAM ainda não possui janelas de definição para todos os conceitos matemáticos presentes na base de conceitos. A Figura 44 apresenta o menu de conceitos pré-requisitos da atividade ÁREA_QUADRADO, que é apresentado quando o estudante clica o button Conceitos.

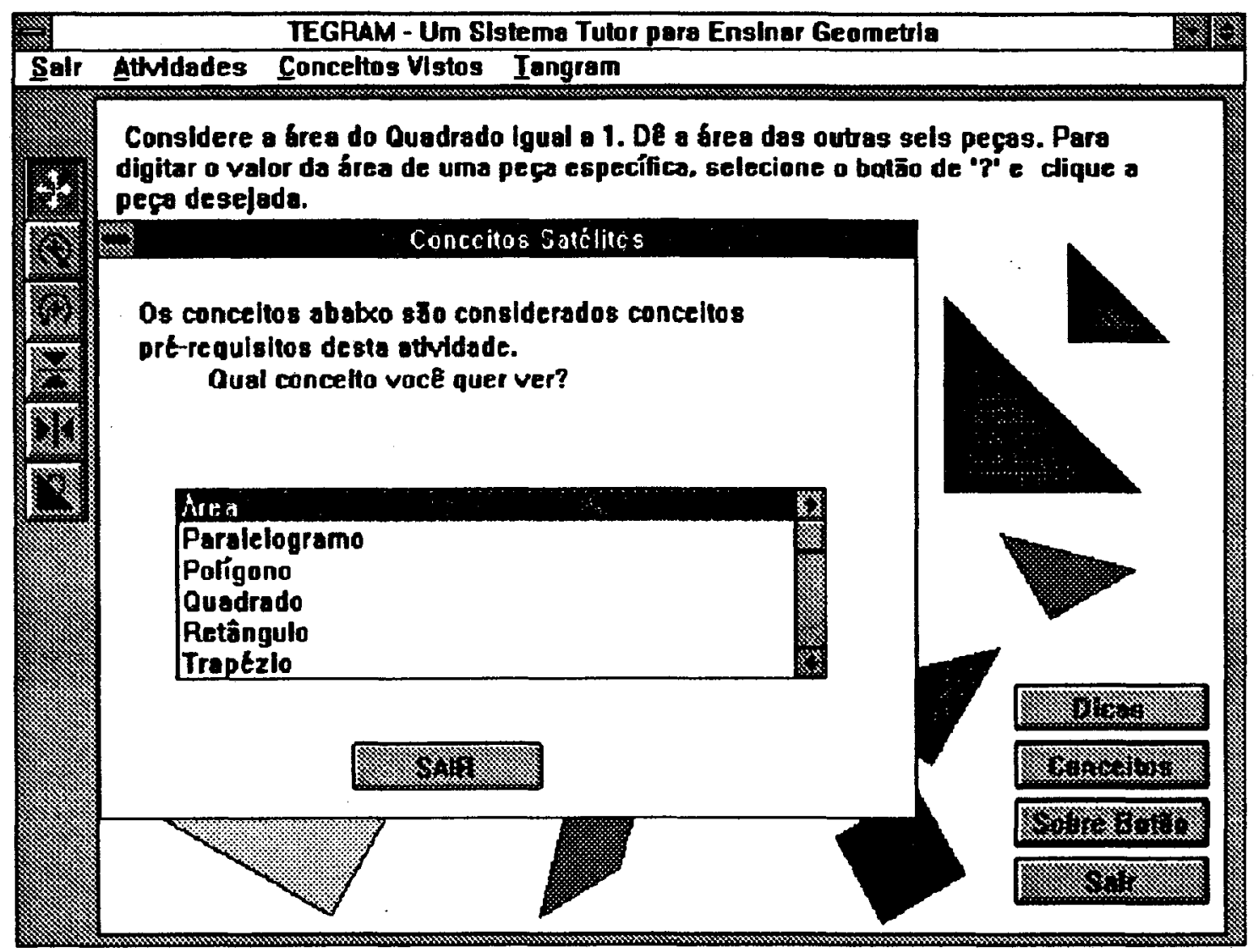

Figura 44: Exemplo do menu de conceitos pré-requisitos.

O button Sobre Botão fornece um help, explicando a função do ícone selecionado no menu de ícones da janela TTOOLBAR. De acordo com a janela da atividade apresentada na Figura 44, a janela TTOOLBAR contém um menu formado por seis ícones, que permite ao estudante realizar transformações geométricas sobre as peças do Tangram que estão na janela TCANVAS. Os seis ícones são:

1) O primeiro é denominado BOTÃO DE MOVIMENTAÇÃO. Este ícone permite ao estudante clicar a peça desejada e arrastá-la para outra posição na janela TCANVAS.

2) Selecionando o segundo ícone, denominado BOTÃo DE ROTAÇÃO, o estudante pode clicar a peça desejada e o sistema irá rotacioná-la no sentido horário. A Figura 45 apresenta o help fornecido pelo sistema quando o estudante clica o button Sobre Botão e o ícone selecionado na janela TTOOLBAR é o segundo. 


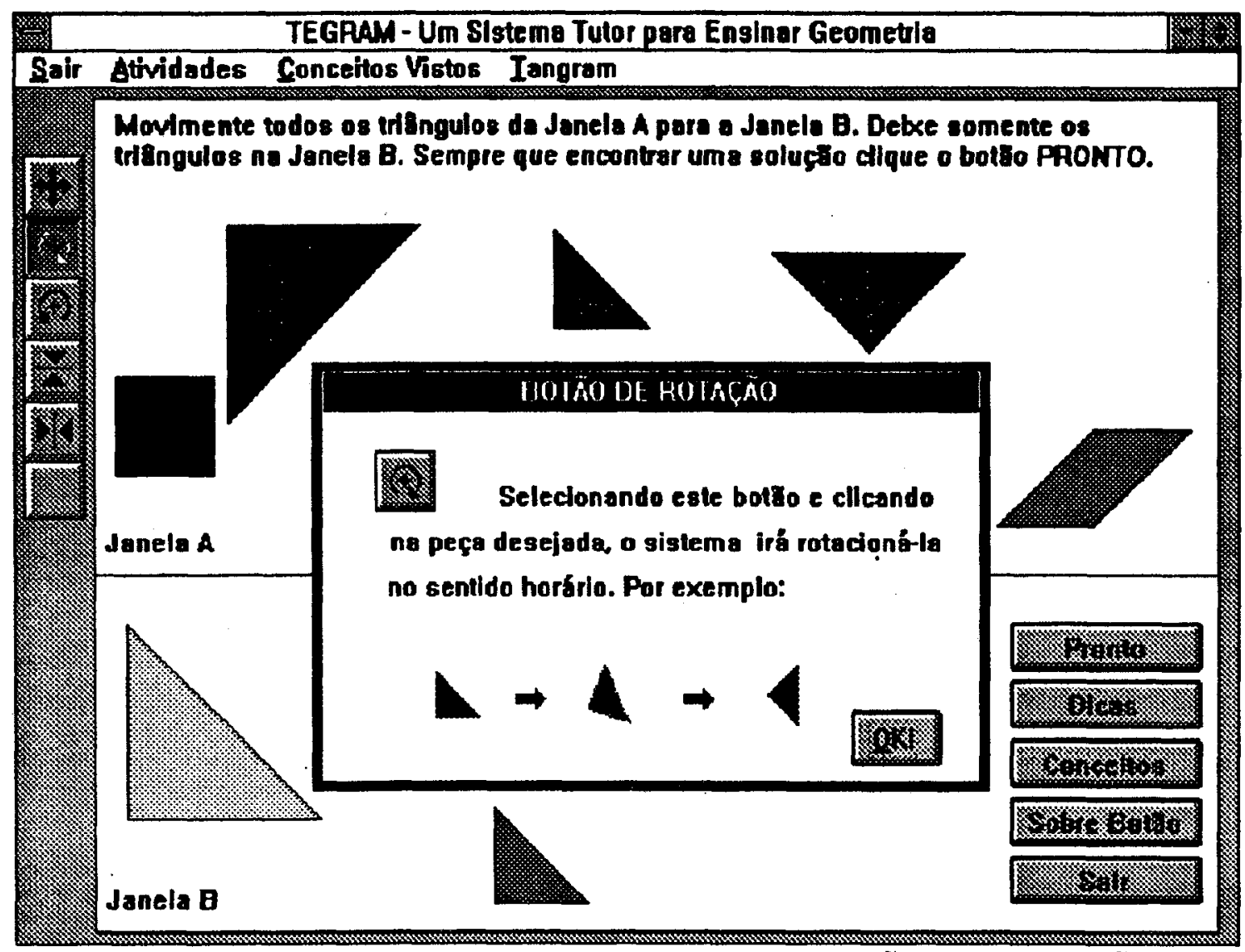

Figura 45: Estudante clicou o button Sobre Botão (BOTÃO DE ROTAÇÃO).

3) O terceiro ícone, BOTÃO DE ROTAÇÃO, é parecido com o segundo. Em vez de rotacionar a peça no sentido horário, este ícone permite rotacionar a peça no sentido anti-horário.

4) O quarto ícone é denominado BOTÃO DE REFLEXÃO. A Figura 46 mostra o help fornecido pelo sistema, quando o estudante clica o button Sobre Botão e o ícone selecionado da janela TTOOLBAR é o quarto, que permite ao estudante selecionar a peça desejada. $O$ sistema reflete esta peça usando um eixo de reflexão horizontal.

5) Selecionando o quinto ícone, BOTÃo DE REFLEXÃO, o estudante pode clicar a peça desejada e o sistema faz uma reflexão desta peça usando um eixo de reflexão vertical.

6) O sexto ícone é denominado BOTÃO DE ENTRADA DE DADOS, que no menu de ícones da Figura 46 está em branco. Este ícone é utilizado somente pelas atividades que calculam área ou perímetro, pois exigem entrada de dados por parte do estudante. Por exemplo, a Figura 47 apresenta a janela da atividade ÁREA_QUADRADO. Selecionando o ícone de entrada de dados e clicando uma das sete peças do Tangram, o sistema apresenta uma janela de entrada de dados. No caso das atividades de área, o sistema pede ao estudante a área da peça selecionada e espera uma resposta do estudante. Em seguida, o sistema avalia a resposta e retorna um feedback ao estudante. 


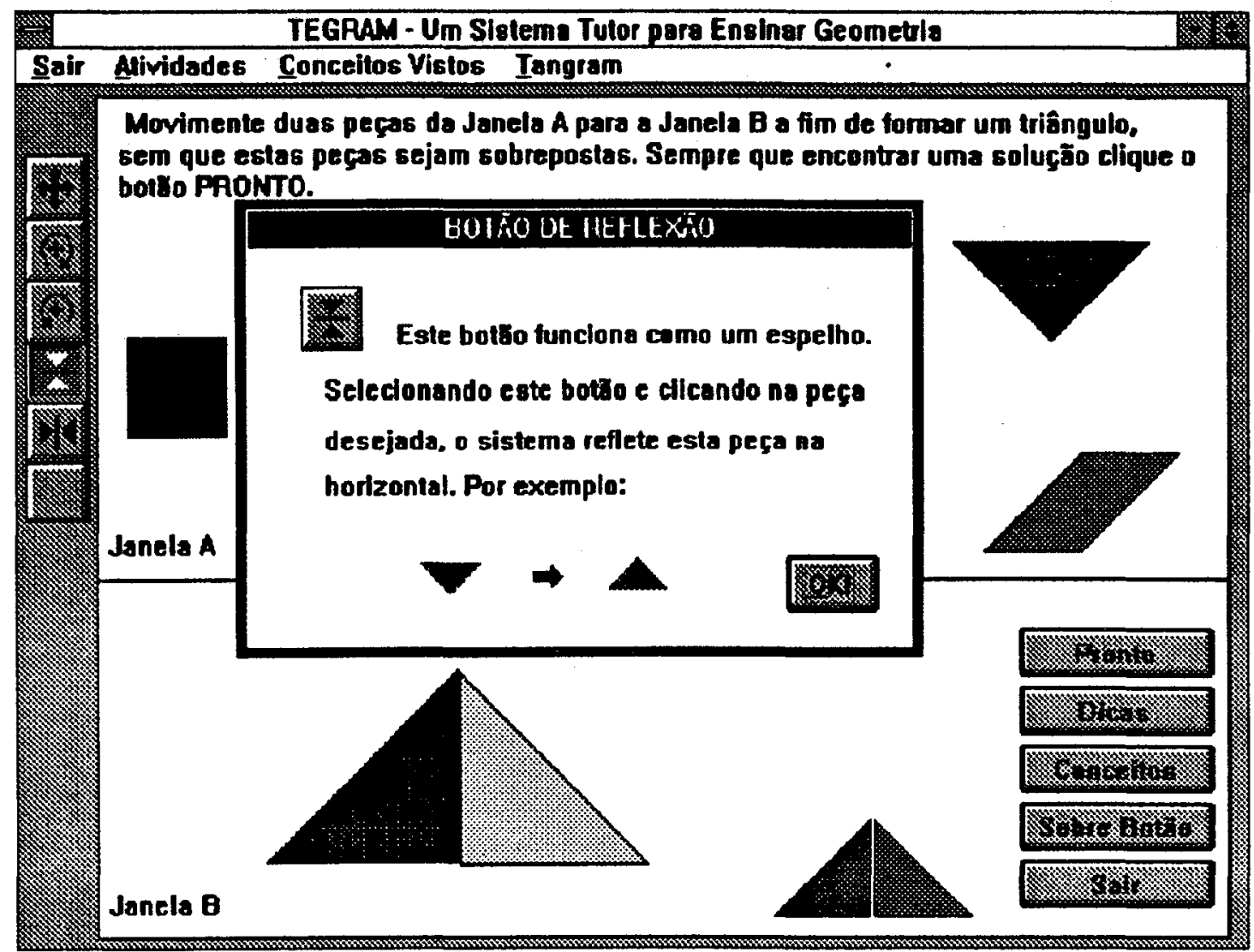

Figura 46: Estudante clicou o button Sobre Botão (BOTÃo DE REFLEXÃO).

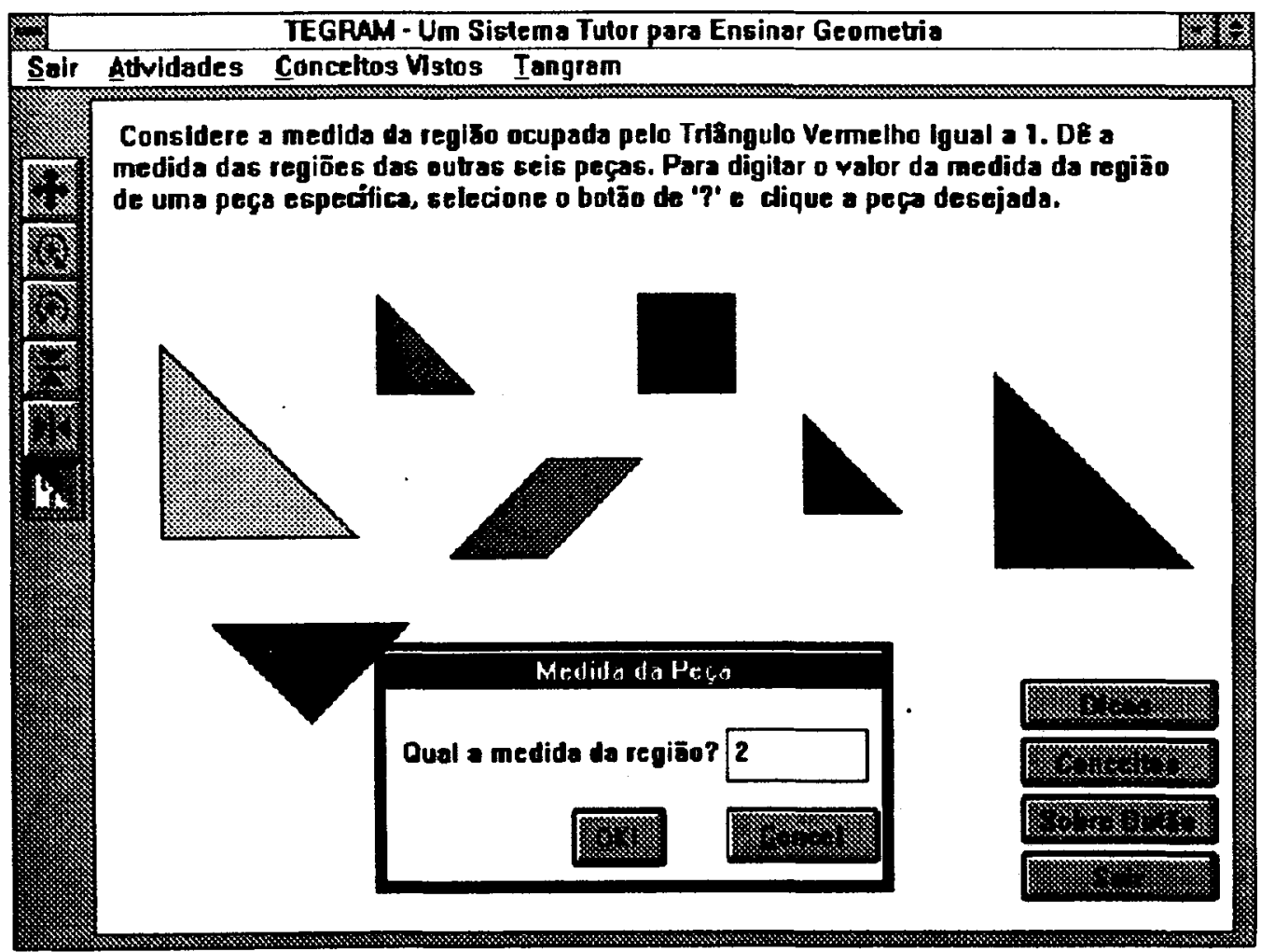

Figura 47: Estudante clicou o button Sobre Botão (BOTÃo DE ENTRADA DE DADOS). 


\subsection{Exemplo de uma sessåo com um estudante}

Executando o sistema TEGRAM, a primeira janela apresentada ao estudante é a de apresentação do sistema, conforme mostra a Figura 48.

Logo a seguir, para identificar o usuário, ou seja, o estudante que irá interagir com o sistema, é apresentada a primeira janela de identificação do sistema (Figura 49). Nela o sistema pede ao estudante que digite o seu nome completo. Feito isso, o sistema faz uma pesquisa na base de estudantes para verificar se este nome está presente ou não. Em caso negativo, este estudante é considerado novato no sistema. Caso contrário, o estudante não é novato, ou seja, já existe seu na base de estudantes do sistema.

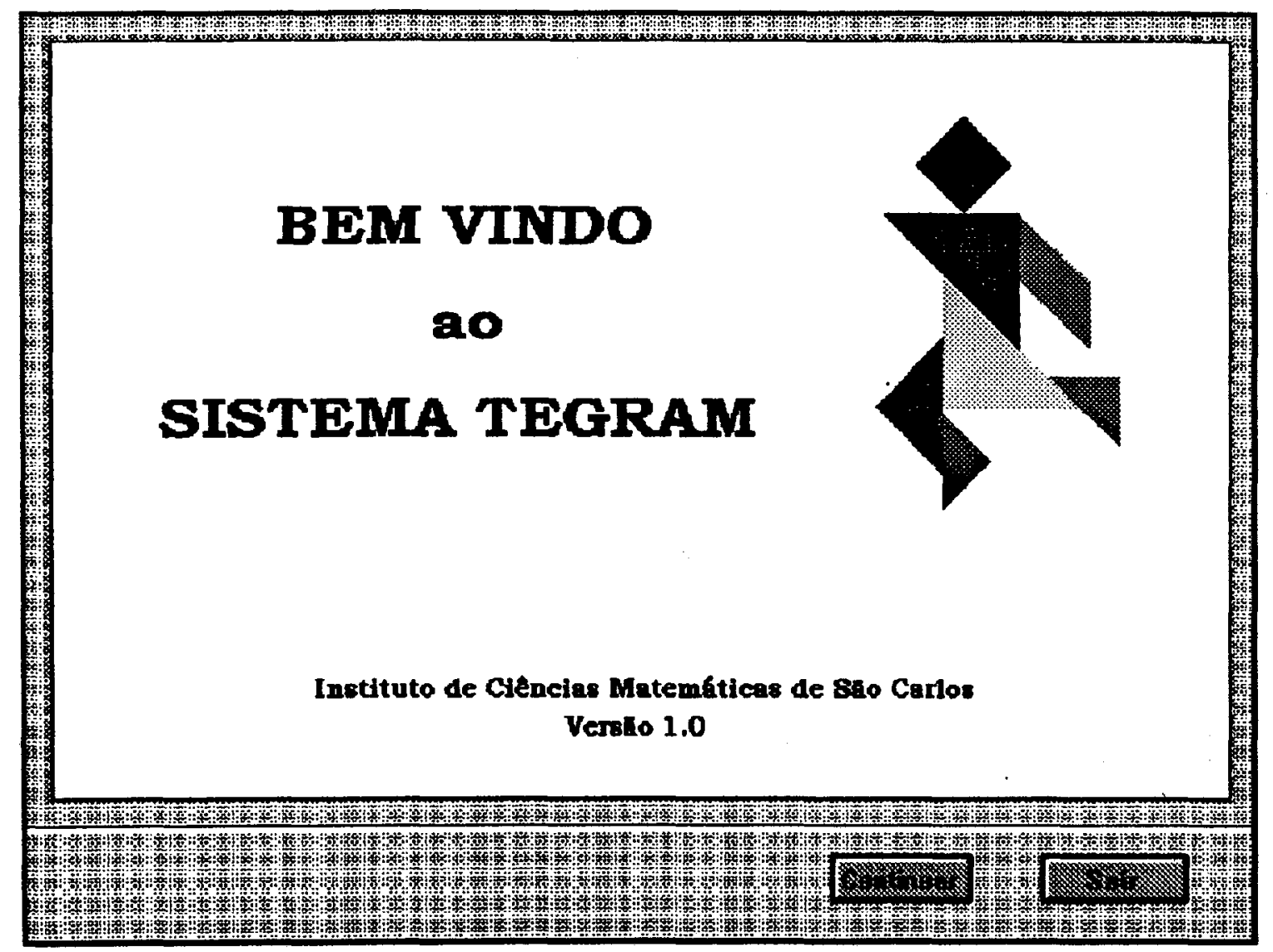

Figura 48: Janela de apresentação do sistema TEGRAM. 


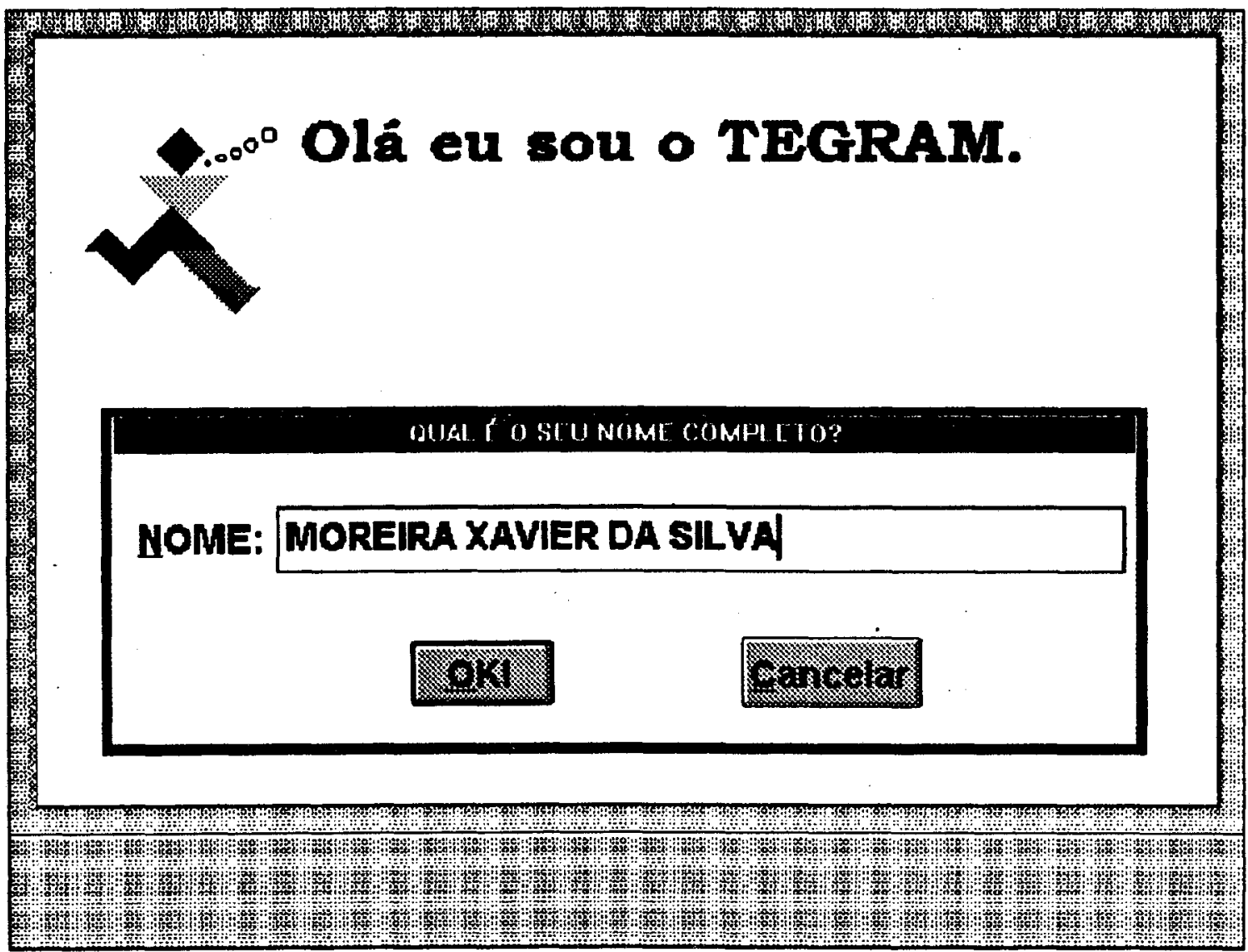

Figura 49: Primeira janela de identificação do sistema TEGRAM.

\subsubsection{Estudante novato}

Supondo que o estudante é considerado novato no sistema, a primeira decisão tutorial realizada pelo módulo tutorial é fazer com que o módulo de comunicação de atividades apresente a segunda janela de identificação (Figura 50). Nela o sistema pede ao estudante que digite a senha de acesso ao sistema e a série escolar que está cursando. A partir deste momento e durante toda a interação, o sistema constrói e/ou atualiza o modelo deste estudante.

Como o estudante é considerado novato no sistema, o módulo tutorial ativa uma outra decisão tutorial com o objetivo de apresentar a janela de definição do Tangram. A Figura 32 apresenta esta janela. Através dela o sistema define o Tangram e os passos necessários para sua construção. Esta janela é fundamental para o estudante conhecer o Tangram, pois todas as atividades propostas pelo sistema vão utilizar as sua sete peças. Ela é apresentada pelo sistema somente quando o estudante é novato. 


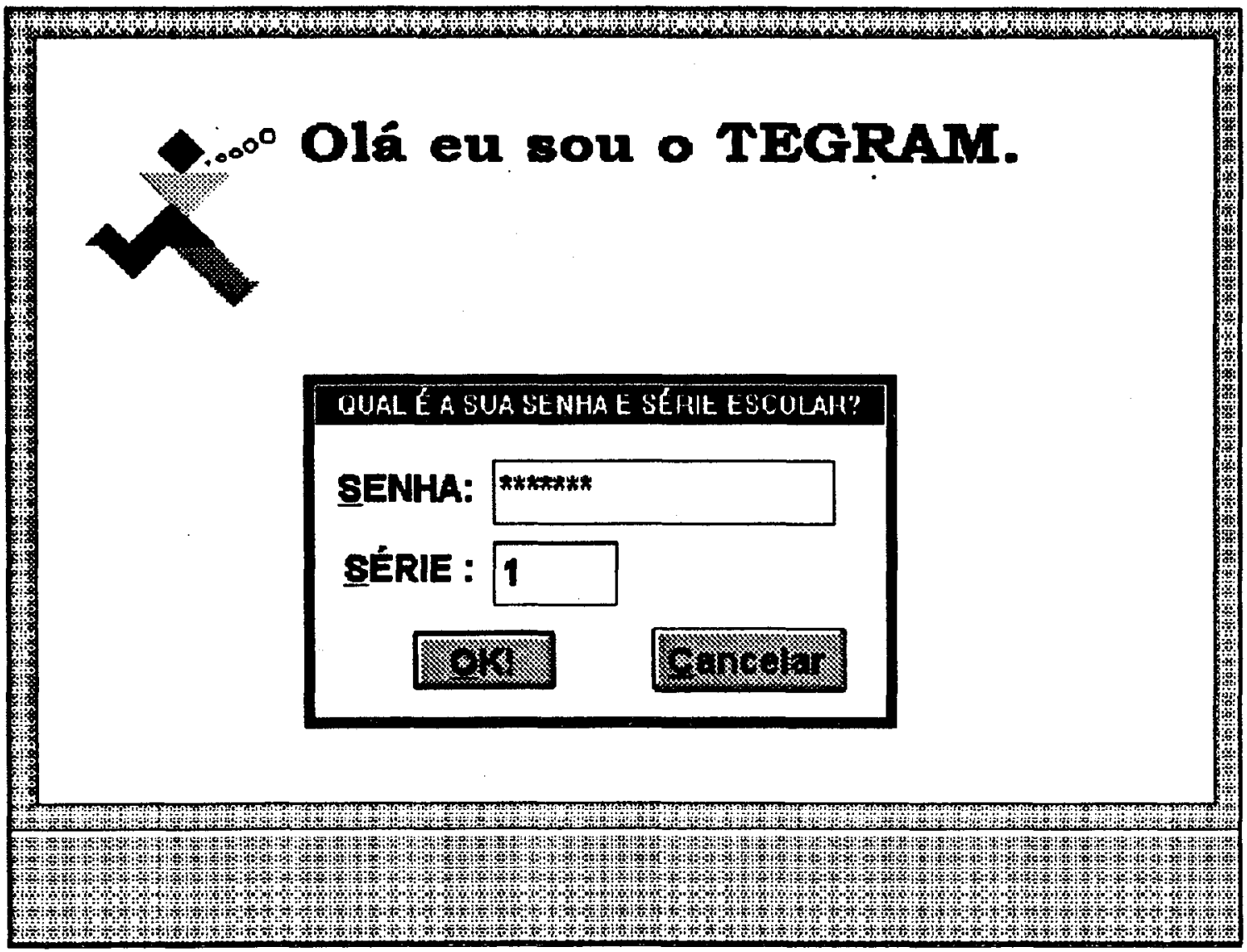

Figura 50: Segunda janela de identificação do sistema TEGRAM.

Supondo que o estudante do nosso exemplo esteja na primeira série, o sistema constrói para ele a rede de conceitos, a partir do Slot 3 da estrutura dos conceitos. Os nós da rede são os conceitos matemáticos a serem explorados e os arcos entre eles são as relações de precedência entre os conceitos. As relações de precedência são obtidas através do Slot 6 da estrutura dos conceitos matemáticos. A partir desta rede, o sistema atualiza a lista de conceitos nucleares a ser explorada pelo estudante (Slot 7 do modelo do estudante).

Para o estudante do exemplo, a lista de conceitos nucleares é [C01,C02,C03]. A partir desta lista, o sistema ensina o conceito $\mathrm{CO} 1$ (primeiro conceito matemático da lista). Para explorar este conceito, existe uma lista de atividades a serem realizadas, que é formada pelo Slot 5 da estrutura dos conceitos e ordenada de acordo com o nivel de dificuldade da atividade (Slot 3 da estrutura das atividades). Assim, a lista de atividades que exploram o conceito $\mathrm{C} 01$ é [A23]. Note que temos somente uma atividade para explorar o conceito C01 (IDENTIFICAR_QUADRADO). Isto não é desejável no sistema. Desta forma, novas atividades terão que ser construídas, proporcionando uma reestruturação na base de conceitos e atividades do sistema TEGRAM. 
Continuando na interação sistema/estudante, o módulo tutorial ativa uma decisão tutorial para que o módulo de comunicação de atividades construa, dinamicamente, durante a interação com o estudante, um menu de atividades. Neste menu, as atividades estão ordenadas de acordo com o nivel crescente de dificuldade existente entre elas (Slot 3 da estrutura das atividades). Desta forma, as atividades são apresentadas ao estudante através do menu de atividades, e ele é livre para escolher as atividades a realizar. Neste exemplo, o menu contém somente uma atividade, cujo nome é IDENTIFICAR_QUADRADO, conforme mostra a Figura 51.

A Figura 51 apresenta a janela principal do sistema TEGRAM, do nivel da primeira série. Esta janela tem por objetivo gerenciar toda a interação entre o sistema e $o$ estudante. A janela principal contém um menu superior denominado "menu principal" do sistema, que é formado pelas seguintes op̧ões: $\underline{\text { Sair, }}$ Atividades, $\underline{\text { Conceitos Vistos e }}$ Tangram. A opção Sair permite o estudante finalizar a execução do sistema. Antes de finalizar, o módulo tutorial ativa uma decisão tutorial para salvar o modelo do estudante atual na base de estudantes. A opção Atividades mostra um menu contendo todas as atividades a serem realizadas, neste momento, as quais exploram um único conceito nuclear.

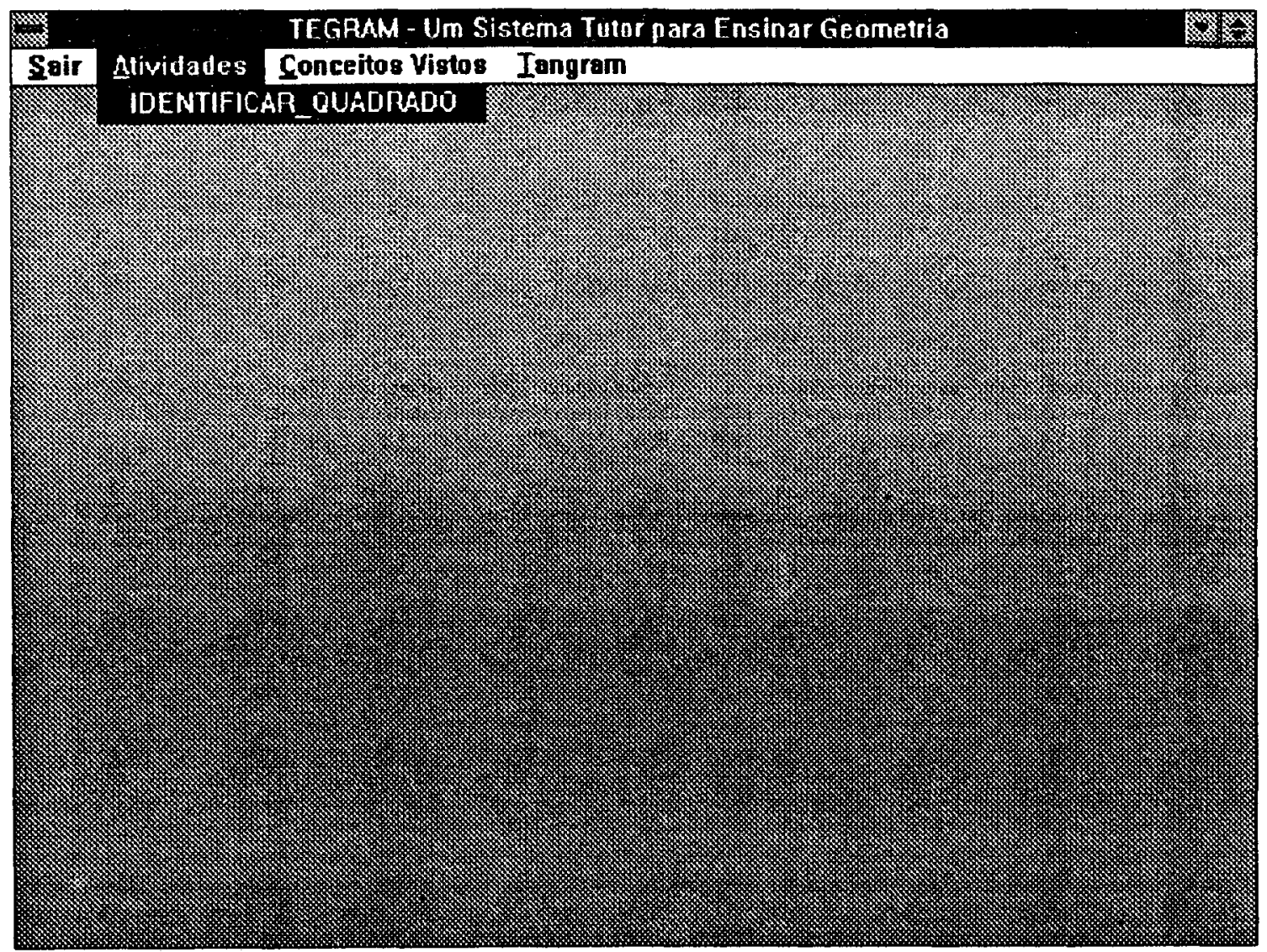

Figura 51: Exemplo do menu de atividades.

A opção Conceitos Vistos apresenta um menu contendo todos os conceitos nucleares vistos pelo estudante, que são os considerados supostamente aprendidos pelo 
estudante (Slot 8 do modelo do estudante). Os conceitos somente aparecerão neste menu quando o estudante aumentar o seu nivel de conhecimento no sistema, ou seja, se ele está na primeira série e passa para a segunda série. Quando isto acontece, todos os conceitos relacionados com a primeira série aparecem no menu de Conceitos Vistos. Cada conceito visto tem associado um outro menu contendo todas as atividades relacionadas com ele. São apresentadas somente as atividades que tenham nivel menor que o nivel de conhecimento do estudante atual. Por exemplo, se o estudante está na terceira série, as atividades a serem apresentadas nos conceitos vistos serão da primeira e da segunda série, se existirem tais atividades. Este menu foi construido a fim de possibilitar ao estudante refazer uma atividade, ou mesmo para o sistema propor a revisão de algum conceito visto.

A opção Tangram, do menu principal, permite que o estudante veja novamente a janela que define o Tangram e os passos necessários para construi-lo (Figura 32). Esta janela já foi apresentada pelo sistema no início da sessão, quando o sistema reconhece o estudante como sendo novato. Porém, pode ser vista novamente, caso o estudante tenha alguma dúvida sobre o Tangram.

Supondo que a atividade IDENTIFICAR_QUADRADO tenha sido escolhida, o sistema ativa o "procedimento de janela" a ela relacionado e apresenta a janela contendo todas as informações relevantes sobre esta atividade. A Figura 52 apresenta a janela da atividade IDENTIFICAR_QUADRADO.

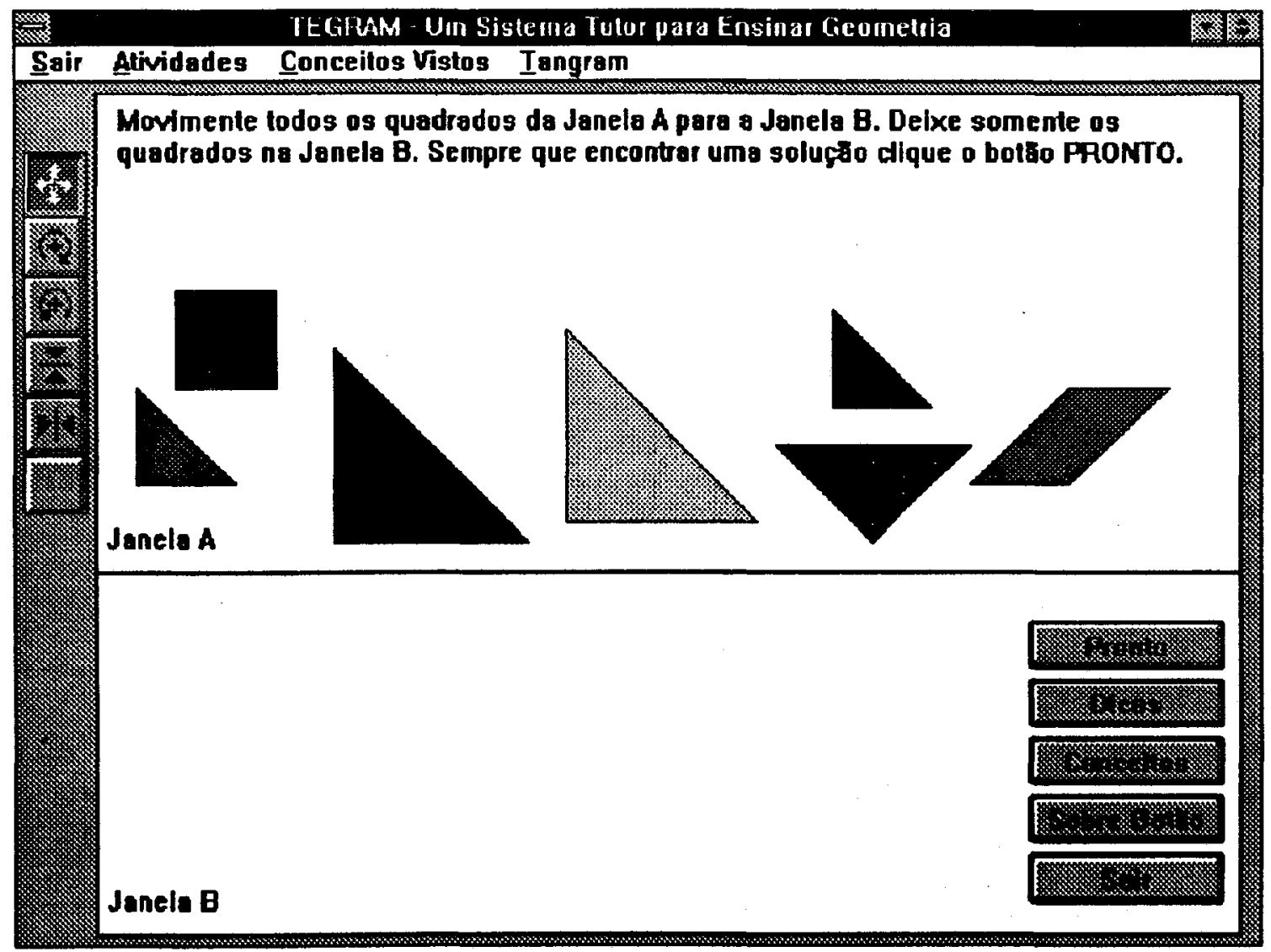

Figura 52: Janela da atividade IDENTIFICAR_QUADRADO. 
Se o estudante movimentou para a Janela B somente o quadrado azul e clicou o button Pronto, então o sistema avalia o que o estudante fez na Janela B e retorna um feedback avisando que ele teve sucesso, conforme mostra a Figura 53. Para avaliar o que $o$ estudante fez nesta atividade, o sistema ativa um procedimento que reconhece todas as peças do Tangram presentes na Janela B, que foram movimentadas pelo estudante da Janela A. A partir deste reconhecimento, o sistema dá um feedback ao estudante informando $\mathrm{o}$ que ele fez na atividade. $\mathrm{O}$ mesmo procedimento de avaliação realizado pelo sistema nesta atividade (IDENTIFICAR_QUADRADO) é também utilizado pelas atividades

IDENTIFICAR_PARALELOGRAMO.

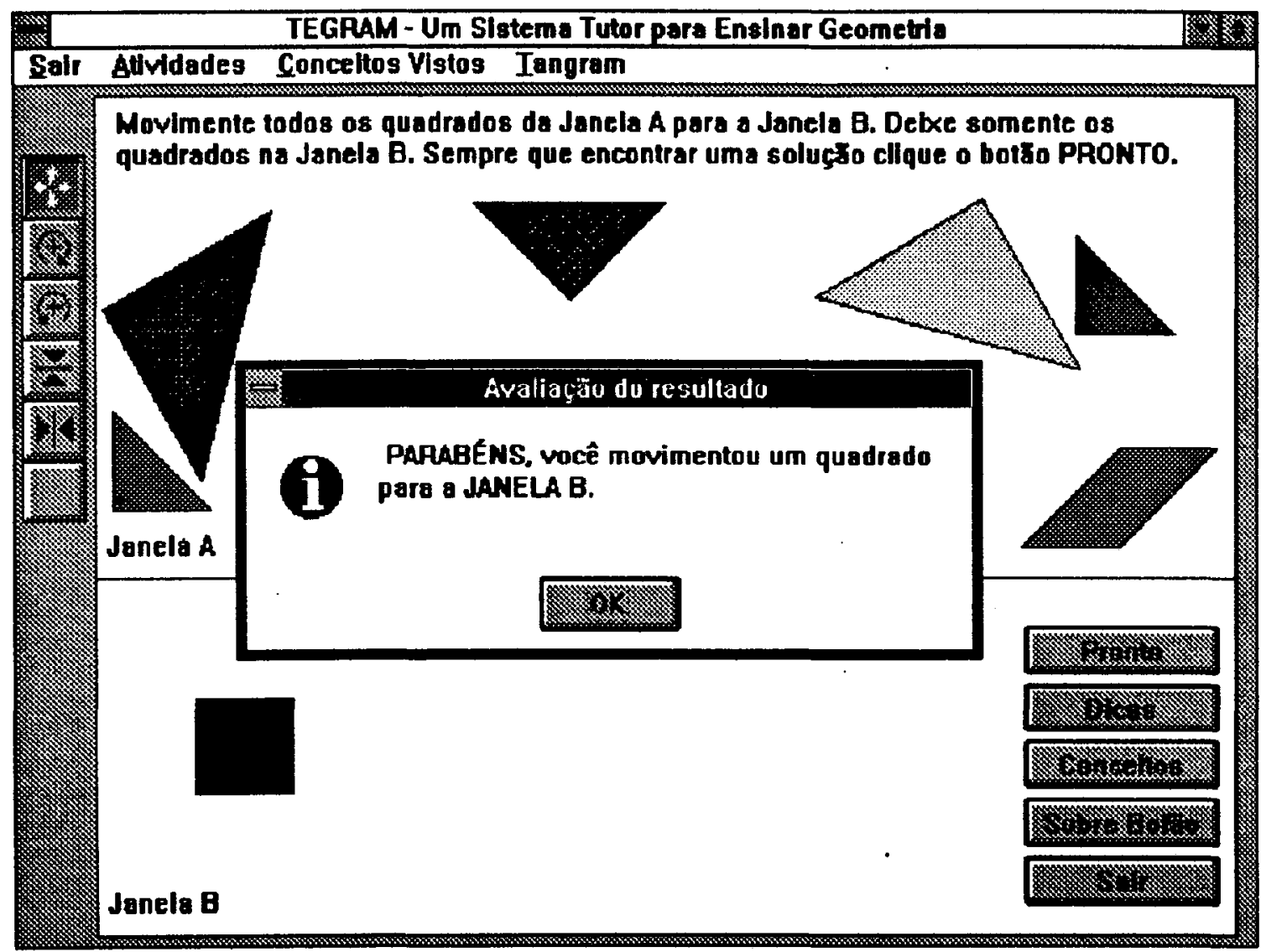

Figura 53: Estudante clicou o button Pronto da atividade IDENTIFICAR_QUADRADO.

Após avaliar os procedimentos do estudante, o sistema calcula o seu desempenho nesta atividade (DA). Como o estudante do nosso exemplo teve sucesso, o seu DA é igual a 10. Feito isso é calculado o desempenho global do estudante (DG) no conceito que está sendo explorado. Este cálculo é feito da seguinte maneira:

$\mathrm{DG}=(\mathrm{DA} 1+\ldots+\mathrm{DAi}) / \mathrm{N}$, onde

- DAi é o desempenho na atividade Ai realizada pelo estudante.

- DA1 + ... + DAi é a soma dos desempenhos de todas as atividades realizadas que exploram o conceito proposto. 
- N é o número de atividades realizadas que exploram o conceito que etá sendo explorado.

- Se DG > 5.0 então o sistema passa a explorar os conceitos do próximo nivel de conhecimento.

- Se DG $\leq 5.0$ então o sistema continua explorando este mesmo conceito matemático.

Como, neste caso, só há uma atividade relacionada com o conceito matemático proposto pelo sistema, e o DA é igual a 10, então o DG é também igual a 10 (DG=10/1). Desta forma, é proposto o próximo conceito da lista de conceitos nucleares do modelo do estudante. Neste momento, o sistema atualiza o Slot 7 (lista de conceitos nucleares) e o Slot 8 (lista de conceitos supostamente aprendidos) do modelo do estudante. No nosso exemplo, a lista de conceitos nucleares é [ $\mathrm{C01}, \mathrm{C02}, \mathrm{C} 03]$. Então o sistema exclui o conceito C01 da lista do Slot 7 e o insere na lista de conceitos do Slot 8. O Slot 7 fica então com a lista [C02, $\mathrm{C03}]$ e o Slot 8 com a lista [C01].

$\mathrm{O}$ próximo conceito a ser explorado é o $\mathrm{C02}$. Supondo que o estudante já realizou todas as atividades que exploram os conceitos $\mathrm{C0} 2$ e $\mathrm{C} 03$, teve um desempenho global satisfatório (DG > 5.0), a lista de conceitos nucleares está vazia (Slot 7) e a lista de conceitos supostamente aprendidos está com [C01,C02,C03] (Slot 8). Quando o estudante chega a esta situação, o seu nível de conhecimento é elevado pelo sistema. Por exemplo, como o estudante é do nível um (primeira série), o sistema o promove para o nivel dois e atualiza o Slot 3 (série escolar) do modelo do estudante. Observe que a série escolar é apenas uma informação relativa e não corresponde, à exceção da sessão inicial, à realidade escolar do usuário. A partir disto, o sistema constrói novamente a rede de conceitos para este estudante (agora do nível dois) e atualiza a lista de conceitos nucleares (Slot 7 do modelo do estudante).

A lista de conceitos nucleares atualizada é [C04,C05,C06,C07,C09], que são os conceitos matemáticos (CNs) da segunda série. Como o sistema aumentou o nível de conhecimento do estudante, a opção Conceitos Vistos do menu principal contém os três conceitos vistos da primeira série (C01, C02 e C03). A Figura 54 mostra o menu de Conceitos Vistos com: QUADRADO, TRIÂNGULO e PARALELOGRAMO. Clicando no conceito QUADRADO, o sistema apresenta as atividades a ele relacionadas (neste exemplo, somente a atividade IDENTIFICAR_QUADRADO). 


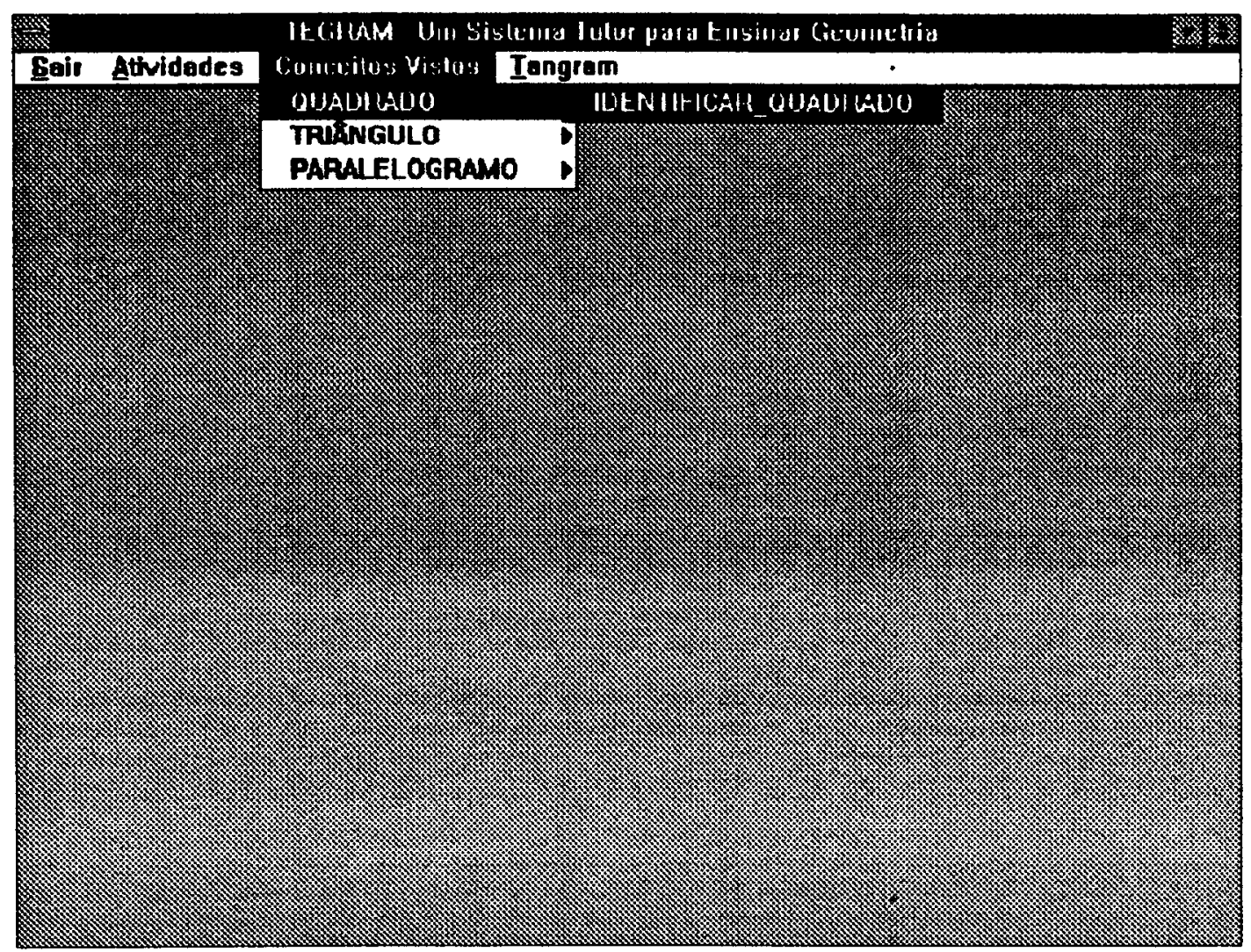

Figura 54: Estudante clicou a opção Conceitos Vistos.

Suponhamos que o estudante já viu o conceito C04 (POLÍGONO) e agora está realizando uma das atividades que exploram o conceito C05 (FORMAR_QUADRADO). A Figura 55 apresenta a janela da atividade QUADRADO_2_PEÇAS, que propõe ao estudante construir os possíveis quadrados na Janela B com duas das sete peças do Tangram, apresentadas na Janela A. Supondo que o estudante construiu um quadrado na Janela B e clicou o button Pronto para obter uma resposta, o sistema lhe dá um feedback informando que ele construiu um quadrado corretamente com duas peças, conforme mostra a Figura 56.

Para avaliar o que o estudante fez nesta atividade (QUADRADO_2_PEÇAS) e nas outras atividades cujo objetivo é compor e decompor as peças do Tangram a fim de formar figuras geométricas com um número limitado de peças, o sistema ativa uma seqüência de passos. Inicialmente, reconhece as peças do Tangram estão na Janela B, que foram movimentadas pelo estudante da Janela A. Feito isso, o módulo tutorial ativa os procedimentos que fazem parte do submódulo rede de definições para verificar o que foi construido na Janela B. Por exemplo, na atividade QUADRADO_2_PEÇAS o sistema combina as peças (duas a duas) que estão na Janela B e ativa os procedimentos formou_quadrado2( ), formou_triângulo2( ), formou_paralelogramo2( ), formou_trapézio_isósceles2( ) e formou_trapézio_retângulo2( ). Após a execução destes procedimentos, o sistema retorna um feedback informando o que o estudante fez na atividade. 


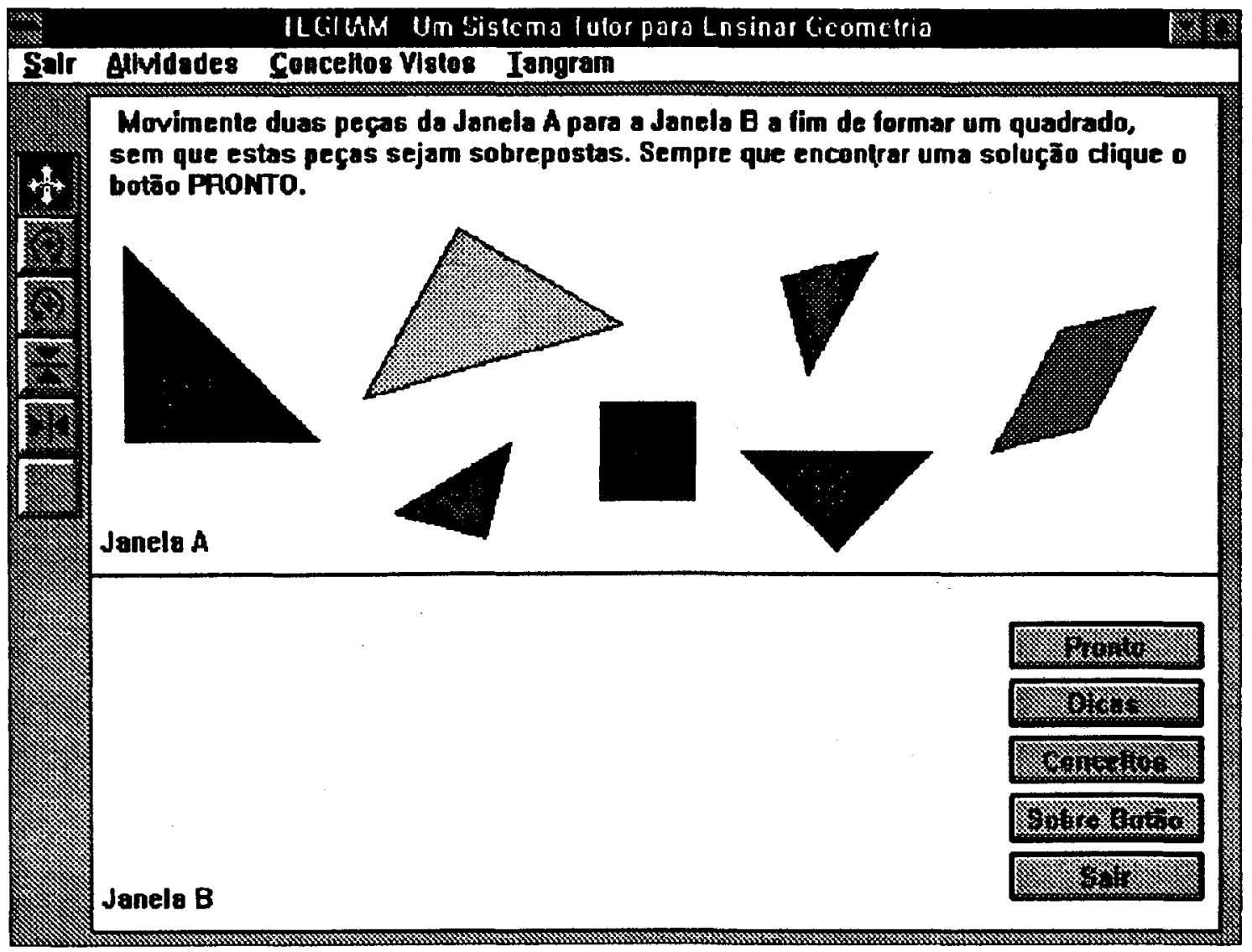

Figura 55: Janela da atividade QUADRADO_2_PEÇAS.

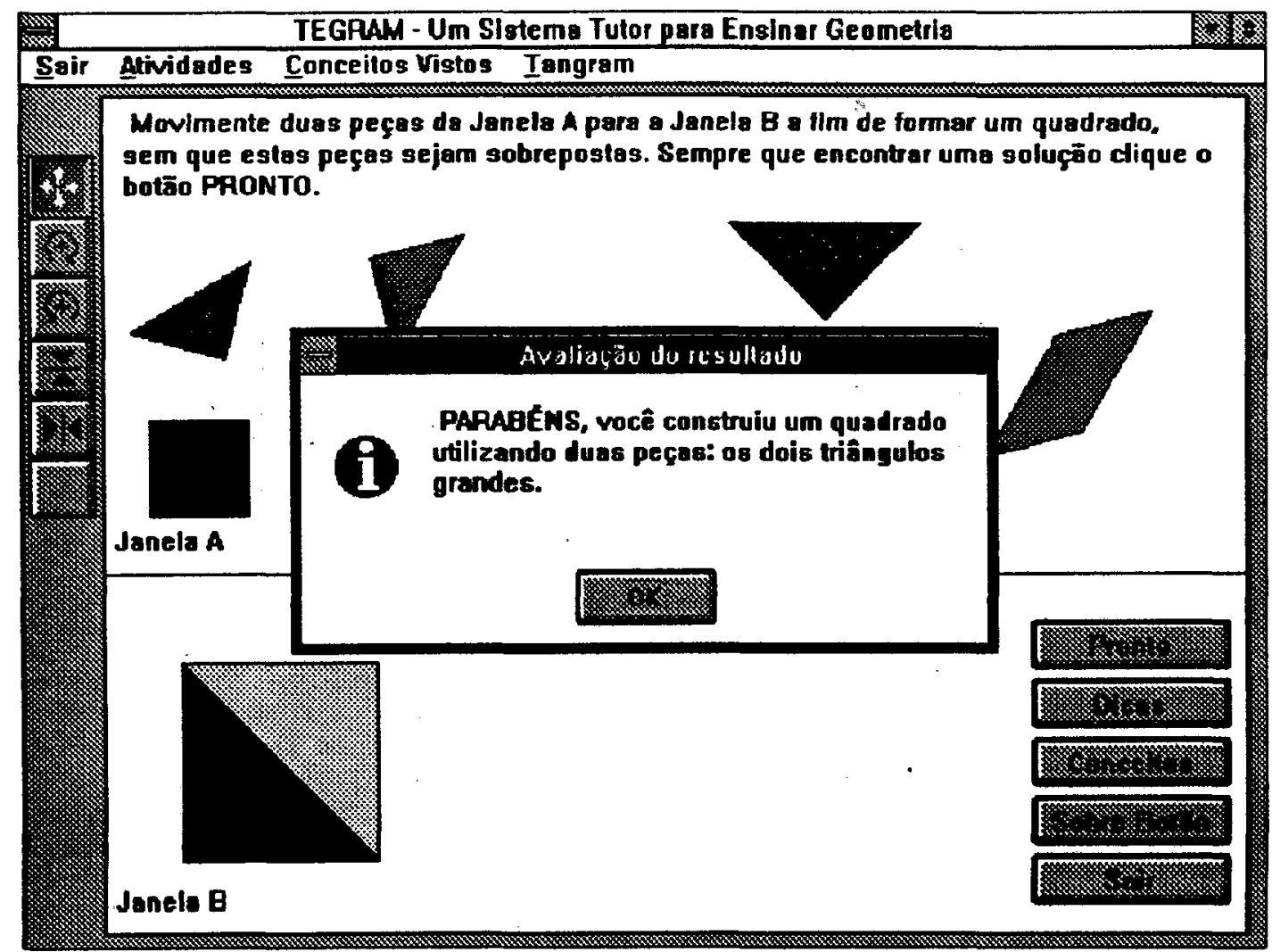

Figura 56: Estudante clicou o button Pronto da atividade QUADRADO_2_PEÇAS. 
Imaginando que o estudante tenha realizado todas as outras atividades que exploram o conceito $\mathrm{C} 05$ e teve um desempenho global satisfatório, o sistema vai propor o conceito C06 (FORMAR_TRIÂNGULO). A lista de conceitos nucleares do modelo do estudante (Slot 7$)$ é igual a $[\mathrm{C06}, \mathrm{C07}, \mathrm{C09}]$ e a lista de conceitos supostamente aprendidos (Slot 8) é [C04,C05].

Se neste momento o estudante do nosso exemplo não quer mais utilizar o sistema, ele clica a opção Sair do menu principal. 0 módulo tutorial, por sua vez, ativa a decisão tutorial para salvar o modelo do estudante na base de estudantes e encerra a execução do sistema TEGRAM. Este modelo é inserido na base de estudantes, de uma maneira ordenada, de acordo com o nome do estudante.

\subsubsection{Estudante nåo novato}

Após repetir todos os passos da seção 5.4., vamos supor que o estudante não seja novato no sistema, ou seja, seu modelo já existe na base de estudantes. Por exemplo, o estudante é o mesmo do exemplo anterior (seção 5.4.1.)

Como ele agora não é novato, o módulo tutorial ativa uma decisão tutorial para apresentar uma terceira janela de identificação do sistema, conforme mostra a Figura 57. Nela, é pedido ao estudante que digite somente a senha de acesso ao sistema, a mesma que digitou na primeira sessão (estudante novato).

Se a senha foi digitada corretamente, o módulo tutorial ativa uma nova decisão tutorial a fim de recuperar todas as informações deste estudante, presentes na base de estudantes. Estas informações representam o modelo do estudante e é o ponto de partida para iniciar a sessão.

Como é o caso de um não novato, o sistema não constrói inicialmente a rede de conceitos. É utilizada a lista de conceitos nucleares (Slot 7) do modelo do estudante para conduzir a interação. Como o estudante é o mesmo do exemplo anterior, a lista de conceitos nucleares é igual a [C06,C07,C09]. Desta forma, o sistema começa ensinando o conceito C06.

Daqui em diante, a interação com o estudante não novato é semelhante à interação sistema/estudante novato, conforme apresentamos na seção 5.4.1. 


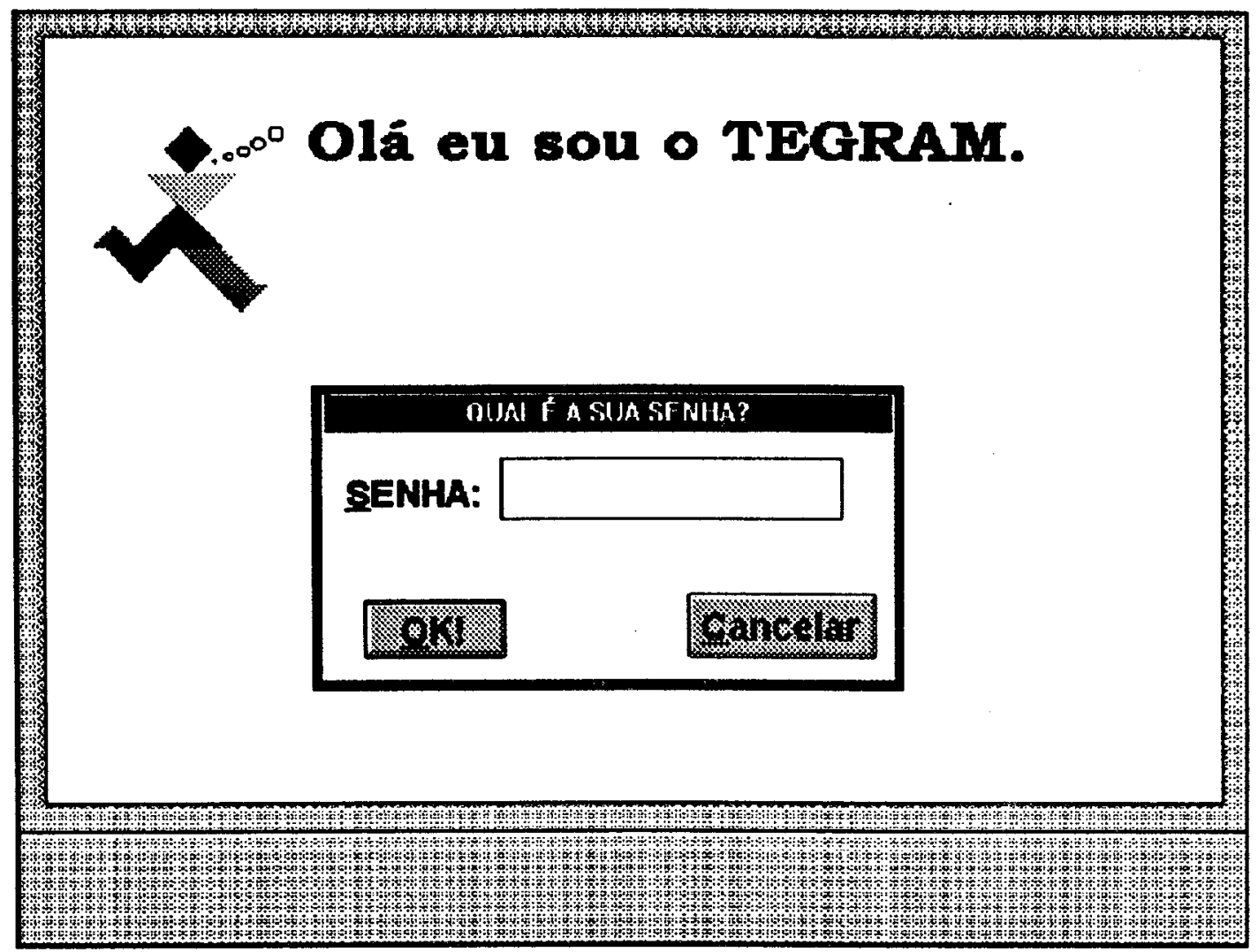

Figura 57: Terceira janela de identificação do sistema.

\subsection{Considerações finais}

Neste capítulo apresentamos os conceitos matemáticos presentes na base de conceitos e as atividades implementadas que exploram alguns deles.

Para melhor visualizar o sistema TEGRAM, apresentamos também um exemplo de interação entre o sistema e um estudante novato da primeira série. Todas as janelas utilizadas durante esta interação foram apresentadas. Encerrada a sessão, este mesmo estudante executa novamente o sistema. Assim, este capítulo também apresentou o modo como o sistema trata a interação com um estudante não novato.

Muito trabalho deve ser feito para que este protótipo se torne uma ferramenta para auxiliar o processo de ensino-aprendizagem. Para que o sistema TEGRAM seja utilizado na prática, em algumas escolas, alguns trabalhos serão propostos no próximo capítulo. 


\section{CAPÍTULO 6}

\section{CONCLUSÕES}
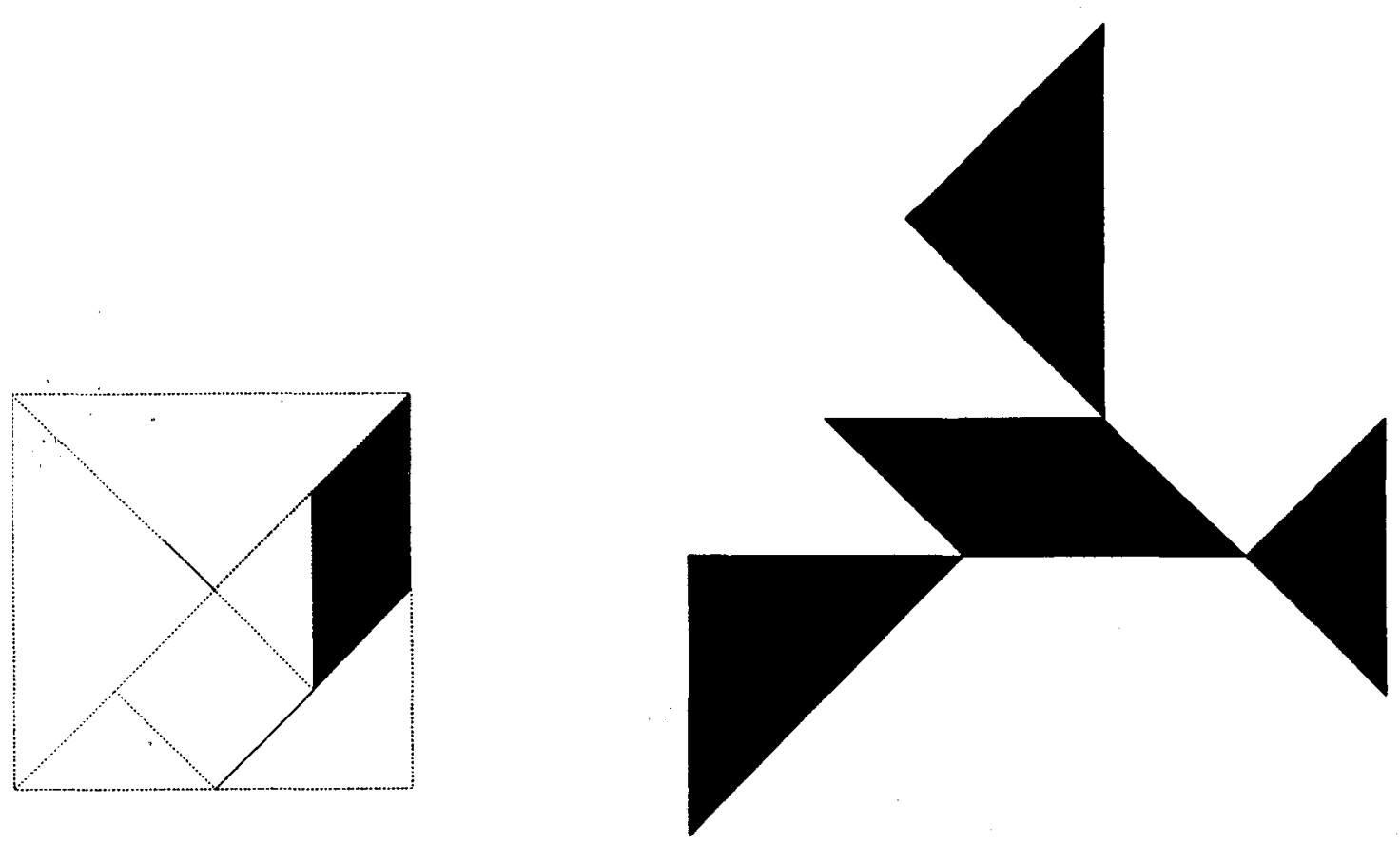


\subsection{Considerações iniciais}

idéia de utilizar computadores na Educação é antiga. Como acontece com
todas as ferramentas alternativas, a proposta do uso de computadores para
auxiliar o processo de ensino-aprendizagem, através de sistemas tutores, requer certos cuidados para que seus objetivos sejam realmente alcançados, e todos os esforços não produzam conseqüências negativas.

Longe de ser um substituto do professor na sala de aula, o sistema tutor deve ser considerado um assistente computacional, uma ferramenta de auxílio, complementação e aperfeiçoamento, que possibilite melhorias na qualidade do ensino. $\mathrm{O}$ sistema tutor é, antes de tudo, uma ferramenta de suporte ao processo de ensino-aprendizagem, ajustada às necessidades de revisão, diversificação, flexibilidade, resolução de problemas e progresso nos conteúdos, entre outras.

$\mathrm{O}$ papel do professor num ambiente como este se transforma à medida em que o estudante se torna mais participativo, oferecendo oportunidades para a discussão de conceitos que estão além do domínio explorado pelo sistema tutor. Além disto, o professor é o supervisor desta interação (sistema/estudante), é quem define porque, quanto e como o sistema deve ser utilizado. A produtividade do estudante no processo de ensino-aprendizagem, através da utilização do sistema tutor, dará ao professor parâmetros para realimentar o sistema.

Com as caracteríticas apresentadas acima, o sistema tutor pode proporcionar um ambiente diferente dos modelos utilizados em aulas tradicionais, tornando-as altamente estimulantes para o estudante.

Enfim, os computadores não devem ser vistos como uma panacéia para resolver todos os problemas educacionais. É necessário determinar precisamente o que pode ser feito pelo assistente computacional e o que cabe ao tutor humano (professor). Além disto, o modo pelo qual se espera que o sistema atinja seus objetivos tem que ser cuidadosamente estabelecido. Após experimentos controlados, envolvendo estudantes e tutores humanos, as tarefas de responsabilidade do sistema tutor podem ser julgadas levando em conta os objetivos a serem alcançados no processo de ensino-aprendizagem.

\subsection{Contribuições deste trabalho}

Este trabalho apresentou o estudo, a definição e a implementação de um protótipo do sistema TEGRAM (sistema Tutor para Ensinar conceitos de Geometria plana baseado no tangRAM). O TEGRAM é um sistema tutor destinado a auxiliar o processo de ensino-aprendizagem de conceitos de Geometria Plana a estudantes do 10 grau. 
O TEGRAM utiliza o Tangram para despertar a curiosidade e o interesse dos estudantes em relação aos conceitos matemáticos propostos por ele. $O$ Tangram é um jogo chinês milenar, também utilizado como material didático nas aulas de Matemática. É formado por sete peças que têm formas geométricas bastante conhecidas: cinco triângulos, um quadrado e um paralelogramo.

A arquitetura do sistema TEGRAM possui quatro componentes: módulo do domínio, modelo do estudante, módulo tutorial e módulo de comunicação de atividades. Cada um deles exerce uma função diferente. Esta arquitetura se baseia na arquitetura básica de Sistemas Tutores Inteligentes (STIs), apresentada no capitulo dois.

O objetivo deste trabalho é construir um sistema que, mesmo não atendendo a todos os requisitos de um STI, possa auxiliar o processo de ensino-aprendizagem de alguns conceitos matemáticos relacionados com a Geometria Plana.

Pode ser que o sistema TEGRAM não seja considerado um STI por alguns autores, mas possui algumas características requeridas pelos STIs. Inicialmente, sua arquitetura segue a arquitetura básica proposta pelos STIs. Através dela, o sistema tenta auxiliar o processo de ensino-aprendizagem incorporando técnicas de Inteligência Artificial (IA) de modo a fazê-lo capaz de saber o quê ensinar, a quem ensinar e como ensinar.

O sistema TEGRAM possui um módulo especialista que reconhece todas as soluções das atividades propostas (definição de STI apresentada na seção 2.1.2). Este módulo de reconhecimento faz parte do módulo do domínio (rede de definições). Além disso, a base de conceitos representa parte do conhecimento a ser explorado de forma declarativa e separada das informações de controle ("como" ensinar).

O sistema TEGRAM possui capacidades próprias, embora limitadas, de modelagem e diagnóstico dos estudantes, tentando fornecer um ensino mais individualizado. Dependendo do nível de conhecimento do estudante, o sistema monitora a interação, apresentando atividades que exploram alguns conceitos matemáticos. Realizando estas atividades, o estudante pode assimilar os conceitos subjacentes às atividades de uma forma intuitiva e a formalização destes conceitos, por parte do estudante, é realizada somente $a$ posteriori.

O sistema ainda não possui capacidades próprias para explicar as razões que o levam a tomar certas decisões. Apesar do TEGRAM não possuir estratégias de ensino representadas explicitamente, o sistema preocupa-se em informar os erros cometidos pelo estudante nas atividades. Como, quando e que tipo de feedback fornecer ao estudante são pontos importantes explorados no sistema.

O controle do aprendizado existente no sistema TEGRAM é balanceado entre o sistema e o estudante (controle de iniciativa mista). Este controle é fundamental, pois como o sistema tem por objetivo encorajar os estudantes a tornarem-se aprendizes ativos e criativos, este tipo de controle dará oportunidades para que eles explorem livremente as atividades propostas. Desta maneira, uma importante vantagem da utilização destes sistemas é que o estudante poderá saber qual o seu progresso, sem precisar esperar por uma prova ou um exame final. Ele estará sendo continuamente avaliado. 
Enfim, a utilização do sistema TEGRAM, bem como a de computadores em geral, no processo de ensino-aprendizagem, não eliminam a necessidade de professores, nem reduz o seu status. Ao contrário, permite ao professor economizar tempo e trabalho, enquanto enfrenta uma tarefa muito mais ampla. Os sistemas computacionais liberam o professor para tarefas mais criativas na sala de aula. Desta forma, ao atribuir certas tarefas mecanizáveis às máquinas, o professor poderá desempenhar seu papel principal: atuar como um ser humano.

O planejamento e a implementação do protótipo desenvolvido neste trabalho marcam o início da construção do projeto TEGRAM: um projeto maior que tem por objetivo contruir um ambiente de ensino-aprendizagem de conceitos relacionados à Matemática que tenha as características básicas de um STI.

A partir deste trabalho, reforçamos a idéia de que para o sucesso da pesquisa de sistemas computacionais destinados a auxiliar o processo de ensino-aprendizagem, é indispensável a multidisciplinaridade. Para o desenvolvimento deste protótipo foi de grande importância a ajuda prestada por profissionais da área de Educação Matemática e Pedagogia.

Além dos pontos descritos acima, este trabalho apresentou uma revisão bibliográfica sobre Sistemas Tutores Inteligentes (STIs). A importância do assunto tratado neste trabalho pode ser justificada pelo grande número de contribuições encontradas, tanto na área de Educação quanto na área de Ciência da Computação. De acordo com a revisão bibliográfica realizada, nota-se que a pesquisa em STIs é recente, constituindo uma realidade experimental que ainda carece de uma fundamentação teórica. A literatura nesta área consiste, em sua maioria, de trabalhos descrevendo implementações e abordagens específicas. Evidentemente, a falta de uma teoria geral dificulta em muito a avaliação, a classificação e a comparação dos STIs existentes. Isto mostra que a área de pesquisa em STIs pode ser muito explorada.

Devido à situação descrita acima, é importante obter contribuições nesta área que caminhem a um ponto comum. Este ponto é a resposta (nada óbvia) a uma questão básica [VIC92, p.63]:

"Que tipo de ambiente de ensino-aprendizagem queremos - ou devemos ou podemos - oferecer às pessoas que desejaim utilizar sistemas computacionais para ensinar/aprender?"

A publicação de trabalhos sobre STIs no Brasil é ainda pouca. A partir da revisão realizada, observamos que as pesquisas no Brasil sobre o uso do computador na Educação (incluindo STIs ou não) concentram-se principalmente em São Carlos (USP - Universidade de São Paulo), Campinas (UNICAMP), Porto Alegre (UFRGS Universidade Federal do Rio Grande do Sul e PUC-RGS), Brasília (UNB Universidade de Brasília) e Recife (UFPE - Universidade Federal de Pernanbuco). 


\subsection{Propostas de trabalhos futuros}

Algumas pesquisas que podem seguir em decorrência da complementação dos estudos deste trabalho são apresentadas nesta seção.

Existem alguns trabalhos imediatos que podem ser realizados diretamente sobre 0 protótipo desenvolvido, e que são descritos a seguir.

Para explorar os conceitos matemáticos presentes na base de conceitos, várias atividades foram propostas. Dentre estas, somente algumas já foram implementadas. Assim, aproveitando a experiência das atividades implementadas, uma próxima fase poderia compreender a implementação das demais.

Todos os conceitos matemáticos devem possuir uma janela de definição. Esta janela será apresentada ao estudante quando o conceito for considerado satélite em uma atividade. Neste protótipo, definimos e implementamos a janela de definição do conceito matemático ÁREA. É indispensável, portanto, que a continuação deste projeto englobe o estudo, a definição e a implementação das janelas de definição de todos os conceitos matemáticos presentes na base de conceitos.

Para que este protótipo possa ser utilizado na prática é necessário construir helps explicando o seu funcionamento, os menus e todos os recursos utilizados pelo sistema que necessitam de uma explicação para o usuário (estudante). Assim, um próximo trabalho é iniciar a construção de um help on line do sistema TEGRAM, via a ferramenta Help Compiler do Windows.

Com a finalização deste trabalho, surgiram novas idéias de projetos que necessitam de mais pesquisas e investigações. Algumas destas idéias são descritas a seguir.

Para melhor explorar os conceitos matemáticos existentes, novas atividades necessitam ser investigadas e propostas. A experiência com as atividades implementadas nos proporcionou o feedback necessário para a reformulação bem como para a construção de novas atividades. Além de construir novas atividades, é necessário ampliar os conceitos matemáticos existentes na base de conceitos do sistema TEGRAM. Isto resultará na atualização e/ou manutenção da base de conceitos e da base de atividades do sistema.

Uma das próximas fases deste projeto é construir uma interface específica para o professor, ou seja, um módulo de interação que apresenta ao professor como o sistema está organizado internamente. Isto é fundamental para 0 professor, pois este checará 0 comportamento do sistema. Algumas informações que podem ser apresentadas são: quais conceitos matemáticos formam a base de conceitos; quais as relações de precedência existentes entre os conceitos matemáticos apresentadas no grafo de conceitos; quais as atividades presentes na base de atividades e suas relações com os conceitos, entre outras. Estas informações devem ser apresentadas ao professor graficamente, possibilitando-o navegar pelos conceitos e atividades do sistema. Além de permitir a visualização do sistema internamente, este módulo pode permitir ao professor modificar algumas informações, tais como: as relações de precedência entre os conceitos, as séries escolares apropriadas para ensinar cada um deles, etc. 
O módulo de interação com o professor pode, também, mostrar as informações de um estudante específico. Estas informaç̃̃es são os slots do modelo do estudante presentes na base de estudantes.

Para facilitar a verificação por parte do estudante e/ou professor da evolução do usuário (estudante) nas sessões com o sistema, é necessário verificar a possibilidade de construir um módulo que apresente esta evolução, via gráficos, desde que ele utilizou o sistema pela primeira vez. Além disso, este módulo pode traçar um perfil do estudante.

Para que o modelo do estudante represente mais corretamente o estudante que está utilizando ou que já utilizou o sistema, é necessário investigar se existem mais algumas informações que possam ser incluídas na estrutura do modelo do estudante ou utilizar de outra forma as já existentes. Por exemplo, o sistema poderia tentar detectar o caminho percorrido pelo estudante na realização de uma determinada atividade; detectar as razões que levaram o estudante a errar, etc.

Por último, para investigar a eficácia do sistema TEGRAM em promover uma maior individualização no processo de ensino-aprendizagem, é de fundamental importância uma próxima fase experimental. Durante esta fase, cada sessão cumprida pelo estudante servirá de feedback para realimentar o sistema (por exemplo, poderá proporcionar novos parâmetros de como calcular o desempenho dos estudantes nas atividades realizadas) e servirá para o professor avaliar se o estudante está aprendendo ou não. Além disso, os estudantes podem determinar o sucesso ou não do sistema, pois eles, melhores que ninguém, podem fornecer ao professor informações que ajudam a enriquecer o sistema (podem dizer o que e como aprenderam). Sendo a aprendizagem muito dificil de ser medida, não é dificil prever que é quase impossível alcançá-la quando o estudante é deixado fora do processo de decisões. As formas pelas quais o estudante pode participar ainda precisam ser largamente pesquisadas e aspectos cognitivos não podem deixar de ser considerados. 


\section{BIBLIOGRAFIA CITADA}
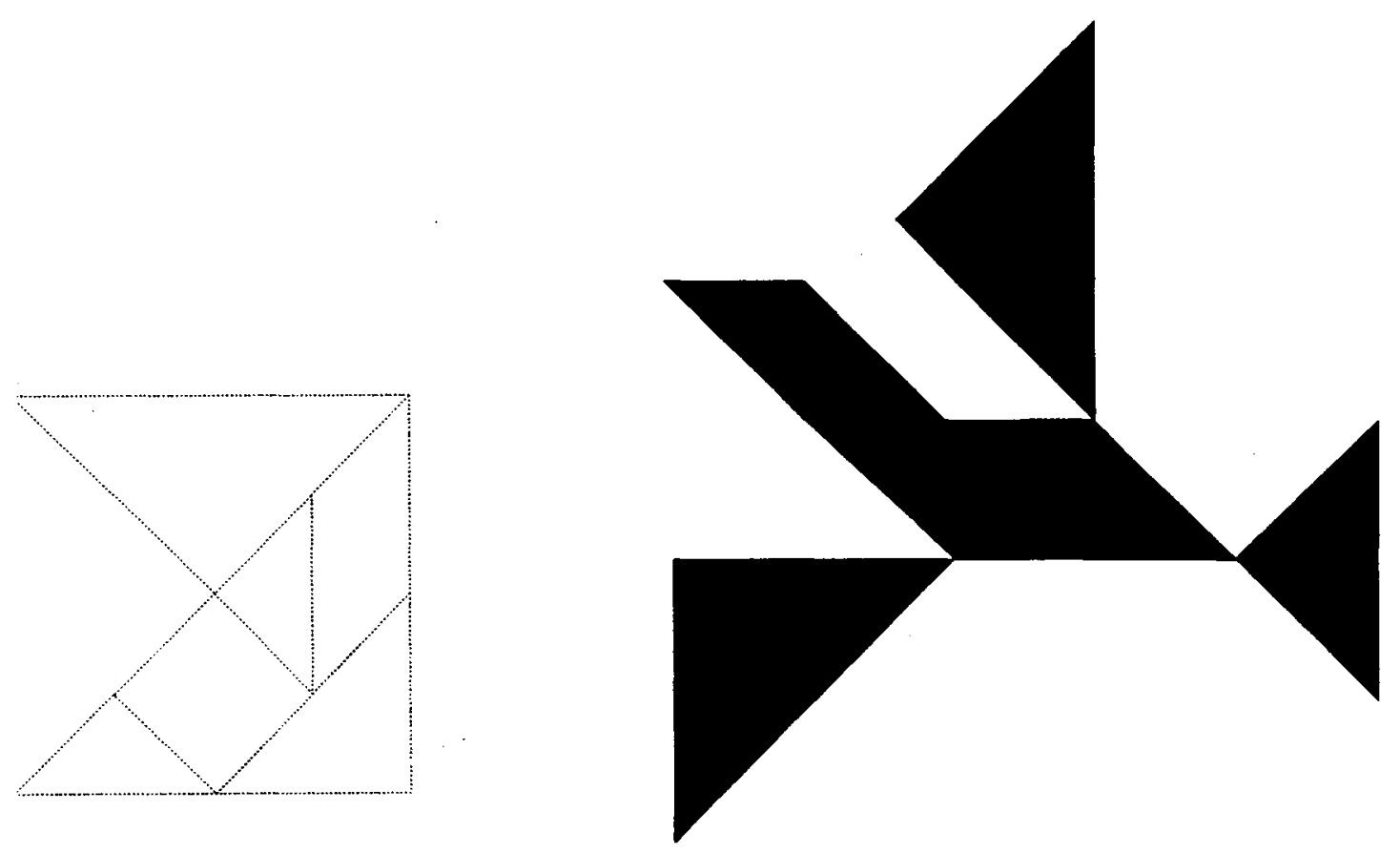
[AIK89] AIKEN, R.M. The impact of artificial intelligence on education: opening new windows. In: MARÍ, V.; STEPÁNKOVÁ, O. \& ZDRÁHAL, Z., ed. Lecture Notes in Artificial Intelligence: Artificial Intelligence in Higher Education. Prague, Springer-Verlag, october 1989. n.451, p.113.

[AMA83a] ATIVIDADES MATEMÁTICAS: 22a série do $1 \underline{0}$ grau. São Paulo, Secretaria do Estado da Educação - Coordenadoria de Estudo e Normas Pedagógicas, 1983. v.1, 119p.

[AMA83b] ATIVIDADES MATEMÁTICAS: $2 \underline{a}$ série do $1 \underline{o}$ grau. São Paulo, Secretaria do Estado da Educação - Coordenadoria de Estudo e Normas Pedagógicas, 1983. v.2, 110p.

[AMA84] ATIVIDADES MATEMÁTICAS: $1 \underline{a}$ série do 10 grau. São Paulo, Secretaria do Estado da Educação - Coordenadoria de Estudo e Normas Pedagógicas, 1984. 200p.

[AMA86] ATIVIDADES MATEMATICAS: 3a série do $1 \underline{0}$ grau. São Paulo, Secretaria do Estado da Educação - Coordenadoria de Estudo e Normas Pedagógicas, 1986. 213p.

[AMA91] ATIVIDADES MATEMÁTICAS: 4a série do 10 grau. São Paulo, Secretaria do Estado da Educação - Coordenadoria de Estudo e Normas Pedagógicas, 1991. 330p.

[ARU92] ARUN KUMAR, B; DURAISWAMY, K. \& SARUKESI, K. A new approach to machine learning systems and its application to the development of an ITS. Journal of Artificial Intelligence in Education, v.3, p.51-61, 1992.

[BAR90] BARNARD, Y.F.; ERKENS, G. \& SANDBERG, J.A.C. Interaction in intelligent tutoring systems. Journal of Structural Learning, United Kingdom, v.10, n.3, p.197-213, june 1990.

[BAR82] BARR, A. \& FEIGENBAUM, E.A. Applications-oriented AI research. In: BARR, A. \& FEIGENBAUM, E.A., ed. The Handbook of Artificial Intelligence. Addison-Wesley, Reading MA, 1982. v.2, cap.9, p.283290. 
[BAR93] BARRON, B. \& KANTOR, R.J. Tools to enhance math education: the JASPER SERIES. Communications of the ACM, v.36, n.5, p.52-54, may 1993.

[BIE91] BIELAWSKI, L. \& LEWAND, R. An overview of intelligent systems. In: BIELAWSKI, L. \& LEWAND, R., ed. Intelligent systems design: integrating expert systems, hypermedia, and database technologies. Wiley, 1991. cap. 1, p.3-15.

[BRA88] BRACHMAN, R.J. The basics of knowledge representation and reasoning. AT\&T Technical Journal, v.67, n.1, p.7-24, january-february 1988.

[BRA93] BRAUN, L. Help for all the students. Communications of the $A C M$, v.36, n.5, p.66-69, may 1993.

[BRE88] BREUKER, J. Coaching in help systems. In: SELF, J., ed. Artificial Intelligence and Human Learning: Intelligent Computer-Aided Instruction. London, Chapman \& Hall, 1988. p.310-337.

[BR078] BROWN, J.S. \& BURTON, R.R. Diagnostic models for procedural bugs in basic mathematical skills. Cognitive Science, v.2, p.155-192, 1978.

[BR082] BROWN, J.S. \& BURTON, R.R. Pedagogical natural language, and knowledge engineering techniques in SOPHIE I,II and III. In: SLEEMAN, D.H. \& BROWN, J.S., ed. Intelligent Tutoring Systems. Orlando, Academic Press, 1982. p.227-282.

[BUR92] BURGER, M. \& DESOI, J. The cognitive apprenticeship analogue: a strategy for using ITS technology for the delivery of instruction and as a research tool for the study of teaching and learning. International Journal of Man-Machine Studies, v.36, p.775-795, september 1992.

[BUR88] BURNS, H. \& CAPPS, C.G. Foundations of intelligent tutoring systems: an introduction. In: POLSON, M.C. \& RICHARDSON, J.J., ed. Foundations of Intelligent Tutoring Systems. London, Lawrence Erlbaum Associates Publishers, 1988. p.1-19.

[BUR82a] BURTON, R.R. \& BROWN, J. S. An investigation of computer coaching for informal learning activities. In: SLEEMAN, D.H. \& BROWN, J.S., ed. Intelligent Tutoring Systems. Orlando, Academic Press, 1982. p.79-98.

[BUR82b] BURTON, R.R. Diagnosing bugs in a simple procedural skill. In: SLEEMAN, D.H. \& BROWN, J.S., ed. Intelligent Tutoring Systems. Orlando, Academic Press, 1982. p.157-183.

[CAR70] CARBONELL, J.R. AI in CAI: an artificial intelligence approach to computer assisted instruction. IEEE Transactions on Man-Machine Systems, v.11, n.4, p.190-202, december 1970. 
[CER87] CERCONE, N. Knowledge representation: an overview. Indian Journal of Technology, v.25, p.521-543, december 1987.

[CLA83] CLANCEY, W.J. GUIDON. Journal of Computer-Based Instruction, v.10, n.1-2, p.8-15, Summer 1983.

[CLA88] CLANCEY, W.J. The role of qualitative models in instruction. In: SELF, J., ed. Artificial Intelligence and Human Learning: Intelligent ComputerAided Instruction. London, Chapman \& Hall, 1988. p.49-68.

[COR92] CORBETT, A.T. \& ANDERSON, J.R. Lisp intelligent tutoring system: research in skill acquisition. In: LARKIN, J.H. \& CHABAY, R.W., ed. Computer-Assisted Instruction and Intelligent Tutoring Systems: Shared goals and complementary approaches. London, Lawrence Erlbaum Associates, 1992. p.73-110.

[COS88] COSTA, E.; DUCHENOY, S. \& KODRATOFF, Y. A resolution based method for discovering student's misconceptions. In: SELF, J., ed. Artificial Intelligence and Human Learning: Intelligent ComputerAided Instruction. London, Chapman \& Hall, 1988. p.156-164.

[CUM89] CUMMINGS, J.B. Computers, the cutting edge of learning. Computer \& Graphics, v.13, n.1, p.111-113, 1989.

[DIE92] DIESSEL, T. \& LEHMANN, A. An ITS for engineering domains: concept, design and applicatioon. In: TOMEK, I., ed. Lecture Notes in Computer Science: Computer Assisted Learning - ICCAL'92. Canadá, Springer-Verlag, june 1992. n.602, p.161-173.

[DIE93] DIESSEL,T.; LEHMANN, A. \& VASSILEVA, J. Individualised course generation using a "slightly intelligent" system. In: Seventh International PEG93 Conference - PEG93 - AI Tools and the classroom: Theory into Practice. Edinburgh, july 1993. Proceedings. Edinburgh, july 1993. v.I, p.83-96.

[DIL89] DILLENBOURG, P. Designing a self improving tutor: PROTOTEG. Instructional Science, v.18, p.193-216. 1989.

[DUC89] DUCHASTEL, P.C. ICAI systems: issues in computer tutoring. Computers in Education, v.13, n.1, p.95-100, 1989.

[DUC90] DUCHASTEL, P.C. Discussion: formal and informal learning with hypermedia. In: JONASSEN, D.H. \& MANDL, H., ed. Designing Hypermedia for Learning. NATO ASI Series, Springer Verlag, 1990. p.135-143.

[DUG92] DUGDALE, S. The design of computer-based mathematics instruction. In: LARKIN, J.H. \& CHABAY, R.W., ed. Computer-Assisted Instruction and Intelligent Tutoring Systems: Shared goals and complementary approaches. London, Lawrence Erlbaum Associates, 1992. p.11-45. 
[ELS93] ELSOM-COOK, M. Student modelling in intelligent tutoring systems. Artificial Intelligence Review, v.7, n.3-4, p.227-240, august 1993.

[EPS90] EPSTEIN, K. \& HILLEGEIST, E. Intelligent instructional systems: teachers and computer-based intelligent tutoring systems. Educational Technology, n.11, p.13-19, november 1990.

[FOR91] FORCHERI, P. \& MOLFINO, M.T. Designing a knowledge-based learning environment for arithmetic concepts. Computers in Education, v.16, n.2, p.143-151, 1991.

[FRY88] FRYE, D.; LITTMAN, D.C. \& SOLOWAY, E. The next wave of problem in ITS: confronting the "user issues" of interface design and system evaluation. In: PSOTKA, J.; MASSEY, L.D. \& MUTHER, S.A., ed. Intelligent tutoring systems: lessons learned. London, Lawrence Erlbaum Associates Publishers, 1988. cap.17, p.451-478.

[GAR88a] GARDNER, M. Tangrams, Part 1. In: GARDNER, M., ed. Time travel and other mathematical bewilderments. NY, W.H. Freeman and Company, 1988. p.27-37.

[GAR88b] GARDNER, M. Tangrams, Part 2. In: GARDNER, M., ed. Time travel and other mathematical bewilderments. NY, W.H. Freeman and Company, 1988. p.39-54.

[GIL88] GILMORE, D. \& SELF, J. The application of machine learning to intelligent tutoring systems. In: SELF, J.A., ed. Artificial Intelligence and Human Learning: Intelligent Computer-Aided Instruction. London, Chapman \& Hall Computing, 1988. p.179-196.

[GIS92] GISOLFI, A.; BALZANO, W. \& DATTOLO, A. Enhancing the Pascal language by a tutor written in Prolog. Computer Education, n.72, p.2932, november 1992.

[GOL82] GOLDSTEIN, I.P. The genetic-graph: a representation for the evolution of procedural knowledge. In: SLEEMAN, D.H. \& BROWN, J.S., ed. Intelligent Tutoring Systems. Orlando, Academic Press, 1982. p.51-77.

[GUN91] GÜNGORDÜ, Z. \& OFLAZER, K. Solving tangram puzzles. In: BARAY, M. \& OZGÜÇ, B., ed. Computer and Information Sciences $V$. Elsevier Science Publishers B.V., 1991. p.691-702.

[HAS93] HASEGAWA, R. TOOTEMA: uma ferramenta para a construção de sistemas tutores inteligentes. São Carlos, 1993. 48p. Mini-dissertação apresentada ao Instituto de Ciências Matemáticas de São Carlos, Universidade de São Paulo. 
[HEG90] HEGAZI, O.M. \& RADY, H.A.K. Intelligent tutoring systems. The Egyptian Computer Journal. Cairo University, Egypt, v.18, n.2, p.93112, 1990.

[HOL87] HOLYOAK, H.P. Cognitive psychology. In: SHAPIRO, S.C.; ECKROTH, D. \& VALLASI, G., ed. Encyclopedia of Artificial Intelligence. Wiley \& Sons - Interscience Publication, 1987, p.115-120.

[HOO91] HOOG, R.; JONG, T. \& VRIES, F. Interfaces for instructional use of simulations. Education \& Computing, v.6, p.359-385, 1991.

[JAM89] JAMSKI, W.D. Six hard pieces. Arithmetic teacher, p.34-35, october 1989.

[JOH87] JOHNSON, W.L. \& SOLOWAY, E. PROUST: an automatic debugger for Pascal programs. In: KEARSLEY, G., ed. Artificial Intelligence and Instruction: Applications and Methods. California, Addison-Wesley, june 1987. p.49-67.

[JON90] JONASSEN, D.H. \& GRABINGER, R.S. Problems and issues in designing hypertext/hypermedia for learning. In: JONASSEN, D.H. \& MANDL, H., ed. Designing Hypermedia for Learning. NATO ASI Series, Springer Verlag, 1990. p.1-25.

[KEA87a] KEARSLEY, G. Overview. In: KEARSLEY, G., ed. Artificial Intelligence and Instruction: Applications and Methods. California, Addison - Wesley, june 1987. p.3-10.

[KEA87b] KEARSLEY, G. Computer-aided instruction, intelligent. In: SHAPIRO, S.C.; ECKROTH, D. \& VALLASI, G.A., ed. Encyclopedia of Artificial Intelligence. John Wiley \& Sons - Interscience Publication, 1987. v.1, p.154-159.

[KEL93] KELLY, A.E.; SLLEMAN, D.H. \& GILHOOLY, K.J. Artificial intelligence in education: using state space search and heuristics in mathematics instruction. International Journal of Man Machine Studies, v.38, p.725-746, 1993.

[KEM92] KEMP, R.H. Intelligent computer assisted instruction: a knowledge-based perspective. The Australian Computer Journal, v.24, n.3, p.121-129, november 1992.

[KIE87] KIERAS, D. Cognitive modeling. In: SHAPIRO, S.C.; ECKROTH, D.; VALLASI, G.A., ed. Encyclopedia of Artificial Intelligence. s.l., Wiley - Interscience Publication, John Wiley \& Sons, 1987. vol.1, p.111-15.

[LEG90] LEGGETT, J.J.; SCHANASE, J.L. \& KACMAR, C.J. Hypertext for learning. In: JONASSEN, D.H. \& MANDL, H., ed. Designing Hypermedia for Learning. NATO ASI Series, Springer Verlag, 1990. p.27-38. 
[LES87] LESGOLD, A. Education applications. In: SHAPIRO, S.C.; ECKROTH, D. \& VALLASI, G.A., ed. Encyclopedia of Artificial Intelligence. John Wiley \& Sons - Interscience Publication, 1987. v.1, p.267-272.

[LID93] LIDTKE, P.K. \& MOURSUND, D. Computers in schools: past, present, and how we can change the future. Communications of the $A C M, v .36, \mathrm{n} .5$, p.84-87, may 1993.

[MAL93a] MALTEMPI, M.V. INTEMA: um gerador de explicações para sistemas tutores inteligentes. São Carlos, 1993. 66p. Mini-dissertação apresentada ao Instituto de Ciências Matemáticas de São Carlos, Universidade de São Paulo.

[MAL93b] MALTEMPI, M.V. \& HASEGAWA, R. Um ambiente para a construção de sistemas tutores inteligentes em matemática. Artigo publicado nos anais do IV Simpósio Brasileiro de Informática na Educação - SBIE 93. Recife 08 a 10 de dezembro, 1993.

[MAN88] MANDL, H. \& LESGOLD, A. Learning issues for intelligent tutoring systems. Springer-Verlag, 1988. 307p.

[MAR93] MARTINS, C.A. Uso de árvores de decisão na geração de hipóteses indutivas em aprendizado de máquina. São Carlos, 1993. 58p. Minidissertação apresentada ao Instituto de Ciências Matemáticas de São Carlos, Universidade de São Paulo.

[MEN89] MENDES, M.D.C. A noção de áreà: possiveis modos de aprender. Campinas, 1989. 160p. Doutorado - Universidade Estadual de Campinas/UNICAMP.

[MEN94] MENDES, M.D.C; NUNES, M.G.V. \& TURINE, M.A.S. A tutoring system for discovering plane geometry using Tangram. In: 1994 International Symposium on Mathematics/Science Education and Technology-AACE 94. San Diego, july 21-23, 1994, p.109-113.

[MIC90] MICHIE, D Human and Machine Learning of Descriptive Concepts. Fifth Generation Computer Systems, ICOT Journal. Institute for New Generation Computer Technology, n.27, p.2-19, 1990.

[MIL 88] MILLER, J.R. The role of human-computer interaction in intelligent tutoring systems. In: POLSON, M.C. \& RICHARDSON, J.J., ed. Foundations of Intelligent Tutoring Systems. London, Lawrence Erlbaum Associates Publishers, 1988. p.143-189.

[MIZ90] MIZOGUCHI, R. Intelligent tutoring systems: the current state of the art. The Transactions of the IEICE, v.E73, n.3, p.297-307, march 1990.

[MUR92] MURRAYS, W.H. \& PAPPAS, C.H. Programação para Windows: versão 3. São Paulo, Makron Books, 1992. 698p. 
[NEG92] NEGRETE, J.M. Dos paradigmas de la intelligencia artificial en el juego del tangrama. Revista Latina de Pensamiento y Lenguage, v.1, n.1, p.5057, diciembre 1992.

[NOR92] NORTON, P. \& YAO, P. Programaąão em Borland C++ para Windows. Rio de Janeiro, Berkeley, 1992. 584p.

[NUN93a] NUNES, M.G.V.; MENDES, M.D.C. \& ANDREUCCI, C.A. Some issues on learning mathematics through intelligent tutoring systems. In: Seventh International PEG93 Conference - PEG93 - AI Tools and the classroom: Theory into Practice. Edinburgh, july 1993. Proceedings. Edinburgh, july 1993. v.I, p.189-202.

[NUN93b] NUNES, M.G.V.; TURINE, M.A.S.; MALTEMPI, M.V. \& HASEGAWA, R. Uso de hipertexto/hipermidia em sistemas tutores inteligentes. Notas Didáticas do Instituto de Ciências Matemáticas de São Carlos USP, março 1993. 32p.

[NUN93c] NUNES, M.G.V.; TAKEHARA, R.S. \& MENDES, M.D.C. A networkbased model for intelligent tutoring systems. In: $X$ Simpósio Brasileiro de Inteligência Artificial - X SBIA. Porto Alegre, outubro 1993. Anais. Porto Alegre, 1993, p.277-288.

[NWA88] NWANA, H.S. \& COXHEAD, P. Towards an intelligent tutor for a complex mathematical domain. Expert Systems, v.5, n.4, p.290-300, november 1988.

[NWA90] NWANA, H.S. Intelligent tutoring systems: an overview. Artificial Intelligence Review, v.4, p.251-277, 1990.

[OBE92] OBEREM, G.E.; MAYER, O. \& MAKEDON, F. ILONA: an advanced CAI tutorial system for the fundamental of logic. Education \& Computing, Elsevier, v.8, p.245-254, 1992.

[OHL 87] OHLSSON, S. Some principles of intelligent tutoring systems. In: LAWLER, R.W. \& YAZDANI, M., ed. Artificial Intelligence and Education. Norwood, Ablex Publication, 1987. v.1, p.203-238.

[OSH82] O'SHEA, T. A self-improving quadratic tutor. In: SLEEMAN, D.H. \& BROWN, J.S., ed. Intelligent Tutoring Systems. Orlando, Academic Press, 1982. p.283-307.

[PAP80] PAPERT, S. LOGO: computadores e educação. São Paulo, Editora Brasiliense, 1980. 253p.

[PAP87] PAPERT, S. Computers in education: conceptual issues. In: SHAPIRO, S.C.; ECKROTH, D. \& VALLASI, G.A., ed. Encyclopedia of Artificial Intelligence. John Wiley \& Sons - Interscience Publication, 1987. v.1, p.181-185. 
[PAR87] PARRA, N. Instrução individualizada. In: PARRA, N., ed. Didática para a escola de 10 e 20 graus. São Paulo, 1987. p.77-92.

[PET92] PETZOLD, C. Programação para Windows 3 - inclui apêndice da versão 3.1. São Paulo, Makron Books, 1992. 1005p.

[POL88] POLSON, M.C. \& RICHARDSON, J. Foundations of intelligent tutoring systems. London, lawrence Erlabum Associates Publishers, 1988. 280p.

[PON84] PONDÉ, L. Inteligência artificial. Revista de Ensino de Ciências, n.11, p.41-43, dezembro 1984.

[PSO88] PSOTKA, J.; MASSEY, L.D. \& MUTHER, S.A. Intelligent tutoring systems: lessons learned. London, Lawrence Erlbaum Associates Publishers, 1988. 552p.

[PY90] PY, D. \& NICOLAS, P. MENTONIEZH: a geometry ITS for figure drawing and proof setting. Journal of Artificial Intelligence in Education, v.1, n.3, p.41-55, Spring 1990.

[PYL87] PYLYSHYN, Z.W. Cognitive science. In: SHAPIRO, S.C.; ECKROTH, D. \& VALLASI, G., ed. Encyclopedia of Artificial Intelligence. Wiley \& Sons - Interscience Publication, 1987, p.120-124.

[RIC89] RICKEL, J.W. Intelligent computer-aided instruction: a survey organized around system components. IEEE Transactions on Systems, Man, And Cybernetics, v.19, n.1, p.40-57, january/february 1989.

[RID88] RIDGWAY, J. Of course ICAI is impossible...worse though, it might be seditious. In: SELF, J., ed. Artificial Intelligence and Human Learning: Intelligent Computer-Aided Instruction. London, Chapman \& Hall, 1988. p.28-48.

[ROS87] ROSENBERG, R. A critical analysis of research on intelligent tutoring systems. Educational Technology, v.27, n.11, p.7-13, november 1987.

[RUS87] RUSSEL, D.M. Alexandria: a learning resources management architecture. In: JONASSEN, D.H. \& MANDL, H., ed. Designing Hypermedia for Learning. NATO ASI Series, Springer Verlag, 1990. p.439-457.

[SAC92] SACK, W. \& SOLOWAY, E. From PROUST to CHIRON: ITS design as iterative engineering; intermediate results are important! In: LARKIN, J.H. \& CHABAY, R.W., ed. Computer-Assisted Instruction and Intelligent Tutoring Systems: Shared goals and complementary approaches. London, Lawrence Erlbaum Associates, 1992. p.239-274.

[SAN87] SANTOS, C.H. \& IMENES, L.M.P. TANGRAM: um antigo jogo chinês nas aulas de Matemática. Revista do Ensino de Ciências, n. 18, p.42-49, agosto 1987. 
[SAN90] SANTOS, V.M. A construção do conhecimento matemático. In: PROJETO IPE. A criança e o conhecimento: retomando a proposta pedagógica do ciclo básico. São Paulo, Secretaria do Estado da Educação, 1990. p.21-35.

[SEL74] SELF, J.A. Student models in computer-aided instruction. International Journal of Man-Machine Studies, v.6, n.2, p.261-276, 1974.

[SEL85] SELF, J.A. A perspective on intelligent computer-aided learning. Journal of Computer-Assisted Learning, v.1, p.159-166, 1985.

[SEL88] SELF, J.A. Artificial Intelligence and Human Learning: Intelligent Computer-Aided Instruction. London, Chapman \& Hall Computing, 1988. 428p.

[SEL90] SELF, J.A. Theoretical foundations for intelligent tutoring systems. Journal of Artificial Intelligence in Education, v.1(4), p.3-14, Summer 1990.

[SEM] SEM - Sociedade de Educação Matemática. Composição e decomposição de figuras: Tangram, construção do conceito de área. Caderno da SEM I, s.d., 25p.

[SLE82] SLEEMAN, D.H. \& BROWN, J.S. Introduction: intelligent tutoring systems. In: SLEEMAN, D.H. \& BROWN, J.S., ed. Intelligent Tutoring Systems. Orlando, Academic Press, 1982. p.1-11.

[SLE87] SLEEMAN, D.H. PIXIE: a shell for developing intelligent tutoring systems. In: LAWLER, R. \& YAZDANI, M., ed. Artificial Inteligence and Education. Ablex, Norwood, 1987. v.1, p.239-265.

[SLE89] SLEEMAN, D.; KELLY, A.E.; MARTINAK, R.; WARD, R.D. \& MOORE, J.L. Studies of diagnosis and remediation with high school algebra students. Cognitive Science, 13, p.551-568, 1989.

[SOU93] SOUSA, M.S.L Design cooperativo: o papel do designer e do usuário na construção de interfaces. São Carlos, novembro de 1993, 139p. Dissertação apresentada ao Instituto de Ciências Matemáticas de São Carlos, Universidade de São Paulo.

[STA90] STAHI, M.M. Software educacional: características dos tipos básicos. In: 10 Simpósio Brasileiro de Informática na Educação, Rio de Janeiro, 1990. Anais. Rio de Janeiro, 1990, p.34-46.

[STE79] STEVENS, A.; COLLINS, A. \& GOLDIN, S.E. Misconceptions in student's understanding. International Journal of Mon-Machine Studies, v.11, p.145-156, 1979. 
[TAK93a] TAKEHARA, R.S. Um modelo em redes para um sistema tutor inteligente. São Carlos, março de 1993. 81p. Mini-dissertação apresentada ao Instituto de Ciências Matemáticas de São Carlos, Universidade de São Paulo.

[TAK93b] TAKEHARA, R.S.; MENDES, M.D.C. \& NUNES, M.G.V. An evaluation strategy based on concepts network. In: Seventh International PEG93 Conference - PEG93 - AI Tools and the classroom: Theory into Practice. Edinburgh, july 1993. Proceedings. Edinburgh, july 1993. v.II, p.661-670.

[TUR93a] TURINE, M.A.S. Um sistema tutor para o ensino de conceitos de geometria através de atividades apoiadas no Tangram. São Carlos, agosto de 1993 . 77p. Mini-dissertação apresentada ao Instituto de Ciências Matemáticas de São Carlos, Universidade de São Paulo.

[TUR93b] TURINE, M.A.S.; NUNES, M.G.V. \& MENDES, M.D.C. TEGRAM: um sistema tutor para o ensino de geometria baseado no Tangram. Artigo publicado nos anais do $I V$ Simpósio Brasileiro de Informática na Educação - SBIE 93, Recife 08 a 10 de dezembro, 1993.

[VAL91] VALENTE, J.A. Usos do computador na educação. In: VALENTE, J.A., ed. Liberando a mente: computadores na educação especial. Campinas, Gráfica Central da UNICAMP, 1991. p.16-31.

[VAL93a] VALENTE, J.A. Diferentes usos do computador na educação. In: VALENTE, J.A., ed. Computadores e conhecimento: repensando a educação. Campinas, Gráfica Central da UNICAMP, 1993. p.1-23.

[VAL93b] VALENTE, J.A. Por quê o computador na educação. In: VALENTE, J.A., ed. Computadores e conhecimento: repensando a educação. Campinas, Gráfica Central da UNICAMP, 1993. p.24-44.

[VAL93c] VALENTE, A.B. A intransigência da transferência de conhecimento. Acesso: Revista da Educação e Informática, FDE, São Paulo, p.23-27, 1993.

[VAN88] VANLEHN, K. Student modeling. In: POLSON, M.C. \& RICHARDSON, J.J., ed. Foundations of Intelligent Tutoring Systems. London, Lawrence Erlbaum Associates Publishers, 1988. p.55-78.

[VAS90] VASSILEVA, J. A classification and synsthesis of student modelling techniques in intelligent computer-assisted instruction. In: NORRIE, D.H. \& SIX, H.W., ed. Lecture Notes in Computer Science: Computer Assisted Learning - ICCAL'90. Hagen, Springer-Verlag, june 1990. n.438, p.202-213. 
[VIC90] VICCARI, R.M. \& MOUSSALLE, N. Tutores inteligentes para o ensino da

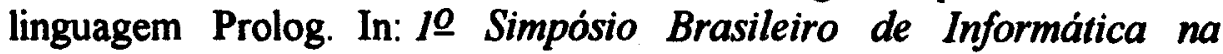
Educação, Rio de Janeiro, novembro de 1990. Anais. Rio de Janeiro, 1990. p.203-220.

[VIC92] VICCARI, R.M. \& OLIVEIRA, F.M. Sistemas Tutores Inteligentes. Universidade Federal do Rio Grande do Sul. Pós Graduação em Ciência da Computação, Instituto de Informática da UFRGS, setembro 1992. $68 \mathrm{p}$.

[VYH90] VYHANDU, P. Computer-aided instruction for the teaching list processing. Education \& Computing, 6, p.177-180, 1990.

[WAL89] WALSH, S.H. The implication of cognitive psychology for computerassisted instruction. Methods Inf. Med., s.l., v.28, n4, p.324-26, 1989.

[WAN92] WANG, H. \& KUSHNIRUK, A. The UNIX tutor. In: FRASSON, C.; GAUTHIER, G. \& MCCALLA. G.I., ed. Lecture Notes in Computer Science: Intelligent Tutoring Systems - ITS'92. Canadá, SpringerVerlag, 1992. n.608, p.317-324.

[WEN87] WENGER, E. Artificial Intelligence and Tutoring Systems: computational and cognitive approaches to the communication of knowledge. Los Altos, California, Morgan Kaufmann Publishers, january 1987. 486p.

[WIN89] WINKELS, R.A. A new framework for describing and designing intelligent tutoring systems. In: MAR'́K, V.; STEPÁNKOVÁ; O. \& ZDRÁHAL, Z., ed. Lecture Notes in Artificial Intelligence: Artificial Intelligence in Higher Education. Prague, Springer-Verlag, october 1989. n.451, p.230-243.

[WO084] WOOLF, B. \& MCDONALD, D. Building a computer tutor: design issues. IEEE Computer, p.61-72, september 1984.

[YAZ87] YAZDANI, M. Intelligent tutoring systems: an overview. In: LAWLER, R.W. \& YAZDANI, M., ed. Artificial Intelligence and Education. Norwood, Ablex Publication, 1987. v.1, p.183-201.

[YIB92] YIBIN, M. \& JIANXIANG, L. Intelligent tutoring system for symbolic calculation. In: FRASSON, C.; GAUTHIER, G. \& MCCALLA. G.I., ed. Lecture Notes in Computer Science: Intelligent Tutoring Systems ITS'92. Canadá, Springer-Verlag, june 1992. n.608, p.132-139.

[YOS92] YOSHIKAWA, A.; SHINTANI, M. \& OHBA, Y. Intelligent tutoring system for electric circuit exercising. IEEE Transactions on Education, v.35, n.3, p.222-225, august 1992 . 


\section{BIBLIOGRAFIA CONSULTADA E RECOMENDADA}


ACESSO. Revista da Educação e Informática. Fundação para o desenvolvimento da Educação — FDE, São Paulo, ano 4, n.9, julho 1993. 36p.

BONAR, J.; CUNNINGHAM, R. \& SCHULTZ, J. An object-oriented architecture for intelligent tutoring systems. In: OOPSLA'86 Proceedings (ACM), september 1986. p.269-276.

BOTTINO, R.M. \& FERRARI, P.L. Intelligent educational systems and mathematical knowledge from a cognitive perspective. In: Seventh International PEG93 Conference - PEG93 - AI Tools and the classroom: Theory into Practice. Edinburgh, july 1993. Proceedings. Edinburgh, july 1993. v.I, p.116-123.

BROWN, J.S. \& VANLEHN, K. Repair theory: a generative theory of bugs in procedural skills. Cognitive Science, v.4, p.379-426, 1980.

BUMBACA, F. Intelligent computer-assisted instruction: a theorical framework. International Journal of Man-Machine Studies, v.29, p.227-255, 1988.

CAULFIELD, P.J. From Brazil to Buncombe county: Freire and posing problems. The Educational Forum, v.55(4), p.307-318, Summer 1991.

CHAN, T-W. Curriculum tree: A knowledge-based architecture for intelligent tutoring systems. In: FRASSON, C.; GAUTHIER, G. \& MCCALLA. G.I., ed. Lecture Notes in Computer Science: Intelligent Tutoring Systems - ITS'92. Canadá, Springer-Verlag, june 1992. n.608, p.140-147.

CLANCEY, W.J. Tutoring rules for guiding a case method dialogue. International Journal of Man-Machine Studies, v.11, p.25-49, 1979.

DESMOULINS, C. On the didactic contract in an ITS for teaching geometry. In: Seventh International PEG93 Conference - PEG93 - AI Tools and the classroom: Theory into Practice. Edinburgh, july 1993. Proceedings. Edinburgh, july 1993. v.I, p.97-107.

DUMSLAFF, U. \& EBERT, J. Structuring the subject matter. In: TOMAK, I., ed. Lecture Notes in Computer Science. Computer Assisted Learning - ICCAL'92. Springer-Verlag, 1992. n.602, p.174-186.

FORD, L. \& YAZDANI, M. Tutoring systems: the state-of-the-art in Great Britain. Expert Systems, v.5(4), p.328-339, november 1988. 
GELEPITHIS, P.A.M \& GOODFELLOW, R. An alternative architecture for intelligent tutoring systems. Interactive Learning International, v.8(1), p.29-36, 1992.

GONÇALVES, L.C. Ensaio sobre o lugar do computador na educação. Revista da Faculdade de Educação, Resenha, 18(2), p.291-299, julho/dezembro de 1992.

IBRAHIM, B. Software engineering techniques for computer-aided learning. Education \& Computing, v.5, p.215-222, 1989.

JONASSEN, D.H. \& MANDL, H. Designing Hypermedia for Learning. NATO ASI Series, Springer Verlag, 1990. 457p.

KAY, A.C. Computers, networks and education. Scientific american, p.101-107, september 1991.

KEARSLEY, G. Artificial Intelligence and Instruction: Applications and Methods. California, Addison-Wesley, june 1987. 351p.

LACASSE, R.; DESJARDINS, F. \& LAMONTAGNE, C. Teaching geometry through triadic elicitation: towards a guide discovery tutoring based interactive learning environment. In: Seventh International PEG93 Conference - PEG93 - AI Tools and the classroom: Theory into Practice. Edinburgh, july 1993. Proceedings. Edinburgh, july 1993. v.II, p.352-365.

LARKIN, J.H. \& CHABAY, R.W. Computer-Assisted Instruction and Intelligent Tutoring Systems: Shared goals and complementary approaches. London, Lawrence Erlbaum Associates, 1992. 280p.

LA TAILLE, Y. Ensaio sobre o lugar do computador na educação. São Paulo, Iglu, 1990. 219p.

LEGREE, P.J. \& GILLIS, P.D. Product effectiveness evaluation criteria for intelligent tutoring systems. Journal of Computer-Based Instruction, v.18(2), p.57-62, Spring 1991.

LESGOLD, A. Toward a theory of curriculum for use in designing intelligent instructional systems. In: MANDL, H. \& LESGOLD, A., ed. Learning issues for intelligent tutorin systems Springer-Verlag, 1988. p.114-137.

LIVERGOOD, N.D. Specification and design procedures, functions, and issues in developing intelligent tutoring systems. Journal Educational Technology Systems, v.19(3), p.251-264, 1991.

LOWENTHAL, F.; MARCOURT, C. \& SOLIMANDO, C. Observing computer for study of problem solving strategies. In: Seventh International PEG93 Conference - PEG93 - AI Tools and the classroom: Theory into Practice. Edinburgh, july 1993. Proceedings. Edinburgh, july 1993. v.II, p.375-388. 
MERRIL, M.D. The role of tutorial and experimential models in intelligent tutoring systems. Educational Technology, v.28(7), p.7-13, july 1988.

MICHENER, E.R. Structuring mathematical knowledge. Massachusetts, p.A.1-A.24, 1978.

MURRAY, T. \& WOOLF, B.P. A knowledge acquisition tool for intelligent computer tutors. SIGART Bulletin, v.2(2), p.9-21, april 1991.

NORMAS PARA ELABORAÇÃO DE DISSERTAÇÕES E TESES. Universidade de São Paulo. Campus de Piracicaba - Escola Superior de Agricultura 'Luiz de Queiroz". Piracicaba, 1987. 64p.

O'SHEA, T.; BORNAT, R.; du BOULAY, B.; EISENSTADT, M. \& PAGE, I. Tools for creating intelligent computer tutors. In: Nato Symposium on Human and Artificial Intelligence. Lyon, October 1981. p.1-30.

RASMUS, D.W. AI and objects. Object Magazine, p.55-57, july-august 1992.

SCULLEY, J. The relationship between business and higher education: a perspective on the 21 st century. Communications of the $A C M$, v.32, n.9, p.1056-1061, september 1989.

SHOTSBERGER, P.G. AI opportunities in mathematics education. In: Seventh International PEG93 Conference - PEG93 - AI Tools and the classroom: Theory into Practice. Edinburgh, july 1993. Proceedings. Edinburgh, july 1993. v.II, p.468-479.

SLEEMAN, D.H. \& BROWN, J.S. Intelligent Tutoring Systems. Orlando, Academic Press, 1982. 345p.

SLEEMAN, D.H. \& SMITH, M.J. Modelling Student's problem solving. Artificial Intelligence, v.16, p.171-188, 1981.

STAGGERS, N. \& NORCIO, A.F. Mental models: concepts for the human-computer interaction research. International Journal of Man Machine Studies, v.38, p.587-605, 1993.

SUTHERS, D.; WOOLF, B. \& CORNELL, M. Steps from explanation planning to model construction dialogues. In: Proceedings of the Tenth National Conference on Artificial Intelligence - AAAI-92. San Jose, july 1992. p.24-30.

VALENTE, J.A. Liberando a mente: computadores na educação especial. Campinas, Gráfica Central da UNICAMP, 1991. 314p.

VALENTE, J.A. \& VALENTE, A.B. Logo: conceitos, aplicações e projetos. McGrawHill, São Paulo, 1988.

VALENTE, J.A. Computadores e conhecimento: repensando a educação. Campinas, Gráfica Central da UNICAMP, 1993. 418p. 
WOOLF, B.P. Representing complex knowledge in an intelligent machine tutor. Computational Intelligence, v.3, p.45-55, 1987.

WOOLF, B.P. \& CUNNINGHAM, P.A. Multiple knowledge sources in intelligent teaching systems. IEEE Expert, p.41-54, Summer 1987. 


\section{GLOSSÁRIO}


Aprendizado de Máquina (Machine Learning): É uma área de pesquisa da Inteligência Artificial que estuda métodos computacionais para adquirir novos conhecimentos, novas habilidades e novos meios de organizar o conhecimento existente, incorporando características dos seres humanos no processo de aprendizagem. Esta área tenta incorporar no sistema computacional aspectos da capacidade humana de aprender. Trabalha com métodos computacionais que fazem com que as máquinas "aprendam" [GIL88] [MIC90] [MAR93].

Bug: Em geral, um bug é alguma falha estrutural (parte defeituosa) revelada por algum comportamento inesperado (defeituoso). Assim, o termo bug é utilizado para se referir a uma parte incorreta de um determinado procedimento [CLA88]. Segundo Polson e Richardson [POL88], bugs são as misconceptions dos estudantes no conhecimento declarativo ou procedimental.

Catálogo de bugs (Bug Catalog): Um conjunto de padrões de erros típicos muito bem analisados e coletados cuidadosamente [PSO88].

Ciência Cognitiva (Cognitive Science): É uma área de pesquisa cujo objetivo é descobrir as capacidades representacionais e computacionais da mente, e sua representação estrutural e funcional no cérebro, e não, simplesmente, tentar entender a atividade mental ou de que forma as entidades inteligentes interagem com seus ambientes. Representa um novo paradigma para entender a cognição (aquisição de conhecimento) [PYL87]. Um paradigma que tem ligações com a ciência computacional, pois preocupa-se com a representação, aquisição e manipulação mental das informações, e a transformação destas em ação ${ }^{1}$. Alguns dos problemas tratados pela Ciência Cognitiva podem ser: interfaces homem-máquina, métodos pedagógicos, técnicas de comunicação, metodologias de aquisição de conhecimento, entre outros.

Conhecimento Declarativo (Declarative Knowledge): Uma forma de representação do conhecimento (estática e estrutural) baseada nos fatos e princípios básicos do domínio a ser representado. Por exemplo, voltagem é simbolicamenté representado como $E$, corrente é representado como I e resistência por $R$.

1 GLLAN, D. Cognitive science preparation for work in artificial intelligence. In: THE ISA/88 INTERNATIONAL CONFERENCE AND EXHIBIT, Houston, 1988. Proceedings. Houston TX, s.ed., 1988. vol.43, pt 4, p.1503-508. 
Conhecimento Procedimental (Procedural Knowledge): Uma forma de representação do conhecimento (ativa e funcional) distinta do conhecimento declarativo. Por exemplo, o conhecimento procedimental que expressa a relação entre voltagem, corrente e resistência poderia ser $E=I R$.

Frames: Um esquema de representação do conhecimento onde as informações sobre um determinado objeto são organizadas como uma coleção de atributos organizados em slots.

Mal-rule: É uma regra modificada do assunto a ser ensinado, capaz de gerar resultados incorretos. É, normalmente, usado para descobrir bugs e determinar quais são as misconceptions que os originaram.

Misconception: É algum conhecimento adquirido pelo estudante de tal forma que contém algum(s) bug(s). Isso faz com que o estudante tenha um ponto de vista com relação ao conhecimento adquirido diferente do especialista, pois este não possui bugs.

Psicologia Cognitiva (Cognitive Psychology): Uma área que estuda como as pessoas adquirem o conhecimento sobre um determinado assunto na interação organismo/meioambiente. Além disto, como elas usam este conhecimento para tomar decisões e resolver problemas. Algumas subáreas da Psicologia Cognitiva são: "perception", "attention", "memory", "thinking" e "language" [HOL87] [KIE87] [WAL89].

Redes Semânticas (Semantic Network): Um esquema de representação do conhecimento baseado em grafos. Os nós representam os objetos, conceitos e entidades. Os arcos representam as ligações que descrevem as relações entre os nós.

Regras de Produção (Production Rules): Um esquema de representação do conhecimento que contém um conjunto de regras, estratégias de controle e uma base de conhecimento.

Sistemas de treinamento (Coach systems): É um ambiente de ensino-aprendizagem que, segundo Brown e Moskowitz 2 , "olha sobre os ombros" do estudante enquanto ele tenta executar tarefas (exercícios), oferecendo conselhos oportunos em momentos certos. Combinado com jogos, este sistema é suficientemente sensivel para fazer comentários relevantes de maneira oportuna, sem comprometer a diversão inerente ao jogo. Segundo Psotka et al., em [PSO88], coach systems também é um tipo de modelagem do estudante, onde o STI interveem somente quando ele tem certeza que o estudante está fazendo alguma coisa errada.

2 BROWN, J.S. \& MOSKOWITZ, G. AI: Windows of opportunity in office automation. Xerox Corporation, july 1985. apud [RIC89]. 


\section{TABELA DE SISTEMAS TUTORES}




\begin{tabular}{|c|c|c|}
\hline Sistema Tutor & Domínio & Referência \\
\hline ATDSE & Subtração básica & [ATT83] $^{1}$ \\
\hline BIP & Programação BASIC & {$\left[\right.$ BAR76] ${ }^{2}$} \\
\hline BUGGY & Subtraçắo básica & [BAR82] [BRO78] \\
\hline CIE & Circuitos Elétricos & [YOS92] \\
\hline DARTS & Números Racionais & [DUG92] \\
\hline DEBUGGY & Subtração básica & [BUR82a] [BUR82b] \\
\hline DIITS & Cáculo de Integral & [YIB92] \\
\hline EDSMB & Multiplicação básica & {$\left[{\text { ATT } 84]^{3}}^{3}\right.$} \\
\hline ENIGMA & Jogo Aritmético & [FOR91] \\
\hline EXCHECK & Lógica básica & [BAR82] \\
\hline GEOMETRY Tutor & Geometria & {$[\mathrm{AND} 85]^{4}$} \\
\hline GREEN GLOBS & Equações Matemáticas & [DUG92] \\
\hline GUIDON I/II & Diagnose médica & [BAR82][CLA83] \\
\hline $\begin{array}{l}\text { HYPOTHETICAL } \\
\text { FRACTIONS Tutor }\end{array}$ & Aritmética com frações & [DUG92] \\
\hline LISP Tutor & Programação LISP & [AND85] 5 [COR92] \\
\hline List Processing Tutor & Processamento de Lista & [VYH90] \\
\hline MENO - Tutor & Programação Pascal básica & [W0084] \\
\hline MENTONIEZH & Geometria & [PY90] \\
\hline NEOMYCIN & Diagnose médica & $\left.{ }^{[\text {CLA81 }}\right]^{6}$ \\
\hline PASCAL Tutor & Linguagem Pascal & [GIS92] \\
\hline PIXIE & Algebra básica & [SLE87] [SLE89] \\
\hline
\end{tabular}

1 [ATT83] ATTISHA, M.G. \& YAZDANI, M. A micro-computer based tutor for teaching arithmetic skills. Instructional Science, 12, p.333-342, 1983. apud [NWA90].

2 [BAR76] BARR, A.; BEARD, M. \& ATKINSON, R.C. The computer as a tutorial laboratory: the Stanford BIP Project. International Journal of Man-Machine Studies, v.8, p.567-596, 1976. apud [NWA90].

3 [ATT84] ATTISHA, M.G. \& YAZDANI, M. An expert system for diagnosing children's multiplication errors. Instructional Science, 13, p.79-92, 1984. apud [NWA90].

4 [AND85] ANDERSON, J.R; BOYLE, D.F. \& REISER, B.J. Intelligent tutoring systems. Science, 228, p.456-462, 1985. apud [NWA88].

5 [AND85] ANDERSON, J.R. \& REISER, B.J. The Lisp tutor. Byte, v.10, n.4, 1985. apud [NWA90].

6 [CLA81] CLANCEY, W.J. \& LETSINGER, R. NEOMYCIN: reconfiguring a rule-based expert system for application to teaching. Proceedings of the 7th International Joint Conference on Artificial Intelligence. Vancouver, Canada. p.829-835, 1981. apud [NWA90]. 


\begin{tabular}{|l|l|l|}
\hline PROTO-TEG & Geometria & [DIL89] \\
\hline PROUST & Programação Pascal & [JOH87][SAC92] \\
\hline QUADRATIC Tutor & Equações quadráticas & [OSH82] \\
\hline SCHOLAR & Geografia da América do SUL & [BAR82][CAR70] \\
\hline SOPHIE I/II/III & $\begin{array}{l}\text { Detecção de problemas em } \\
\text { circuitos eletrônicos }\end{array}$ & [BAR82] [BRO82] \\
\hline $\begin{array}{l}\text { SORT EQUIVALENT } \\
\text { FRACTIONS }\end{array}$ & $\begin{array}{l}\text { Classificação de frações } \\
\text { eqüivalentes }\end{array}$ & [DUG92] \\
\hline UNIX Tutor & Sistema Operacional UNIX & [WAN92] \\
\hline USHI & Engenharia & [DIE92] \\
\hline WEST & Jogo aritmético & [BAR82][BRO78] \\
\hline WHY & Meteorologia & [COL82] \\
\hline
\end{tabular}

7 [COL82] COLLINS, A. \& STEVENS, A.L. Goals and strategies for inquiry teachers. In: GLASER, R, ed. Advances in Instructional Psychology. Hillsdale, Lawrence Erlbaum. v.2, 1982. apud [NWA90]. 